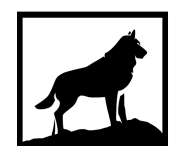

Michigan Technological

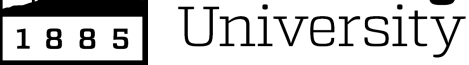

Michigan Technological University Digital Commons @ Michigan Tech

\title{
LAKEBED CHARACTERIZATION USING SIDE-SCAN DATA FOR INVESTIGATING THE LATEST LAKE SUPERIOR COASTAL ENVIRONMENT CONDITIONS
}

Hasan Salih Kulunk

Michigan Technological University, hasan_salih_kulunk@hotmail.com

Copyright 2017 Hasan Salih Kulunk

Recommended Citation

Kulunk, Hasan Salih, "LAKEBED CHARACTERIZATION USING SIDE-SCAN DATA FOR INVESTIGATING THE LATEST LAKE SUPERIOR COASTAL ENVIRONMENT CONDITIONS", Open Access Master's Thesis, Michigan Technological University, 2017.

https://doi.org/10.37099/mtu.dc.etdr/517

Follow this and additional works at: https://digitalcommons.mtu.edu/etdr

Part of the Geotechnical Engineering Commons, and the Other Engineering Commons 


\title{
LAKEBED CHARACTERIZATION USING SIDE-SCAN DATA FOR INVESTIGATING THE LATEST LAKE SUPERIOR COASTAL ENVIRONMENT CONDITIONS
}

\author{
By
}

Hasan Salih Kulunk

\begin{abstract}
A THESIS
Submitted in partial fulfillment of the requirements for the degree of MASTER OF SCIENCE In Integrated Geospatial Technology
\end{abstract}

MICHIGAN TECHNOLOGICAL UNIVERSITY 2017

(C) 2017 Hasan Salih Kulunk 
This thesis has been approved in partial fulfilment of requirements for the Degree of MASTER OF SCIENCE in Integrated Geospatial Technology.

School of Technology

Thesis Co-Advisor: $\quad$ Dr. Eugene Levin

Thesis Co-Advisor: $\quad$ Dr. Ann L. Maclean

Committee Member: Dr. Guy A. Meadows

School Dean: Dr. James Frendewey 


\section{Table of Contents}

List of Tables ............................................................................................. vii

Acknowledgements ......................................................................................................... viii

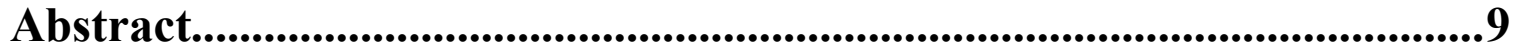

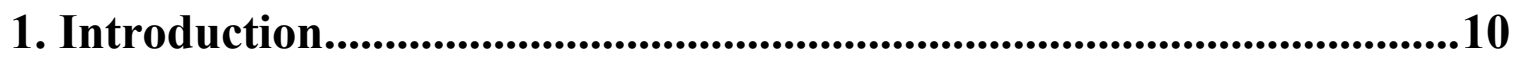

1.1 Current Hydrographic Survey Methods ...............................................13

1.1.1 Vertical depth measurements........................................................ 14

$>$ Lead Line and Sounding Pole ............................................................................. 14

$>$ Drag Wire

$>$ Echo sounding ……………………………………………………………………….... 16

•Single Beam Echo Sounders.............................................................................. 16

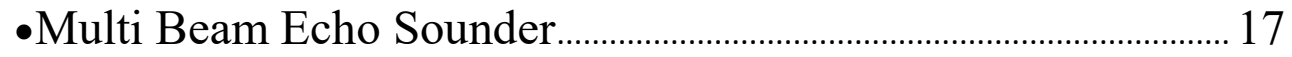

-Phase Differencing Bathymetry Sonar / Interferometer............... 18

•Multiphase Echo Sounder System................................................................. 18

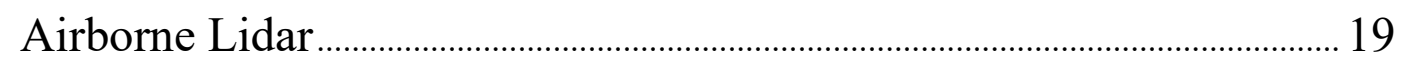

Satellite Derived Bathymetry .................................................................................. 21

•Optical Satellite Derive Bathymetry …………………………………....2 22

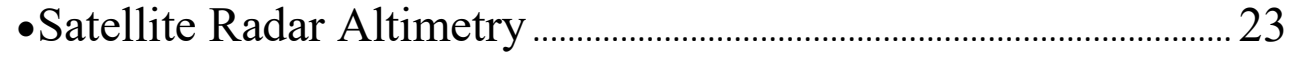

-SAR (Synthetic Aperture Radar) Hydrographic Method.............25

1.1.2 Horizontal position fixing measurements ....................................26

Horizontal position fixing with traditional optical method......................26

-Theodolite Intersection ................................................................................. 27

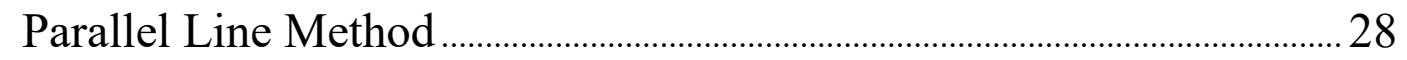


Dlectromagnetic Distance Measuring Systems

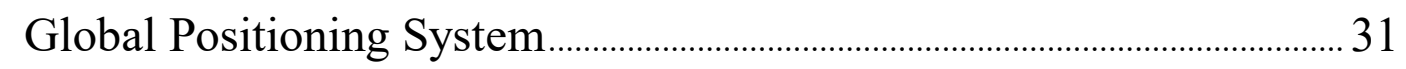

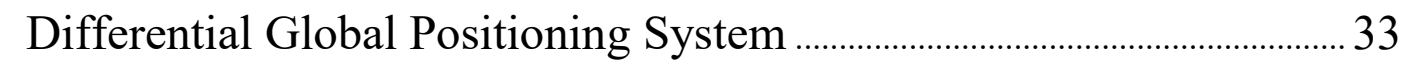

2. Hydrographic Survey Considerations ...........................................34

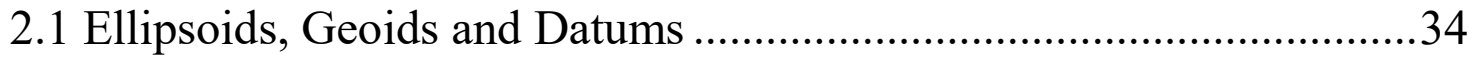

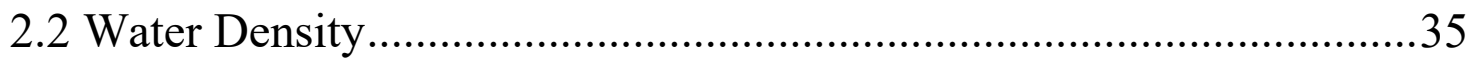

2.3 The Surveying Equipment Movement Effect .....................................35

3 Study Area and Data Collection....................................................................36

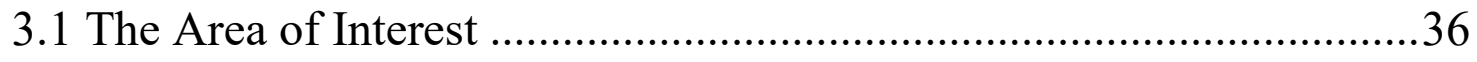

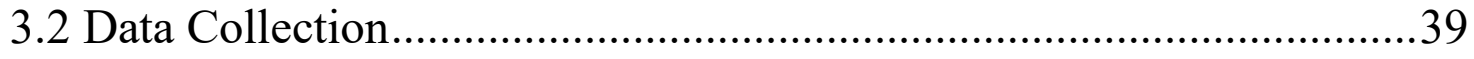

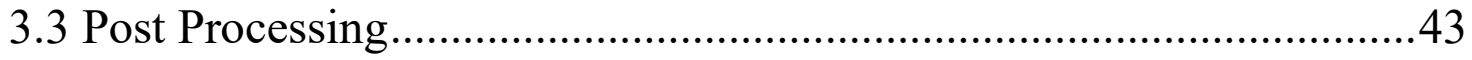

3.3.1 Post Process Iver 3 Side-scan and Edgetech 4125 Side-scan Sonar

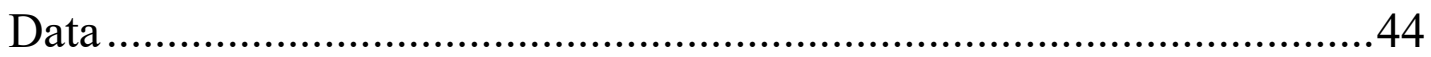

$>$ Increasing the number of classes after looking histogram values.........60 60

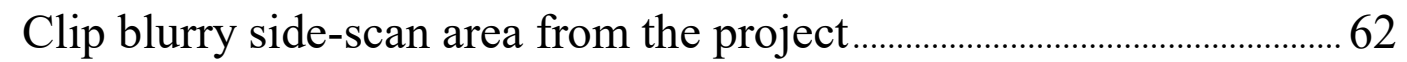

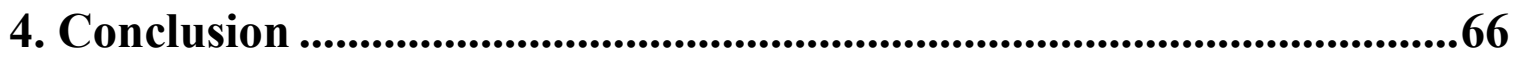

5. Recommendation ...........................................................................................73

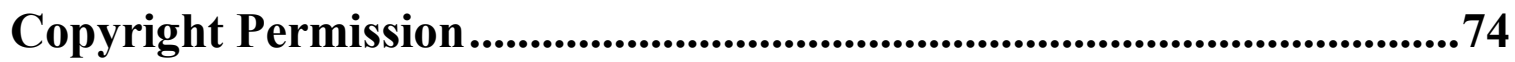

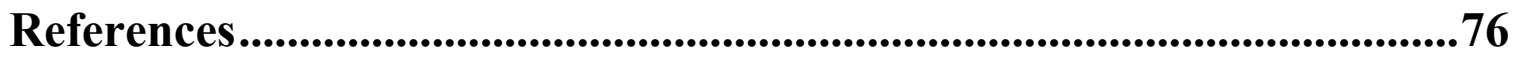




\section{List of Figures}

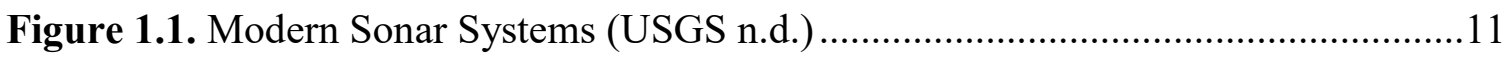

Figure 1.2. Hydrographic Survey by Lead Line methods (Teamsurv n.d.) ....................15

Figure 1.3. Drag Wire method for the safety of navigation (Teamsurv n.d.) ..................16

Figure 1.4. Single Beam Echo Sounder Principle (USGS n.d.) ...................................17

Figure 1.5. Multi Beam Echo Sounder Principle......................................................... 18

Figure 1.6. Multiphase Echo Sounder (Hiller n.d) ....................................................19

Figure 1.7. Airborne Lidar (U.S. Geological Survey Department of the Interior/USGS 2016)

Figure 1.8. Optical SDB Method for Hydrographic Survey (Figure 1.8. Optical SDB Method for Hydrographic Survey (Courtesy UKHO, contains WorldView-2 satellite

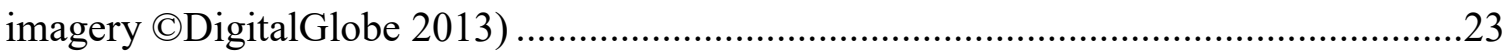

Figure 1.9. Satellite Radar Altimetry Method (NOAA/NESDIS/STAR 2016) ................25

Figure 1.10. Theodolite Horizontal Position Fixing Method (EPA 1987) ....................28

Figure 1.11. The Parallel Line Method (Sciortino, Food and Agriculture Organization of the United Nations 2010). .29

Figure 1.12. The Depth Recording with Traditional Parallel Line Method (Sciortino, Food and Agriculture Organization of the United Nations 2010). .30

Figure 1.13. Bathymetric Survey Vessel Tracked with Total Station (GIM International 2016)

Figure 1.14. GPS Accuracy for Maritime Projects (U.S. Geological Survey Department of the Interior/USGS 2017). 
Figure 1.15. RTK GPS Method for Maritime Projects (U.S. Geological Survey

Department of the Interior/USGS 2016)

Figure 2.1. Ellipse model for different region (Clynch, James R., DMA TECHNICAL MANUAL 8358.1 DATUMS, ELLIPSOIDS, GRIDS, AND GRID REFERENCE SYSTEMS, http://clynchg3c.com/ 2006) .34

Figure 2.2. The Vessel Coordinate System and The Direction of Movements .36

Figure 3.1. The area of interest that five surveying line were chosen for data acquisition (NOAA, http://www.charts.noaa.gov/OnLineViewer/14964.shtml 2017) .38

Figure 3.2. The data collection with the Edgetech 4125 Side-scan sonar, which is towed behind the survey vessel on the map.......

Figure 3.3. The raw side-scan data from Edgetech 4125 Side-scan sonar that is towed behind the survey vessel showing on the Discover 2 screen

Figure 3.4. Iver 3 raw side-scan data showing on the Discover 2 software screen .42

Figure 3.5. Specified area of interest for classification investigation (NOAA, http://www.charts.noaa.gov/OnLineViewer/14964.shtml 2017).

Figure 3.6. Raw side-scan data from Iver 3 on the SonarWiz 7 software screen .44

Figure 3.7. The raw side-scan data from Edgetech 4125 Side-scan sonar that is towed behind the survey vessel showing on the Discover 2 screen 45

Figure 3.8. After the bottom track processing at the side of the port. Blue lines represent the altitude that fitted the edge of the side-scan data .45

Figure 3.9. AGC normalized Iver 3 side-scan data..... .46

Figure 3.10. The AGC normalized Iver 3 side-scan classification result. The nadir area is dominated and affects the classification results in a bad matter. 47 
Figure 3.11. Build the EGN normalization table using all Iver 3 bottom tracked side-scan data then apply the nadir filter with $32 \%$ nadir angle .48

Figure 3.12. After EGN normalization, there is no nadir effect on Iver 3 side-scan data and all sonar values look consistent. .48

Figure 3.13. The Edgetech 4125 bottom tracked side-scan data before applying EGN normalization and nadir filter with $20 \%$ nadir angle

Figure 3.14. After EGN and nadir filter, The Edgetech 4125 side-scan data looks consistent without nadir effect

Figure 3.15. Classification rules were applied to obtain 5-classes classification results..50

Figure 3.16. The Iver 3 classification results with five classes..... .52

Figure 3.17. The Edgetech 4125 classification results with five classes .53

Figure 3.18. A typical cobble class that is matched between actual images of Iver 3 sonar and The Discover 2 .54

Figure 3.19. A typical sandy waves class that mostly indicates the trend of the stamp sands encroachment. The trend is from the Gay Bay to the southeast direction. .55

Figure 3.20. A typical bedrock class. .55

Figure 3.21. The condition map of stamp sands from the east side of Upper Keweenaw57

Figure 3.22. The Iver 3 side-scan showing on the contour map .58

Figure 3.23. The Iver 3 side-scan data stamp sands border (red color 41-50\%). .59

Figure 3.24. The Iver 3 band 1-histogram profile shows the near range of sonar returns that has more than five peaks .60 
Figure 3.25. The Iver 3 band 2-histogram profile shows the far range of sonar returns that has more than five peaks.

Figure 3.26. The shadow in the hollow area appeared as the same color (blue) as the rock/bedrock class that the concept is coming from the typical side-scan shadow problem

Figure 3.27. A considerable difference between the area with a good contrast and blurry area. The results might be gotten because of a wrong normalization result that could come from the blurry area.

Figure 3.28. The Iver 3 side-scan 10-classes classification result .64

Figure 3.29. The Edgetech 4125 side-scan classification result shows that the system cut the shadow area out from the side-scan imagery .65

Figure 4.1. The Iver 3 Side-scan Lakebed Classification Map....................................69

Figure 4.2. The Edgetech 4125 Side-scan Lake Classification Map. .72 


\section{List of Tables}

Table 1.1. Minimum Standards for Hydrographic Surveys (IHO Standards for

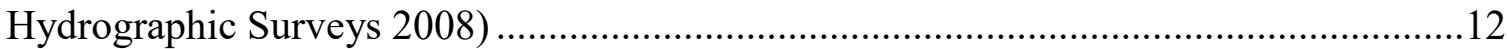

Table 3.1. Data collection information with the Iver 3 sonar ......................................39

Table 3.2. Data collection information with the Edgetech 4125 Side-scan Sonar............40 


\section{Acknowledgements}

I would like to state my appreciation to my co-advisors Professor Eugene Levin, and Professor Ann Maclean, and my committee member Professor Guy Meadows. Additionally, I want to thank Christopher Pinnow for his assistance while I was completing my thesis research at the Great Lake Research Center, Michigan Technological University.

Moreover, I would like to thank Aysen Sozen, Tugay Demirarslan and my family who have stood by me during the process.

Finally, I would like to thank my government for enabling a unique opportunity to complete a Master's Degree in the USA. 


\section{Abstract}

This thesis provides a review of the development of hydrographic survey equipment and supporting geospatial equipment and technology such as GPS. Using SonarWiz, a sonar image processing software package, lakebed classification methodologies were evaluated for mapping Buffalo Reef in Lake Superior located near Gay, Michigan. The goal was to develop an approach to mapping the reef bed and delineating various components of the lake bottom, including stamp sands, which are migrating from the abandoned Gay copper processing stamp mill to the reef. This contamination of the reef is having an adverse effect on habitats important to local flora and fauna.

Sonar data was collected with an Edgetech 4125 side-scan sonar and an Iver3, a fully autonomous under water vehicle sonar, which has bathymetry and side-scan capabilities. Both systems are owned and operated by the Great Lake Research Center at Michigan Technological University.

Sonar image post-processing was complete utilizing SonarWiz 7, ArcGIS 10.5 and ERDAS Imagine. The resulting classification is composed of 6 information classes: cobble, cobble/stamp sand with different level intensity returns (low, medium, and high), trend of stamp sand, sandy waves and shadow which indicates mostly rock/ bedrock. The cobble/stamp sand had two distinct spectral classes: high intensity returns and low intensity returns for Iver 3, three distinct spectral classes: high intensity returns, medium intensity returns and low intensity returns for Edgetech 4125. The Edgetech 4125 classification excluded shadow area automatically.

The final step was an interpretation of lakebed features based on ground truth samples and photographic images from the bottom surface. Recommendations for future research are presented. 


\section{Introduction}

Historically, cities, agriculture, shipping harbors and industries such as such a copper ore processing stamp mills and other activities have been situated on shorelines due to ease of access and development. No consideration was given to the environmental impacts these activities had on the land and near off shore areas. During the 1800s and through most of the 1900s, natural resource exploitation with no regard for environmental degradation was the operating business model. Technology did not exist to monitor changes occurring offshore and negative impacts from industrial activities were not understood or ignored. Even when certain activities ceased, the problems created, such as dumping stamp sands along shorelines and into Lake Superior and connecting waterways continued, causing long-term environmental impacts. Types of impacts include changes in water depth, wave height, current variations, stamp sand drift, and changes in the shoreline.

Hydrographic surveys are crucial to understand the structure of underwater topography and associated changes. These surveys assist in monitoring degradation impacts and remediation efforts. The outcome of a hydrographic survey, also known as a bathymetric survey, is generally plotted as a contour map, which illustrates the depth of a waterbody. Each contour line represents one depth value. This type of contour map assists in mapping the lake or lakebed using survey measurements and SONAR systems (SOund Navigation And Ranging), and facilitates such activities as oil exploration and drilling, marine construction, construction of navigation maps, and pollution remediation (Karacelebi 2014).

Hydrographic surveys are more challenging than land surveys since technicians cannot see underwater. Furthermore, the exact geographic location of the survey vessel may not be known precisely when water depth and lakebed composition are recorded (Sciortino, Food and Agriculture Organization of the United Nations 2010). Historically, surveyors used horizontal (X, Y) measurements collected from buoys, pegs, and calibrated float lines. Calculating depth $(Z)$ was done by a weighted rope (sounding lead) or pole (sounding pole) from the vessel to the lakebed. When the weight reached the lake floor, 
the depth value was recorded. However, this approach was time-consuming, and currents or vessel movements cannot be determined. Consequently, these early depth-recording methods were not as accurate as current acoustic systems.

Current technology uses SONAR systems for gaining acoustic depth measurements and GPS to obtain X, Y horizontal coordinates (Figure 1.1). This technology is costly, but accuracy and precision of the measurements and utility of the data justifies investment costs.

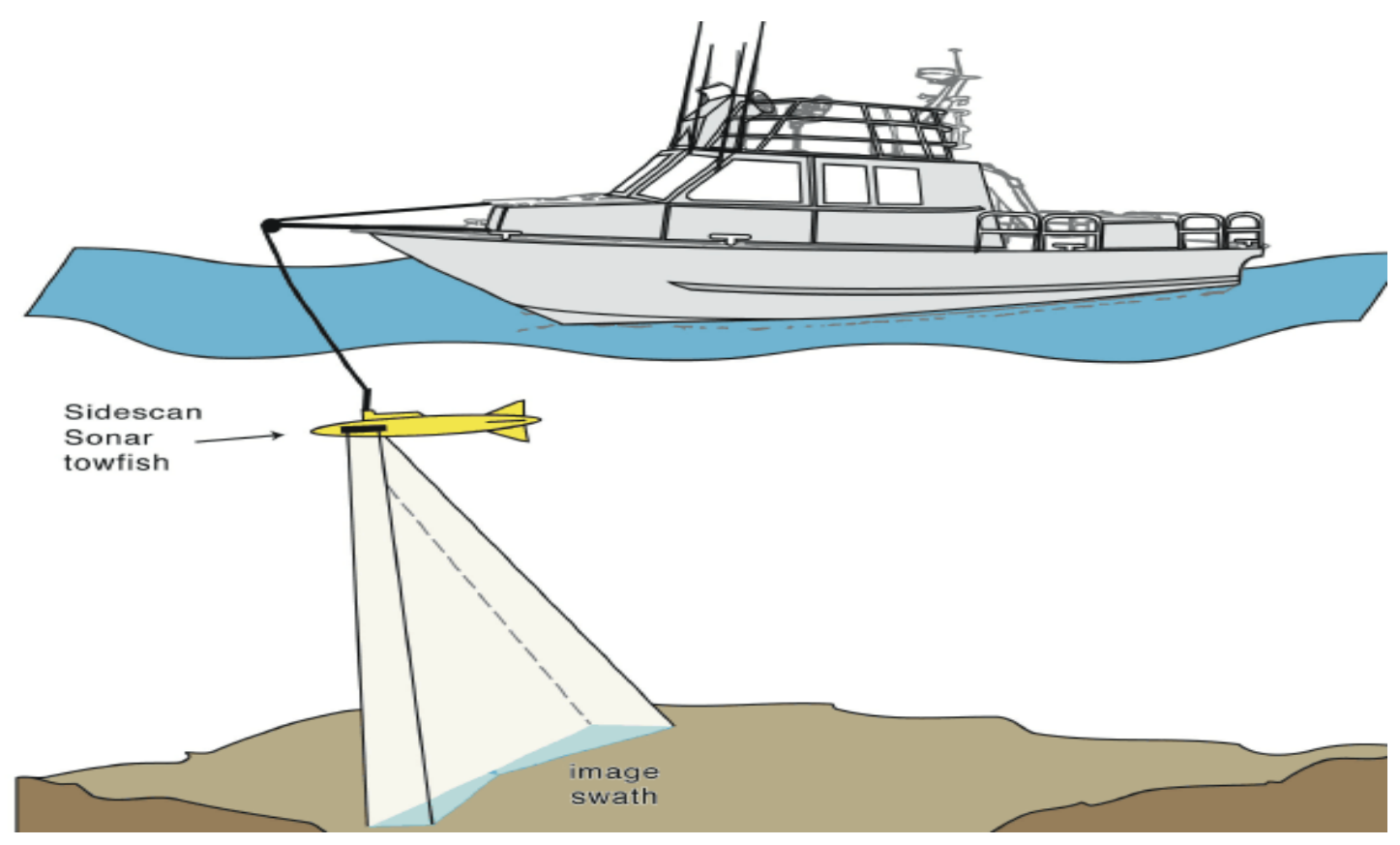

Figure 1.1. Modern Sonar Systems. (U.S. Geological Survey Deapartment of the Interior/USGS, https://coastal.er.usgs.gov/capabilities/shipboard/sonar/sidescan.html 2016).

The precision of bathymetric measurements defines how well use standards are met. Typical bathymetric survey accuracies are dependent on the IHO (International Hydrographic Organization) standards for various purposes. IHO standards, published in 
2008 , for hydrographic surveys ( $5^{\text {th }}$ edition) are the latest version. Table 1.1 summarizes the current minimum standards for hydrographic surveys (Howlett n.d.).

Table 1.1. Minimum Standards for Hydrographic Surveys (IHO Standards for Hydrographic Surveys 2008).

\begin{tabular}{|c|c|c|c|c|}
\hline Order & Special & $1 \mathbf{a}$ & $\mathbf{1 b}$ & 2 \\
\hline $\begin{array}{l}\text { Description of } \\
\text { areas. }\end{array}$ & $\begin{array}{l}\text { Areas where } \\
\text { under-keel } \\
\text { clearance is } \\
\text { critical }\end{array}$ & $\begin{array}{l}\text { Areas shallower } \\
\text { than } 100 \text { meters } \\
\text { where under- } \\
\text { keel clearance is } \\
\text { less critical but } \\
\text { features of } \\
\text { concern to } \\
\text { surface shipping } \\
\text { may exist. }\end{array}$ & $\begin{array}{l}\text { Areas shallower } \\
\text { than } 100 \text { meters } \\
\text { where under- } \\
\text { keel clearance is } \\
\text { not considered } \\
\text { to be an issue } \\
\text { for the type of } \\
\text { surface shipping } \\
\text { expected to } \\
\text { transit the area. }\end{array}$ & $\begin{array}{l}\text { Areas generally deeper } \\
\text { than } 100 \text { meters where a } \\
\text { general description of the } \\
\text { sea floor is considered } \\
\text { adequate. }\end{array}$ \\
\hline $\begin{array}{l}\text { Maximum } \\
\text { allowable } \\
\text { THU 95\% } \\
\text { Confidence } \\
\text { level } \\
\end{array}$ & 2 meters & $\begin{array}{l}5 \text { meters }+5 \% \\
\text { of depth }\end{array}$ & $\begin{array}{l}5 \text { meters }+5 \% \\
\text { of depth }\end{array}$ & 20 meters $+10 \%$ of depth \\
\hline $\begin{array}{l}\text { Maximum } \\
\text { allowable } \\
\text { TVU } 95 \% \\
\text { Confidence } \\
\text { level }\end{array}$ & $\begin{array}{l}\mathrm{a}=0.25 \text { meters } \\
\mathrm{b}=0.0075\end{array}$ & $\begin{array}{l}\mathrm{a}=0.5 \text { meters } \\
\mathrm{b}=0.013\end{array}$ & $\begin{array}{l}\mathrm{a}=0.5 \text { meters } \\
\mathrm{b}=0.013\end{array}$ & $\begin{array}{l}\mathrm{a}=1.0 \text { meters } \\
\mathrm{b}=0.023\end{array}$ \\
\hline $\begin{array}{l}\text { Full Sea floor } \\
\text { Search }\end{array}$ & Required & Required & Not required & Not required \\
\hline $\begin{array}{l}\text { Feature } \\
\text { Detection }\end{array}$ & $\begin{array}{l}\text { Cubic features }> \\
1 \text { meter }\end{array}$ & $\begin{array}{l}\text { Cubic features }> \\
2 \text { meters, in } \\
\text { depths up to } 40 \\
\text { meters; } 10 \% \text { of } \\
\text { depth beyond } 40 \\
\text { meters }\end{array}$ & Not Applicable & Not Applicable \\
\hline
\end{tabular}

Measurement uncertainty is comprised of random and systematic errors. A random error is unrecognized and due to casual offsets during the survey, and variation between measurement systems and/or environmental conditions. They are difficult to quantify. Systematic errors occur due to variations in instrument function and/or its use (Pyhsics Umd n.d.). Total vertical uncertainty depends on individual uncertainty parameters (a, and b) and must be taken into consideration. The variables shown below clarify the maximum allowable total vertical uncertainty for a particular depth measurement: 


$$
T V U= \pm \sqrt{a^{2}+(b x d)^{2}}
$$

Where:

a defines the part of uncertainty which does not depend on the depth

$\mathrm{b}$ defines the part of uncertainty which varies with depth

$\mathrm{d}$ is the depth

b x d defines the part of uncertainty which varies with depth (IHO Standards for Hydrographic Surveys 2008)

As noted previously, hydrographic data provides crucial information about lakebed topography and water-depth values. Additionally, hydrographic data is used to map and quantify different types of lakebed, such as sand, cobble, bedrock and other types of sediments. Using hydrographic data permits mapping of hazardous materials such as stamp sands, and monitoring their movements due to current flow.

\subsection{Current Hydrographic Survey Methods}

There are several methods used to acquire hydrographic data. Hydrographic surveys consist of two components: vertical depth measurements and horizontal fixed positions.

Vertical depth measurements can be fulfilled using:

- Lead line and sounding pole

- Drag Wires

- Echo Sounding

- Airborne Lidar

- Satellite Derived Bathymetry

Horizontal position fixing measurements can be done by using;

- Theodolites

- Electromagnetic Distance Measuring System

- Global Positioning System

- Differential Global Positioning System 


\subsubsection{Vertical depth measurements}

Vertical depth measurements are a crucial method for generating lake bed topography. Depending on feature heights, a 3D model can be generated for assessing habitat condition, investigating sediments, measuring water clarity, and locating historical shipwrecks, etc. In the past, depth measurements were time-consuming and challenging. Older methods failed to meet hydrographic standards and accuracy because of poor precision due to equipment limitations. As measurement technology has improved, vertical measurements are capable of consistently meeting quality control standards. Advancements in sonar technology, such as interferometric sonar and multiphase sonar systems, have resulted in improved depth range measurements. Additionally, derived satellite hydrographic methods can observe large geographic areas and collect consistent hydrographic data for the entire region.

\section{$>$ Lead Line and Sounding Pole}

The lead line is a vertical depth measurement method used since the time of the Ancient Egyptians (from 3,400BC) (Teamsurv, https:/www.teamsurv.com/Why/Hydrographicsurvey-methods n.d.).

The principal of the lead line method is a weighted lineis released from the side of the vessel, and reads the depth value on the line when the weight touches the bottom of the waterbody (Figure 1.2). Measurements were recorded manually. Afterward, the leadsman wraps the lead line and repeats the process. Measurement accuracy, improved with the use a coiled ropein the $19^{\text {th }}$ Century (Teamsurv, https://www.teamsurv.com/Why/Hydrographic-survey-methods n.d.). However, the process was still time and personnel intensive. In addition, sampling frequency was too sparse to obtain an accurate "picture" of the water body bottom. Current movement, tidal variation and small movements of the vessel also contributed to depth inaccuracies at specific points. 
Utilization of the sounding pole method is similar to the lead line hydrographic surveying method. The sounding pole is usually used for shallow areas but the approach is also time-consuming, and depth measurements are limited by the length of the sounding pole.

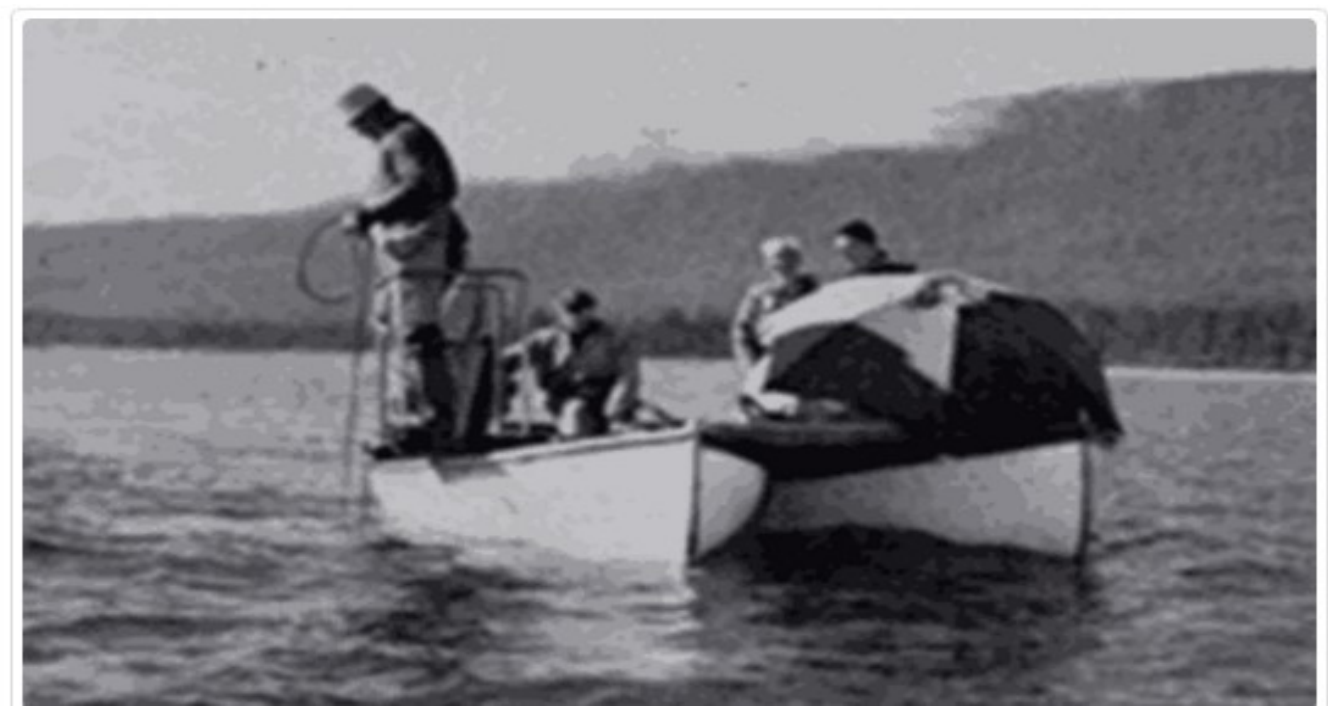

Figure 1.2. Hydrographic survey by the lead line method (Teamsurv, https://www.teamsurv.com/Why/Hydrographic-survey-methods n.d.).

\section{Drag Wire}

The drag wire hydrographic surveying method is used for navigational purposes. A drag wire is attached between two or more vessels (Figure 1.3), with supporting buoys between them to observe the minimum depth of the waterbody. 


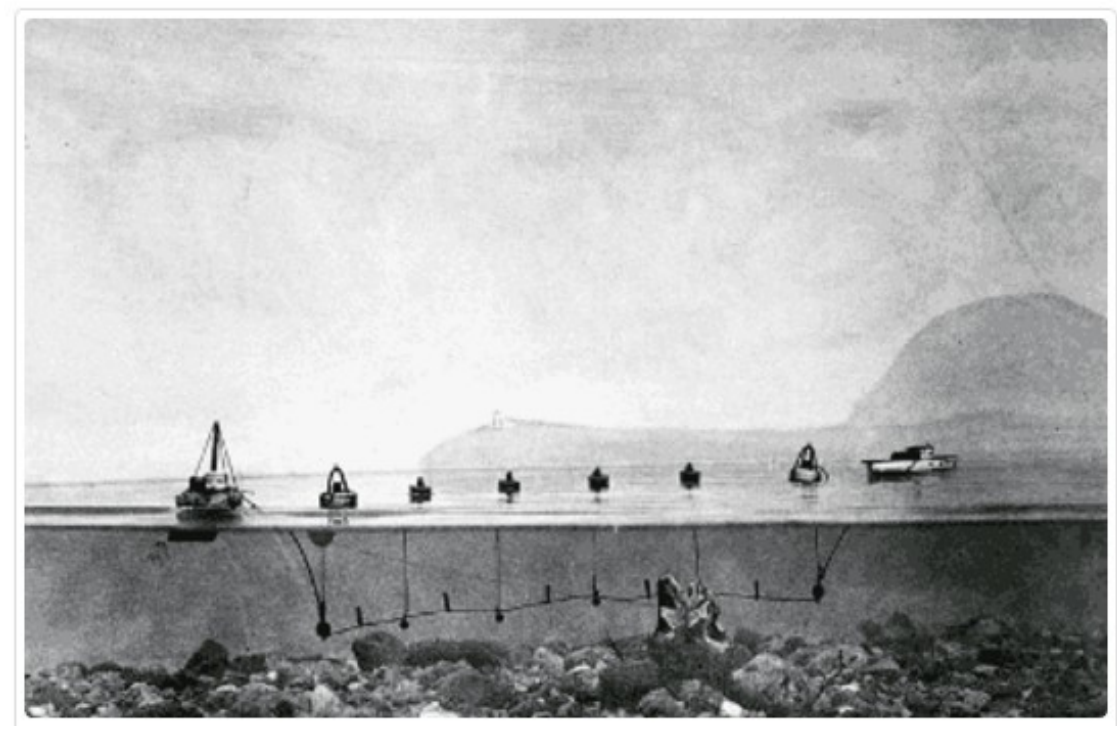

Figure 1.3. Drag wire method for the safety of navigation. (Teamsurv, https://www.teamsurv.com/Why/Hydrographic-survey-methods n.d.).

\section{Echo sounding}

\section{- Single Beam Echo Sounders}

SBES (Single beam echo sounder) systems have a transceiver attached to the side of the vessel. The transceiver emits high-frequency acoustic pulses directly beneath the vessel to the lakebed (Figure 1.4). The pulses "bounce" of the lake floor and return to the transceiver. The time required to return to the transceiver is noted. Vessel movement (pitch, roll, and heave) are measured and compensated for with an MRU (Motion Reference Unit) during data processing (U.S. Geological Survey Deapartment of the Interior/USGS, https://woodshole.er.usgs.gov/operations/sfmapping/singlebeam.htm n.d.). SBES systems are still commonly employed and produce acceptable results. The equipment is affordable particularly for small-scale projects. However, it is too time intensive for mapping large areas. 


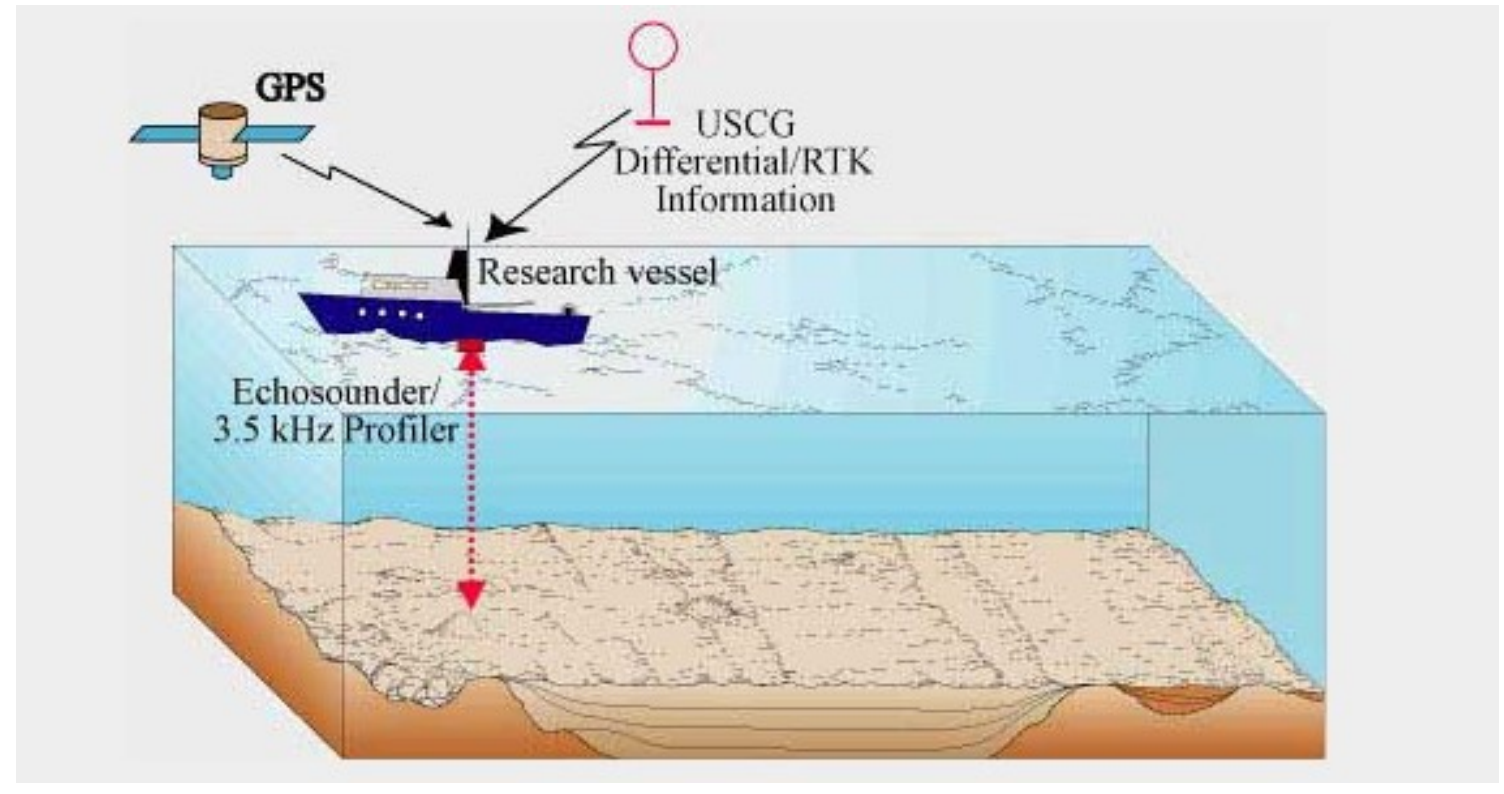

Figure 1.4. Single Beam Echo Sounder Principle (U.S. Geological Survey Deapartment of the Interior/USGS,

https://woodshole.er.usgs.gov/operations/sfmapping/singlebeam.htm n.d.).

\section{- Multi Beam Echo Sounder}

The MBES (Multi Beam Echo Sounder) (Figure 1.5) has more advantages, including improved accuracy, if compared to the SBES. MBES has the ability to delineate a small object as well as provide full bottom coverage (FIG 2007-2010). The system has a wide swath range and ability to observe sound velocity that corrects for the refraction of returning acoustic pulses. This creates a continuous lakebed profile. However, MBES has a restricted swath range, especially in shallow waters. This limitation results in increased costs, time and potentially inaccurate lakebed topographic measurements. 


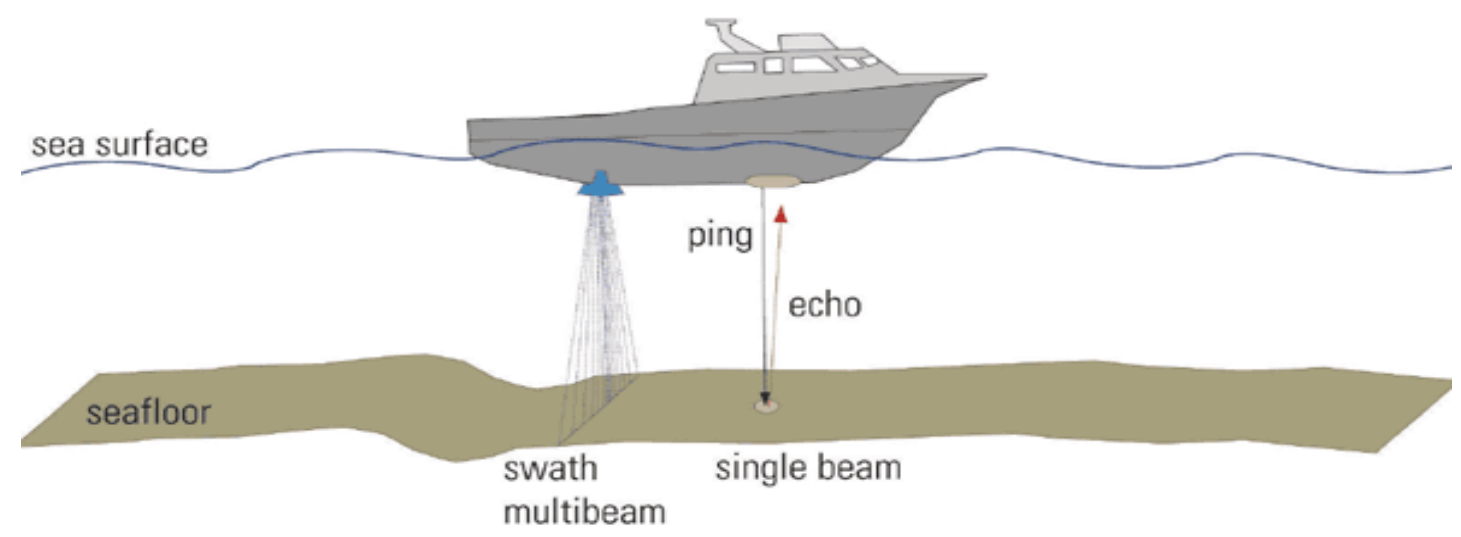

Figure 1.5. Multi Beam Echo Sounder Principle (U.S. Geological Survey Deapartment of the Interior/USGS, https://coastal.er.usgs.gov/capabilities/shipboard/sonar/bathysonar.html 2016).

\section{- Phase Differencing Bathymetry Sonar / Interferometer}

In the late 1990s, a phase differencing bathymetry sonar was introduced (Brison 2015). This type of sonar uses three or four scan staves in parallel to specify the angle of the returning side scan data. Thus, swath range and view angle are wider than MBES in a shallow depth area. The improved technology of the PDBS (Phase Differencing Bathymetry Sonar) makes it a logical choice when compared to SBES, and MBES systems. However, the PDBS is sensitive to water noise, resonance and multipath factors (Brison 2015), and generates point clouds along the lakebed. Hence, along track resolution and the nadir gap are problematic and require post processing.

\section{- Multiphase Echo Sounder System}

The MPES (Multiphase Echo Sounder) system (Figure 1.6) has significant advantages over PDBS and MBES systems. It has more receiver staves which provide beam forming and beam steering to optimize acoustic data collection and was first launched by EdgeTech in 2014 (Brison 2015). Beam steering is a new generation of sonar systems 
with the capability to eliminate the nadir gap and tremendously reduce data noise, while collecting accurate data with a high degree of visual clarity (Brison 2015).

MPES has two transducers mounted on both sides of the vessel. Each transducer has 10 receiver elements and creates 9 phase differences per side. This makes the MPES system more useful by establishing better accuracy with beam forming assistance. More receiver elements record information for the bathymetric sample points, so statistically; users can filter unwanted elements such as artificial returns from the bathymetric data. The resulting bathymetric data are more clear and precise. The MPES system also has a side scan recorder that works with bathymetric data and allows feature detection on the lake floor. Wakes, reverberations, dredge marks and shoals can be quickly identified during the survey (Brison 2015).

- Multi-Phase Echo Sounder (MPES) technology (same as EdgeTech 6205)

- Swath up to $10 \times$ water depth, and IHO SO to up to $9 \mathrm{x}$ water depth.

- Two Bathymetric frequency Options

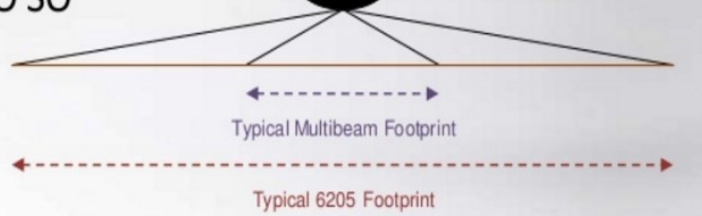

Figure 1.6. Multiphase Echo Sounder (Hiller n.d.).

\section{$>$ Airborne Lidar}

Lidar (Light Detection and Ranging) generates hydrographic surveys utilizing laser reflection of returning pulses from lakebed features. Lidar systems are typically aircraft mounted and cover both terrestrial and aquatic environments (Figure 1.7).

The underlying principle of a Lidar system for measuring waterbody depth uses the time delay from when the pulse is transmitted until it returns to the receiver. (Office of Coast Survey 2016). Lidar systems rely on two wavelengths to determine water depth. Highfrequency green light $(532 \mathrm{~nm})$ can penetrate the water body and reflect off the lakebed. 
Low-frequency infrared light $(1064 \mathrm{~nm})$ reflects from the water's surface. Surveyors determine water depths using these reflections. With good water clarity, Lidar systems can map depths just over 75 meters (GIM International 2016).

Mapping rugged areas in shallow waters such as those found off the coastal areas of Alaska, the North Atlantic Coast and the Caribbean (Office of Coast Survey 2016) are especially challenging. Airborne,Lidar systems are cost effective and safer, when compared to using ship based systems in these hazardous areas. In addition, Lidar can determine lake bed classification and stretch more than $100 \mathrm{~km}$ from the coastline (GIM International 2016).

Bathymetric Lidar sensors are composed of four major components:

- GPS receiver

- IMU (Inertial measurement unit)

- Laser scanner

- Sensor (GIM International 2016)

The GPS (Global Positioning System) receiver is crucial for positional location. It is calculated via geometric computation from at least four satellites that gives aircraft instantaneous $\mathrm{X}, \mathrm{Y}$ and $\mathrm{Z}$ location. For positional accuracy requirements and standards, the GPS receiver is a critical component for depth measurements.

The IMU mounted inside the Lidar system calculates the movement (roll, pitch, and yaw) of the aircraft. This is important because, without these corrections, there are many distortions and wrong positional information resulting in poor hydrographic data values.

The Laser scanner component sends specified wavelengths (green, infrared etc.) in a particular form to the surface of the water and bottom of the waterbody to measure depth and topography based on reflection characteristics.

The sensor reads the returning signals. Based on these readings, surveyors can manipulate the measurement data to create various types of hydrographic surveys. Some sensors can process $>100,000$ points/second in shallow water (GIM International 2016). 
Hydrographic Lidar sensors are more easily impacted by environmental conditions when compared to other types of sonar. It is important to consider weather conditions, vegetation density in the project area, and water turbidity (GIM International 2016). Weather conditions such as clouds, fog, and high humidity can cause false returns to the sensor. Vegetation, which is highly reflective of infrared light, can create a misleading point cloud and complicate data processing. Turbidity is also an important environmental factor when collecting Lidar bathymetric data. Project areas with high turbidity create challenges for Lidar bathymetric surveys because the green light cannot penetrate the water. Instead, it is dispersed in the water column.

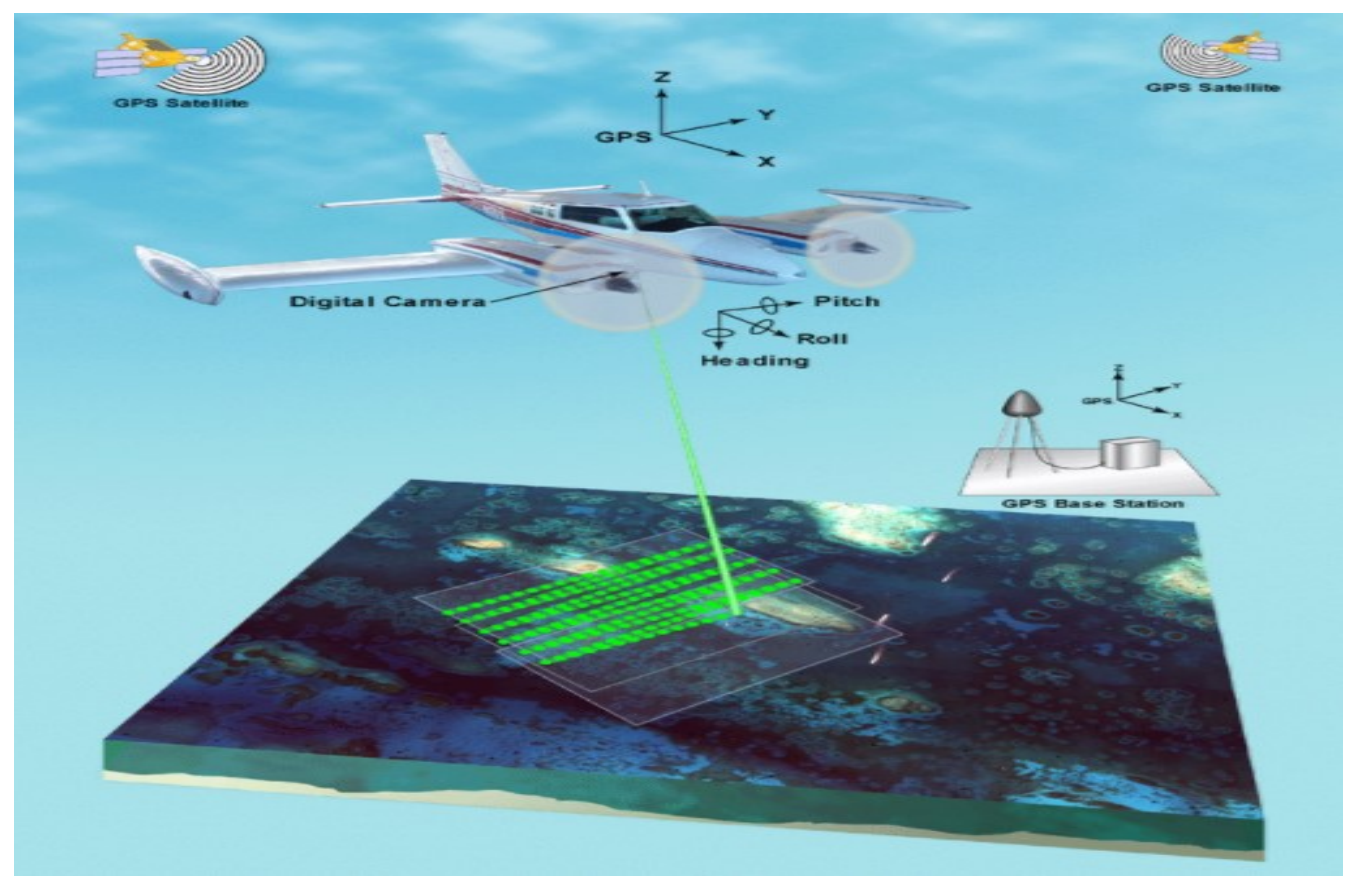

Figure 1.7. Airborne Lidar (U.S. Geological Survey Department of the Interior/USGS 2016).

\section{Satellite Derived Bathymetry}

SDC (Satellite Derived Bathymetry) is a hydrographic survey method found on satellites such as Landsat and WorldView2. Using reflected sunlight or specific light from the electromagnetic spectrum, the depth value of waterbody can be observed. 


\section{- Optical Satellite Derive Bathymetry}

The first Optical SDB was developed in the 1970's (Teamsurv, https://www.teamsurv.com/Why/Hydrographic-survey-methods n.d.). Optical SBD uses reflected sunlight to measure the depth of the waterbody. Shallow areas are shown as bright, while deeper areas are black in the same SDB images. However, black areas may also represent shadow. Recent developments in the technology have improved this hydrographic survey method by improving the resolution and utilizing multiple spectral bands. Generally, an optical SDB method can measure depths up to 30 meters with good water clarity and weather conditions (Figure 1.8) (Base Platform n.d.).

Overall, optical SDB provides:

- Good coverage with depth and image limitations that is better than SBES and traditional lead line method, but not accurate as MBES. Feature detection cannot be implemented as successfully as with MBES.

- Better object detection than lead line hydrographic survey method. However, optical SDB cannot determine depths as precisely as SBES with side scan or MBES.

- Good positional accuracy as SBES or MBES. It is better than lead line hydrographic survey method.

- Poorer depth accuracy than SBES, MBES, and traditional lead line method. (CSPSWG 2015)

It is important to note an optical SDB requires previously determined depths for calibrating the satellite information. It must be calibrated for each bottom type of the waterbody, and water column properties in the intended project area (Base Platform n.d.).

This limitation can be overcome by utilizing a MIP (Modular Inversion Processor) that provides an optical SDB to collect hydrographic data without the dependence of the depth information (Base Platform n.d.). This is a physics-based method that considers the 
physical relationship between measured light and water column depth (Base Platform n.d.).

Typical optical SDB specifications:

- Depths $0-30 \mathrm{~m}$

- Spatial resolution $2-15 \mathrm{~m}$

- Vertical accuracy 0.5m +/- 10\% depth CE90 (Circular Error) (Base Platform n.d.)

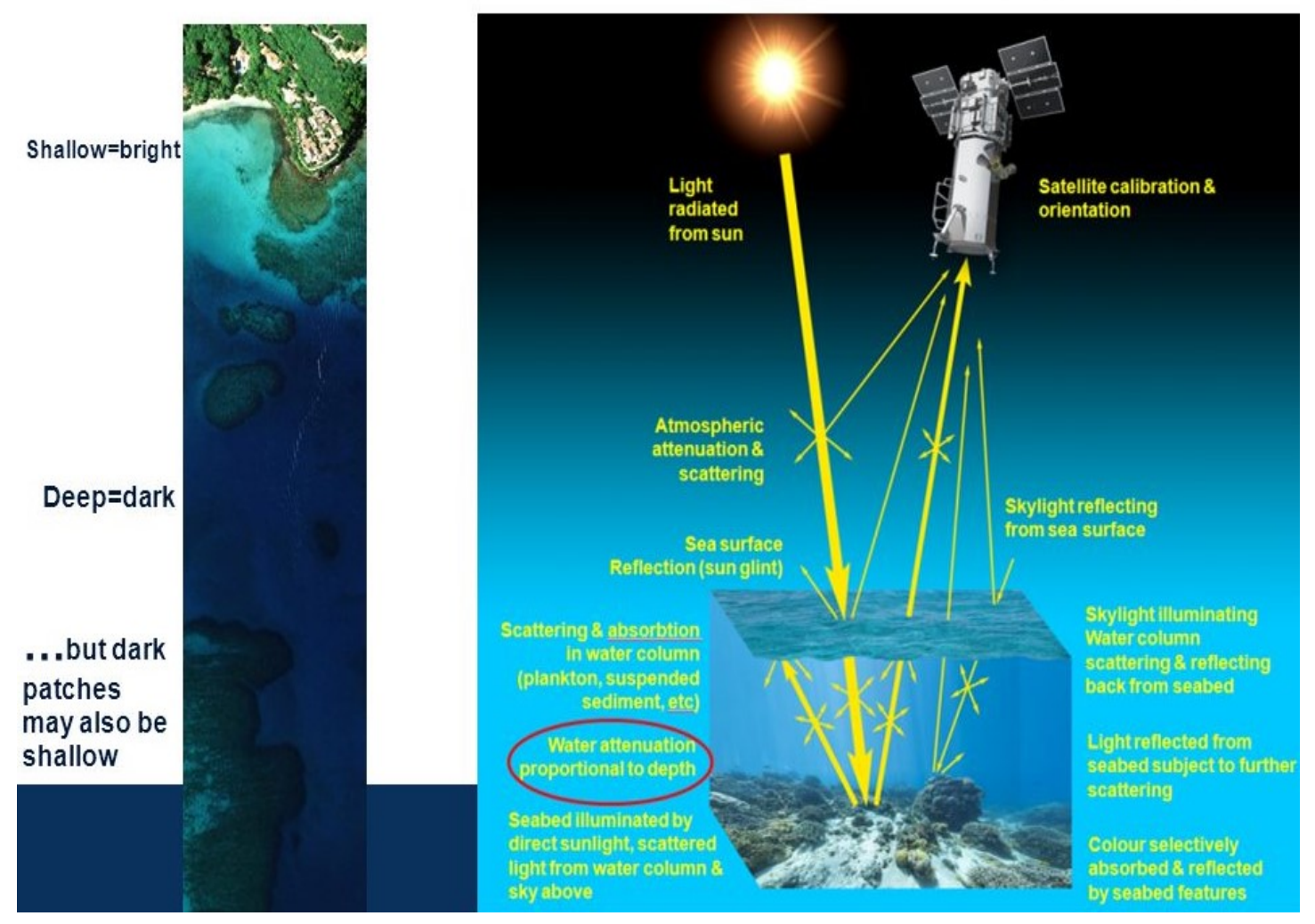

Figure 1.8. Optical SDB Method for Hydrographic Survey (Figure 1.8. Optical SDB Method for Hydrographic Survey (Courtesy UKHO, contains WorldView-2 satellite imagery CDigitalGlobe 2013).

\section{- Satellite Radar Altimetry}

In physics, the ocean surface is considered flat, but in some cases the ocean surface will become bumpy due to changes in the earth's gravitational field. (Sandwell, and Smith 
1990). Even though this rise and fall cannot be seen with the naked eye, radar technology can observe this roughness.

Satellite Radar Altimetry (Figure 1.9) is a hydrographic depth measuring technique calculating waterbody surface height with a satellite mounted radar altimeter. This technology determines waterbody surface depths and lakebed topography for very large areas such as an ocean. Satellite Radar Altimetry is capable of detecting inward and outward bulges on the sea surface and provides similar information about the lake floor topography. Satellite radar altimetry method is used to infer the occurrence of mountains below the water's surface (NOAA/NESDIS/STAR 2016). However, this topography should be at least a mile high and wide. Underwater mountains have gravitational anomalies surrounding them that pull on the earth's gravity field, making the water bulge (NOAA/NESDIS/STAR 2016).

Satellite radar altimetry has several advantages for bathymetric surveys over large areas such as oceans. First, it generates smoother, more uniform bathymetric data. Secondly, it records signals much faster than echo sounding and efficiently samples large areas. This information contributions to understanding the role of the ocean in entire geologic processes of the earth. Finally, the topography of the ocean floor is crucial for acquiring information about the possibility of natural disasters such as tsunami (IEEE 2005). Satellite radar altimetry is not accurate and does not give small detail as echo sounding method. The best hydrographic model of the ocean combines proper (conventional) echo soundings with satellite radar altimetric bathymetry (NOAA/NESDIS/STAR 2016). 


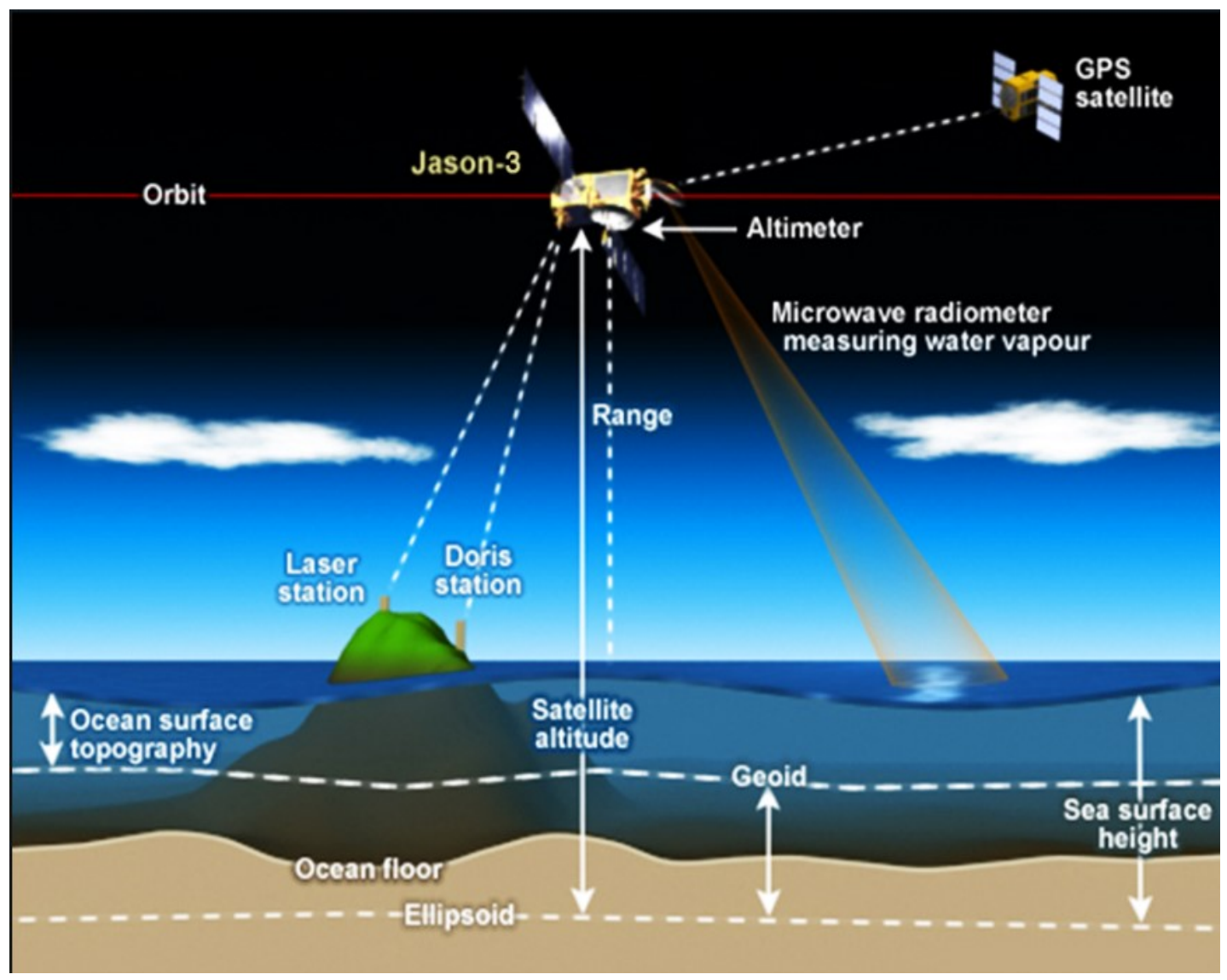

Figure 1.9. Satellite Radar Altimetry Method (NOAA/NESDIS/STAR 2016).

\section{- SAR (Synthetic Aperture Radar) Hydrographic Method}

SAR (Synthetic Aperture Radar) hydrographic survey methods consider waterbody roughness. SAR is an active remote sensing instrument utilizing microwaves $(10 \mathrm{~mm}-1$ m) to create images for hydrographic applications (Weignen Huang, Bin Fu 2004). This system collects viable data regardless of weather conditions or time of day.

SAR technology is similar to satellite radar altimetry because it infers waterbody topography from variations of the water surface. For example, when tidal currents occur, some elevated topographic features become visible on SAR systems. This is a crucial practice for marine navigation to reduce the chances of a shipwreck. In addition, SAR hydrographic methods derive uniform bathymetric information over large waterbodies. Another benefit of using SAR hydrographic technology is that it is cheaper and faster 
than sounding methods. However, the quality of lake floor topography currently does not meet IHO standards. Hence, the best approach is to combine SAR hydrographic data with a sounding system to map lakebed topography. This method uses depth profiles from acoustic sounders to interpolation the SAR imagery. (Weignen Huang, Bin Fu 2004). Therefore, SAR technology can reduce the number of ship tracks yet still meet IHO standards, and save time (Weignen Huang, Bin Fu 2004).

Using a SAR system and soundings can be very time and cost effective. The approach to using both sounding system and SAR system concurrently consists of four steps. They are sounding data tracks for SAR system adjustment, tidal data, wind speed and direction at the time of SAR survey, and SAR image (Weignen Huang, Bin Fu 2004).

\subsubsection{Horizontal position fixing measurements}

Creating the topography of the lake floor requires both vertical and horizontal information. Horizontal position fixing is crucial to precisely determine vertical depth measurements on the lakebed (Office of Coast Survey n.d.). Lakebed classifications, environmental coastal management, handling hazardous materials near the coastline, marine navigation, petroleum exploration and so on requires horizontal position information. Thus, surveyors developed horizontal fixing position methods for hydrographic surveys from the start. Early horizontal positional information using traditional methods resulted in mediocre accuracy because of lack of precision. Nowadays, there are several ways to obtain precise offshore positional information.

\section{Horizontal position fixing with traditional optical method}

Obtaining horizontal information with the traditional optical method is an older type of measurement. During the observation, water body should be very calm. Horizontal position fixing with the traditional optical method can be implemented in two ways: from the shore using two theodolites or from the vessel using a sextant (EPA 1987). 


\section{- Theodolite Intersection}

The theodolite intersection method (Figure 1.10) calculates a horizontal position for the vessel. Using two theodolites from different locations, and observing the angle of a reference point and the reflector mounted on the vessel simultaneously. According to Ingham (1975), the precision of the single angle measurement, is \pm 15 seconds with an intercept angle near $45^{\circ}$ and a range of $5 \mathrm{~km}(3.1 \mathrm{mi})$, and gives an accuracy of $\pm 1 \mathrm{~m} \mathrm{(3.3}$ ft.) (EPA 1987).

This approach is challenging for several reasons. First, vessel movement causes two theodolite measurements at the same time when there should be only one, resulting in small but critical angle changes. When distance is considered, these small angle variations cause vessel location points with larger errors than anticipated. For better accuracy, measuring angles should be between $30^{\circ}$ and $150^{\circ}$. In addition, the line between the two theodolites should intersect at almost right angles at the vessel point (EPA 1987). Finally, environmental conditions such as weather conditions (fog, rain, hot vapor, windy weather (causes wavy water surface)), vessel movement, currents, and rocky places crossing the survey path will affect the quality of the position fixing adversely. However, the theodolite horizontal position fixing method can be beneficial for shallow and very stable waters, harbors and very restrictive areas where a survey vessel cannot be operated. Even though theodolite horizontal positioning gives an acceptable accuracy for all three classes of IHO standards from the $300 \mathrm{~m}$ of the onshore, this method is not commonly used anymore because of the technological advancements and improved equipment (Sciortino, Food and Agriculture Organization of the United Nations 2010). 


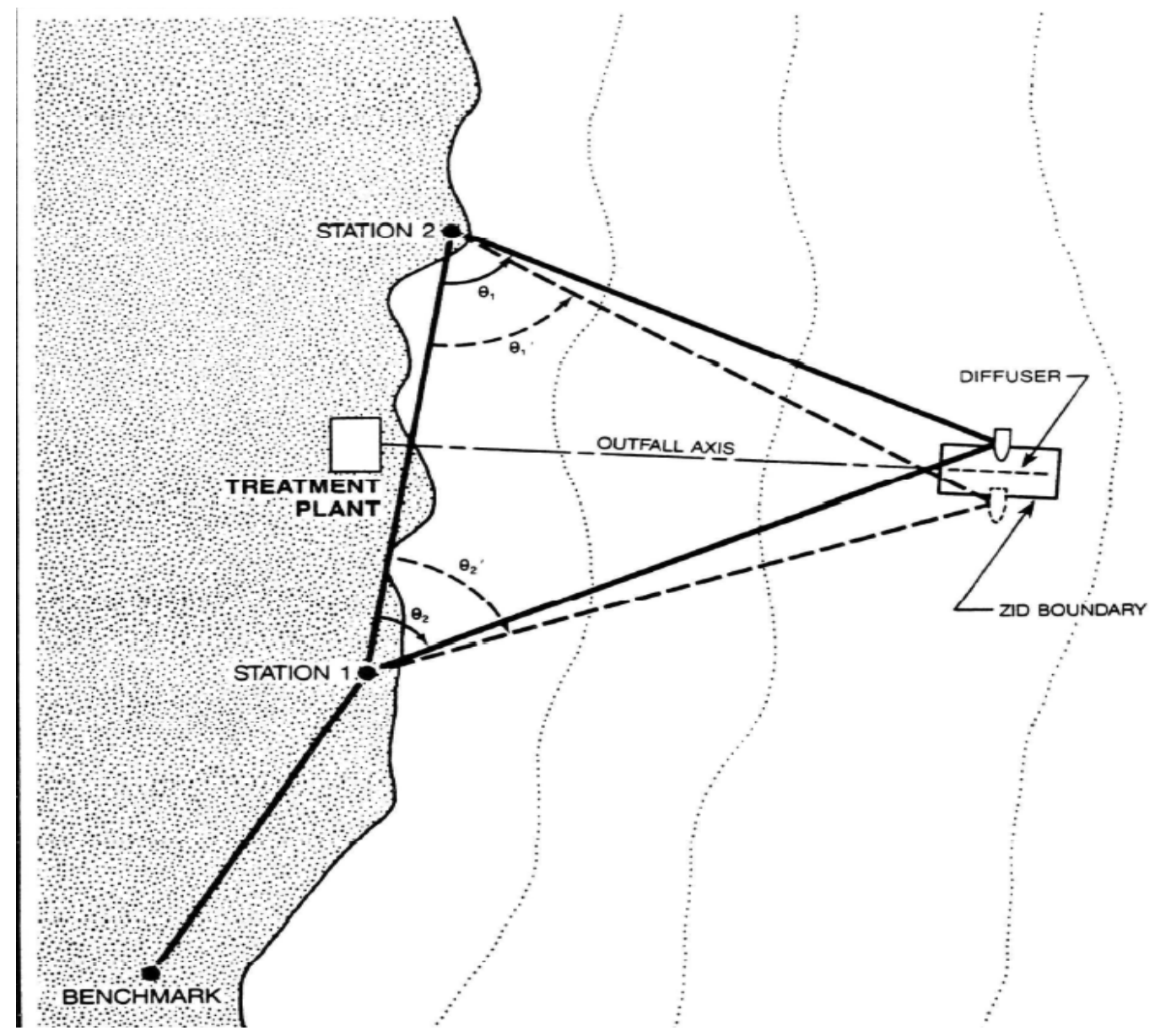

Figure 1.10. Theodolite Horizontal Position Fixing Method (EPA 1987).

\section{$>$ Parallel Line Method}

The parallel line method (Figures 1.11 and 1.12) is a very old horizontal position fixing method that covers the intended survey area in perfectly calm weather and water conditions. The hand-held optical square and the calibrated sounding chain are used to create soundings operations. The rule of the parallel line method establishes parallel straight baselines tied with rods on the water surface. At every 5 meters a steel peg is nailed for irregular topography, and 10 meters for flat terrain (Sciortino, Food and Agriculture Organization of the United Nations 2010). Using a hand-held optical square creates a location of buoys offshore that surveyors can collect depth recordings using a traditional calibrated sounding chain. The operator reads the depth of the point from the seafloor, and the reading is manually recorded. 


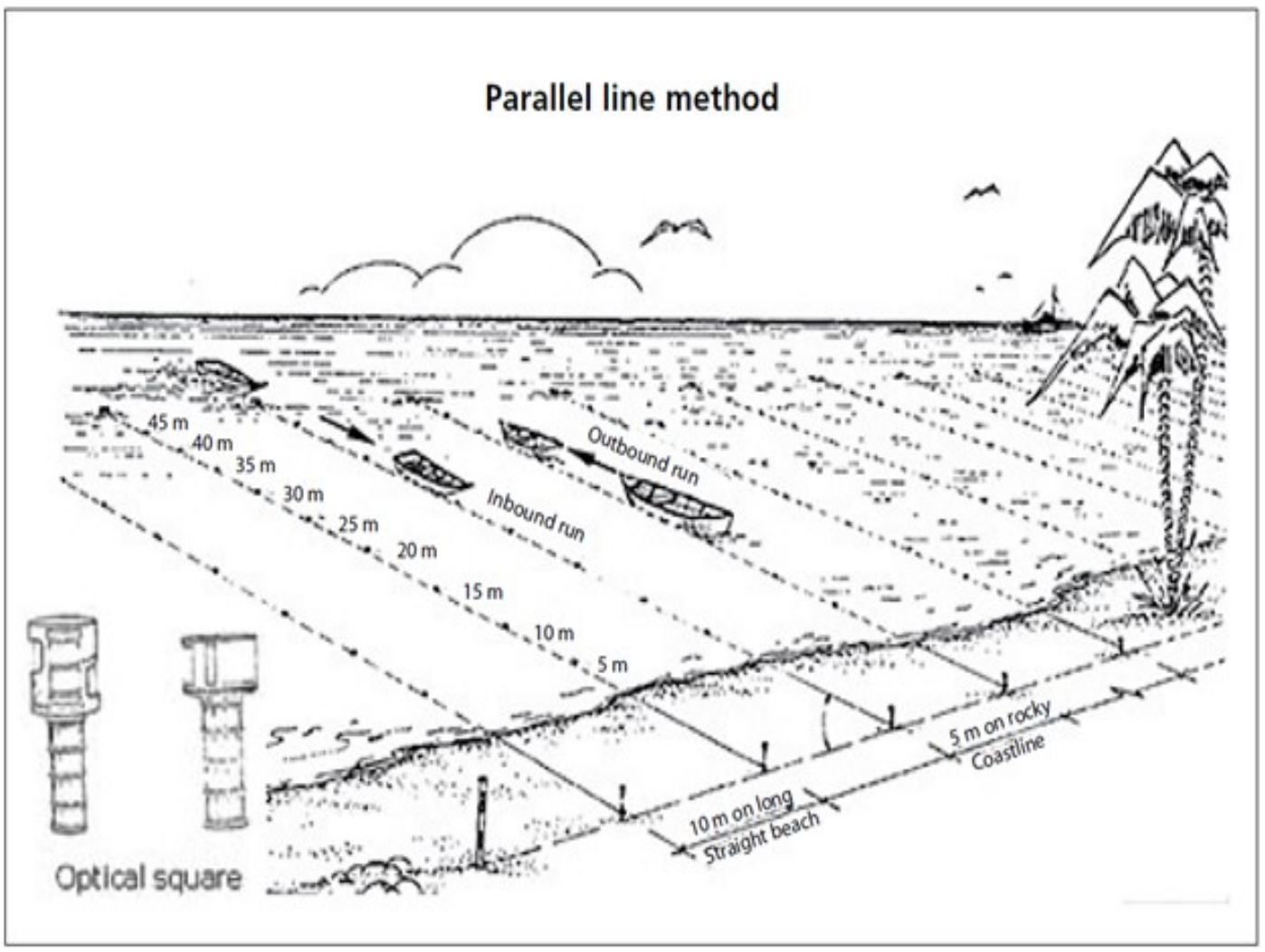

Figure 1.11. The Parallel Line Method (Sciortino, Food and Agriculture Organization of the United Nations 2010).

This traditional method is not useful anymore since it is labor intensive, and timeconsuming. 


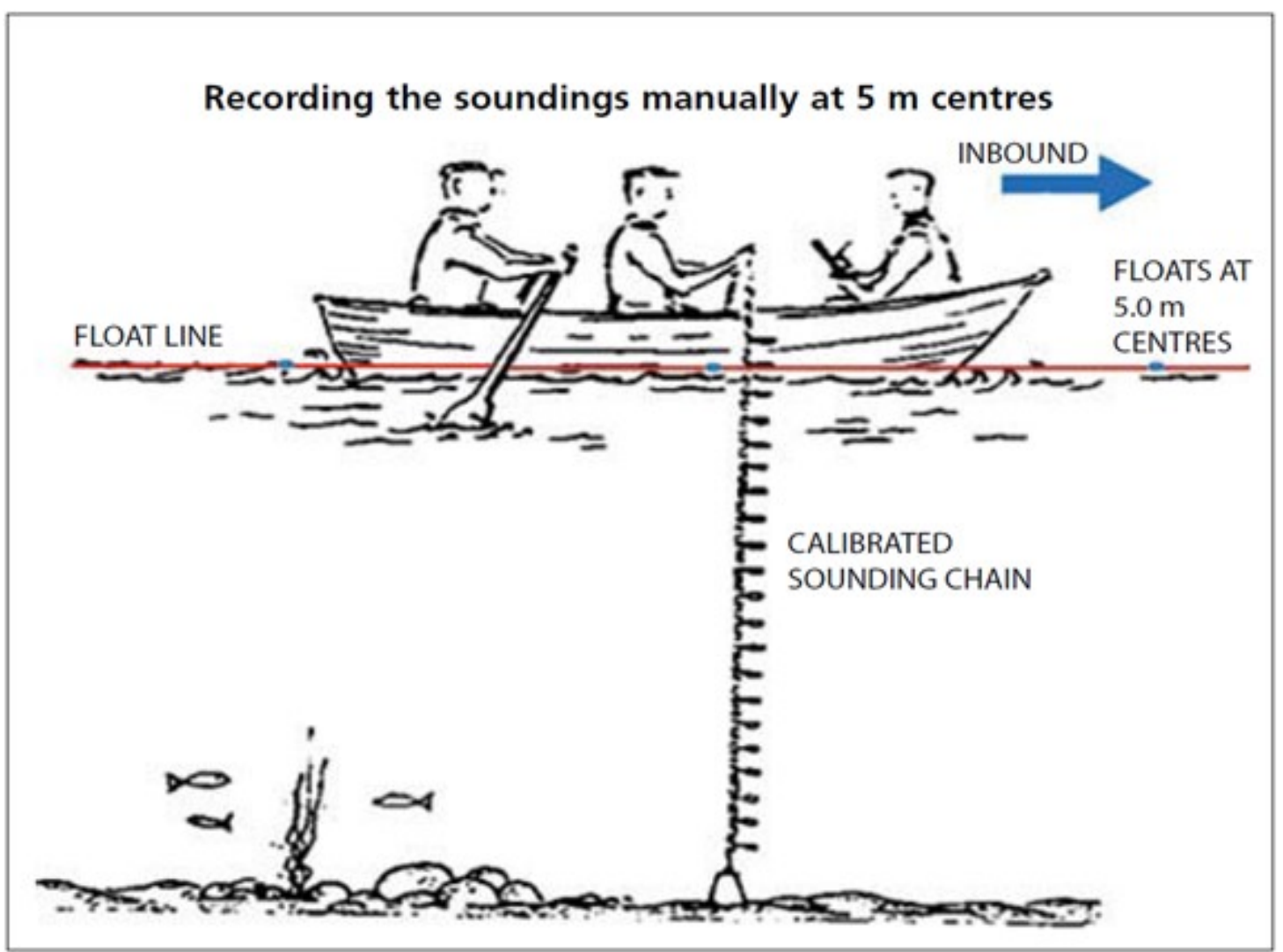

Figure 1.12. The Depth Recording with Traditional Parallel Line Method (Sciortino, Food and Agriculture Organization of the United Nations 2010)

\section{Electromagnetic Distance Measuring Systems}

Technological advancements for positioning measurements have improved significantly. Traditional methods are challenging, time-consuming, and labor intensive. Like any discipline, surveyors need time efficient collection methods, which provide quality data. These requirements have been some of the driving forces in equipment improvements and ease of use.

A good illustration of an electromagnetic measurement system is the Total Station (Figure 1.13). The first total station was manufactured in 1971, and was utilized for maritime projects with a large area (Hoffman 2013). Total station components consist of 
a reflector and the total station measurement instrument. Therefore, for horizontal position fixing of the vessel, the reflector can be mounted to the boat, and the total station can read the angle and distance from the reflector. Afterward, the instrument is setup on a confirmed coordinate location, and can calculate the horizontal position within few millimeters accuracy of the control point. The accuracy of the total station is excellent. Variations of a few millimeters $(5-10 \mathrm{~mm})$ per $\mathrm{km}$ can be achieves while using it for horizontal position fixing (The Constructor n.d.).

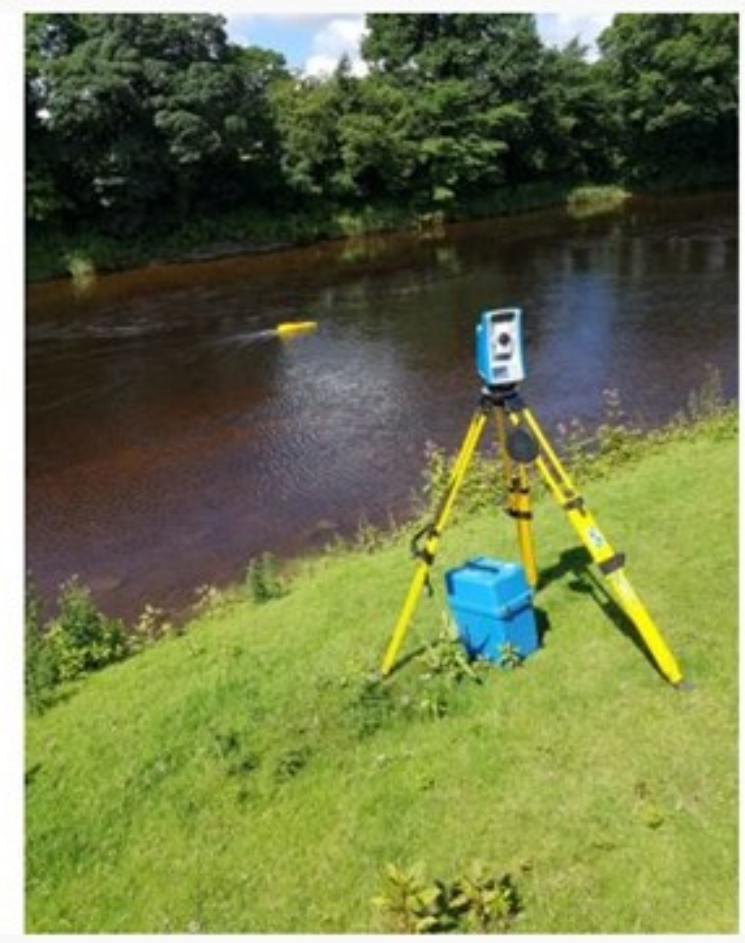

Figure 1.13. Bathymetric Survey Vessel Tracked with Total Station (GIM International 2016).

\subsubsection{Global Positioning System}

GPS (Global Positioning System) can be used to obtain a horizontal position for maritime projects. It is a satellite based system that is available at any time and any location on the earth. For marine projects, a GPS is a handy source for fixing horizontal positions. It is a straightforward, fast, and cost effective. Moreover, surveyors do not need a reference 
point, and satellites provide better observations since changes in elevation are not an impediment.

For determining horizontal position from GPS, surveyors need at least three satellites. However, $4^{\text {th }}$ satellite observation is so important for control. Practically, for maritime projects the vessel GPS receiver needs 4 satellites to calculate its horizontal position.

On the other hand, GPS has some disadvantages for gaining horizontal position. First, a tropospheric delay occurs in heavy weather conditions. Hence, a GPS receiver obtains data with a tropospheric delay. To prevent tropospheric delay, surveyors can operate the survey in optimal weather conditions. Secondly, the atmospheric level of ionosphere should be taken into consideration as it causes a signal delay when the ionospheric layer intensity is near the maximum level. This delay can be corrected for in post processing. Additionally, multipath effects can created incorrect signals and introduce considerable horizontal positional errors. This happens around long structures and reflective surfaces. To minimize this effect, surveyors can manipulate elevation angle of the GPS receiver. Last, but not least, the positional satellite condition (DOP (Dilution of Precision)) is an important issue for getting proper horizontal accuracy. A good satellite geometry always gives better results. The GPS precision is shown in Figure 1.14), and the RTK (Real-time Kinematic) GPS principle in maritime operation is illustrated in Figure 1.15.

\begin{tabular}{|l|l|l|}
\hline $\begin{array}{c}\text { Positioning } \\
\text { Mode }\end{array}$ & \multicolumn{1}{|c|}{$\begin{array}{c}\text { Typical Horizontal Accuracy (5 } \\
\text { SVs, PDOP<4) }\end{array}$} & Maximum Operating Range \\
\hline Static & $\begin{array}{l}\text { Horizontal: } 5 \mathrm{~mm}+1 \mathrm{ppm} \text { Vertical: } \\
10 \mathrm{~mm}+1 \mathrm{ppm}\end{array}$ & $\begin{array}{l}\text { Several } 100 \mathrm{~km} \text { depending on } \\
\text { satellite geometry }\end{array}$ \\
\hline $\begin{array}{l}\text { Real-time } \\
\text { Kinematic }\end{array}$ & Horizontal $1 \mathrm{~cm}+2 \mathrm{ppm}$ & $\begin{array}{l}\text { Recommended: }<10 \mathrm{~km} \\
\text { Vertical: } 2 \mathrm{~cm}+2 \mathrm{ppm}\end{array}$ \\
\hline
\end{tabular}

Figure 1.14. GPS Accuracy for Maritime Projects (U.S. Geological Survey Department of the Interior/USGS 2017). 


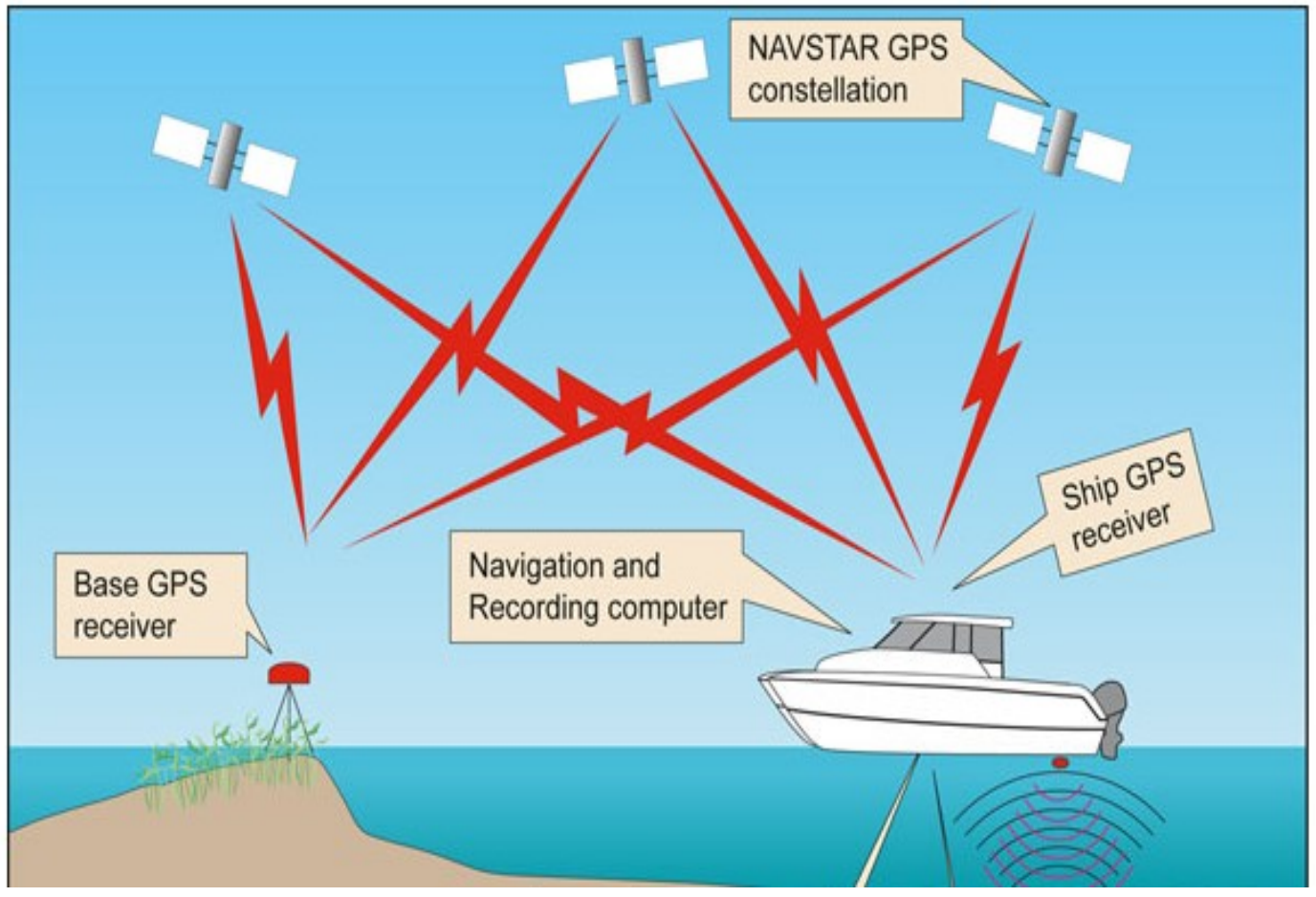

Figure 1.15. RTK GPS Method for Maritime Projects (U.S. Geological Survey Department of the Interior/USGS 2016)

\subsubsection{Differential Global Positioning System}

DGPS (Differential Global Positioning System) is a horizontal positioning method for maritime projects. DGPS provides better accuracy than nominal GPS applications (pseudo-range measurements that vary from $8 \mathrm{~m}$ to $10 \mathrm{~cm}$ ). DGPS uses a reference station that provides corrections to the vessel GPS receiver. Consequently, the result of horizontal position should be better $(<10 \mathrm{~cm})$ than the nominal GPS solution.

Furthermore, differential corrections can be applied in real-time and in post-processing. DGPS can be used for the source of navigation, maritime traffic, route assessment, and horizontal position fixing.

In conclusion, DGPS tends to provide better accuracy than pseudo-range GPS measurements. In addition, DGPS can be used over long distance. However, RTK GPS method is better for a precise horizontal fixing solution. 


\section{Hydrographic Survey Considerations}

\subsection{Ellipsoids, Geoids and Datums}

The earth is not a perfect ellipsoid or spheroid. It has an irregular dynamic shape called a geoid, which changes over time and with gravitational changes. No single geoid (Figure 2.1) can completely define the geometric shape of the earth. A datum defines the reference surface, which is connected to the earth and permits the establishment and use of $\mathrm{X}, \mathrm{Y}$, and $\mathrm{Z}$ coordinate systems. It is critical to understand the datum and its limitations when acquiring locational information. The same coordinates referenced to different datums can place the surveyor in very disparate locations.

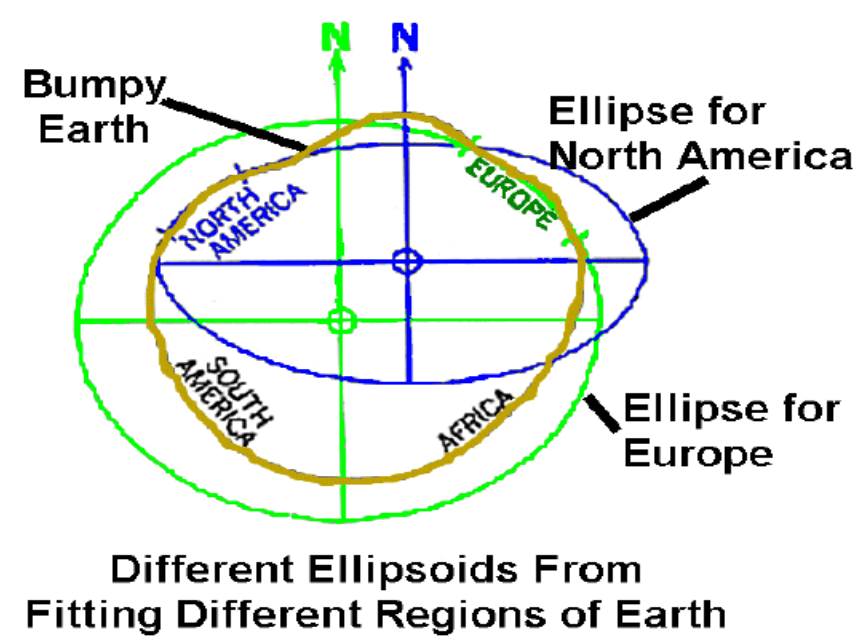

Figure 2.1. Ellipse model for different regions of the earth's surface (Clynch, James R., DMA TECHNICAL MANUAL 8358.1 DATUMS, ELLIPSOIDS, GRIDS, AND GRID REFERENCE SYSTEMS, http://clynchg3c.com/ 2006)

Selecting an appropriate datum is critical for accurate sounding measurements. According to NOAA (NOAA 2017):

- The horizontal datum can be NAD83 (North American Datum, 1983), UTM (Universal Transverse Mercator) for the local operations and WGS84 (World Global System, 1984) for the S-57 file. The S-57 format is a vector conversion 
format for nautical charts developed by the IHO (International Hydrographic Organization) (MapServer 2017).

- Sounding datum can be reduced to MLLW (Mean Lower Low Water). MHW (Mean High Water) can referenced for heights of bridges and overhead cables. On the Great Lakes, sounding data should fit the IGLD (International Great Lakes Datum of 1985).

- All data should work with UTC (Universal Time Coordinated) (NOAA 2017).

\subsection{Water Density}

Water density is congestion in the water column that affects the hydrographic survey. Surveyors should consider water density's impact measurement accuracy, especially the influence on sound velocity when the sonar system is recording depths.

The water density changes by water body type. To illustrate, seawater has higher density than a freshwater (ESRI 2017). In some cases, the water density coupled with high turbidity can prevent the emitted pulses reaching the water bottom, which results in "no data" for those areas.

\subsection{The Surveying Equipment Movement Effect}

During the bathymetric survey, either full autonomous or side-mounted sonar has movement anomalies (pitch, roll and heading). These movements are the most important variables to be accounted for and corrected. Otherwise, the variations cause wrong depth recordings and may fail to meet a specified class accuracy. 
X: Positive Starboard

Y: Positive Forward

Z: Positive Down

Roll: Positive Starboard Down

Pitch: Positive Bow Up

Heading: Positive Clockwise

Figure 2.2. Vessel coordinate system and direction of movements

\section{Study Area and Data Collection}

\subsection{The Area of Interest}

The Keweenaw Peninsula was one of the first copper mining regions in North America and the second largest producer of copper for the world between 1850 and 1929 (W. Charles Kerfoot et al. 2012), (Murdoch 1943), (Benedict 1952). Numerous stamp mills that processed the stamp rock to obtain native copper and silver were constructed around the Keweenaw Peninsula (W. Charles Kerfoot et al. 2012). Waste stamp sands were dumped next to the stamp mills and resulted in massive changes to shoreline topography and adjacent water bodies. No thought was given to this waste product and the environmental impact on maritime ecology and destruction of lakebed habitat.

To investigate the modification and destruction of lakebed habitat, the Buffalo Reef, an area between Grand Traverse Bay and Gay Bay was studied. Gay Bay is considered the source of the stamp sands, which include hazardous metals such as arsenic, chromium, copper and mercury that affect the native fish of Lake Superior. Buffalo Reef is a critical habitat for native fish that that is being filled in toxic stamp sand and needs to be investigated (W. Charles Kerfoot et al. 2012). The movement of the stamp sands extends 
southwestward from Gay Bay. The sand has filled crevices within the reed, and native fish, such as trout and whitefish can no longer spawn on the reef. This condition affects the marine ecosystem balance, fishing economy, and the Buffalo Reef habitat.

Sonar data was collected along 5 transects within the study site (Figure 3.1) The first four lines are from the coast to the offshore in a general west to southeast direction. The fifth transects goes from the southwest to the north east and crosses the eastern end of the first 4 transects. 


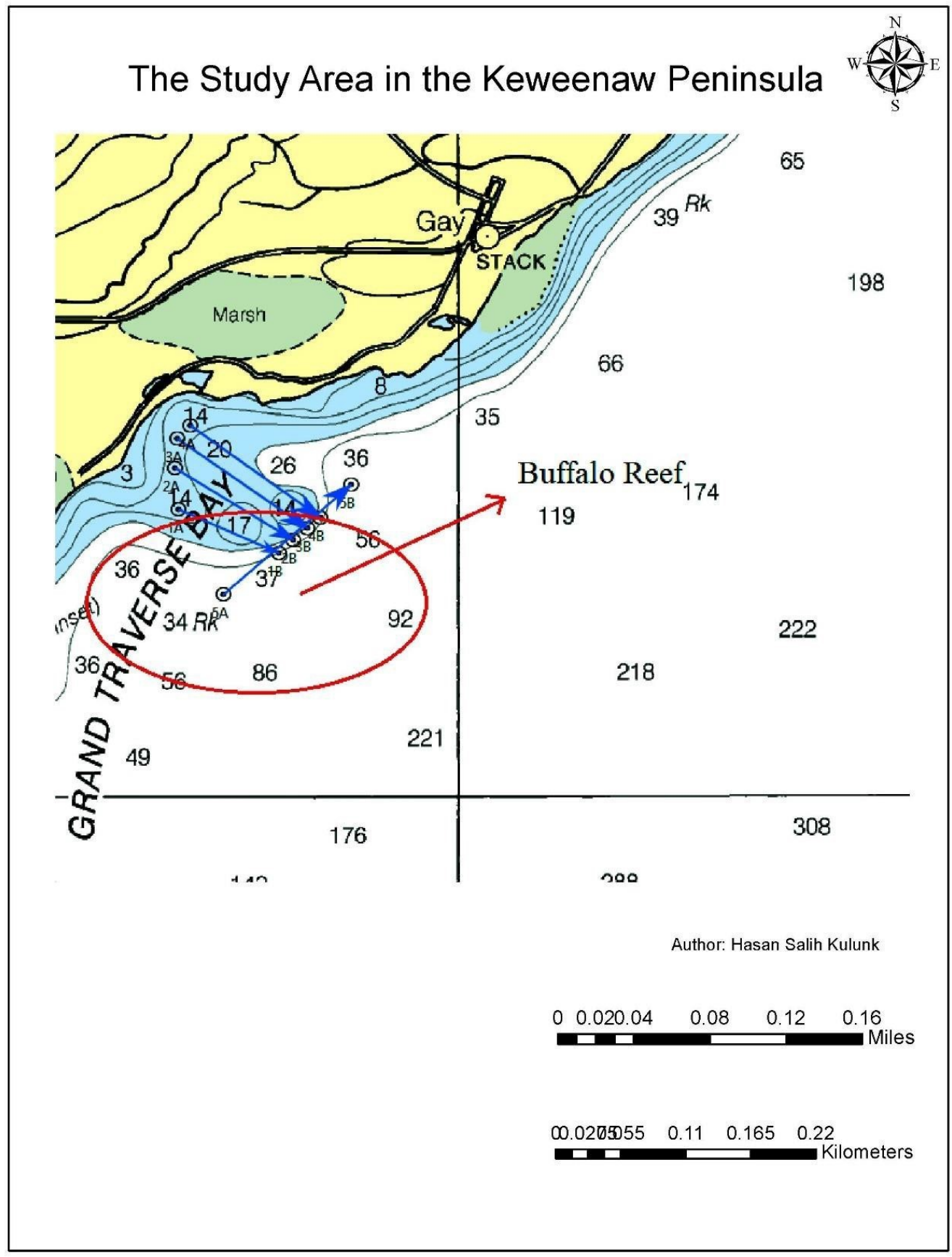

Figure 3.1. The area of interest that five surveying line were chosen for data acquisition (NOAA, http://www.charts.noaa.gov/OnLineViewer/14964.shtml 2017). 


\subsection{Data Collection}

Along the five transect lines, the data was collected by an Edgetech 4125 side-scan sonar which was towed behind the survey ship. Specifications for the Edgetech system are presented in Table 3.2. Additional data was acquired by an Iver3 sonar system, a fully autonomous under water vehicle which has bathymetry and side-scan capabilities. The purpose of using two different systems was to investigate the type and quality of information that can be extracted from each dataset. Data for each sensor was collected on different days. Therefore, some criteria such as wave factor were noted when the Edgetech system was utilized.

Table 3.1. Data collection information with Iver 3 sonar

\begin{tabular}{|l|c|c|c|c|c|}
\hline File Name & T1 & T2 & T3 & T4 & T5 \\
\hline Route & $1 \mathrm{~A}-1 \mathrm{~B}$ & $2 \mathrm{~A}-2 \mathrm{~B}$ & $3 \mathrm{~A}-3 \mathrm{~B}$ & $4 \mathrm{~A}-4 \mathrm{~B}$ & $5 \mathrm{~A}-5 \mathrm{~B}$ \\
\hline First Recording & $11: 06 \mathrm{AM}$ & $11: 33 \mathrm{AM}$ & $12: 04 \mathrm{PM}$ & $12: 34 \mathrm{PM}$ & $1: 05 \mathrm{PM}$ \\
\hline Last Recording & $11: 23 \mathrm{AM}$ & $11: 54 \mathrm{AM}$ & $12: 30 \mathrm{PM}$ & $1: 00 \mathrm{PM}$ & $1: 42 \mathrm{PM}$ \\
\hline Wave & Avoidable & Avoidable & Avoidable & Avoidable & Avoidable \\
\hline Vessel Speed & 2.5 knots & 2.5 knots & 2.5 knots & 2.5 knots & 2.5 knots \\
\hline Starting Depth & 3.6 meter & 9.2 meter & 3.6 meter & 8.1 meter & 8.5 meter \\
\hline $\begin{array}{l}\text { Maximum } \\
\text { Depth }\end{array}$ & 11.3 meter & 10.2 meter & 8.9 meter & 8.6 meter & 13.7 meter \\
\hline Range & 75 meters & 75 meters & 75 meters & 75 meters & 75 meters \\
\hline Direction & NW-SE & SE-NW & NW-SE & SE-NW & NE-SW \\
\hline
\end{tabular}


Table 3.2. Data collection information with the Edgetech 4125 Side-scan sonar

\begin{tabular}{|c|c|c|c|c|c|}
\hline File Name & T1 & $\mathbf{T 2}$ & T3 & T4 & T5 \\
\hline Route & $1 \mathrm{~A}-1 \mathrm{~B}$ & $2 \mathrm{~A}-2 \mathrm{~B}$ & $3 A-3 B$ & $4 A-4 B$ & $5 A-5 B$ \\
\hline First Recording & $10: 25 \mathrm{AM}$ & 11:01 AM & 11:32 AM & 12:01 AM & $12: 30 \mathrm{AM}$ \\
\hline Last Recording & $10: 45$ AM & 11:16 AM & $11: 48$ AM & 12:17 AM & 12:47 AM \\
\hline Wave & $\begin{array}{l}1 \text { foot } \\
(12-15 \text { knots })\end{array}$ & half a foot & $\begin{array}{l}0.75 \text { foot }(10 \\
\text { knots })\end{array}$ & $\begin{array}{r}<0.25 \text { foot } \\
\text { (5 knots) }\end{array}$ & 0.75 foot \\
\hline Vessel Speed & 3.0 knots & 3.2 knots & 3.8 knots & 3.9 knots & 3.6 knots \\
\hline Starting Depth & 15 feet & 15 feet & 15 feet & 15 feet & 55 feet \\
\hline $\begin{array}{l}\text { Maximum } \\
\text { Depth }\end{array}$ & 15 meters & 15 meters & 15 meters & 15 meters & 18 meters \\
\hline Range & 75 meters & 75 meters & 75 meters & 75 meters & 90 meters \\
\hline Direction & NW - SE & NW - SE & NW - SE & NW - SE & SW- NE \\
\hline
\end{tabular}




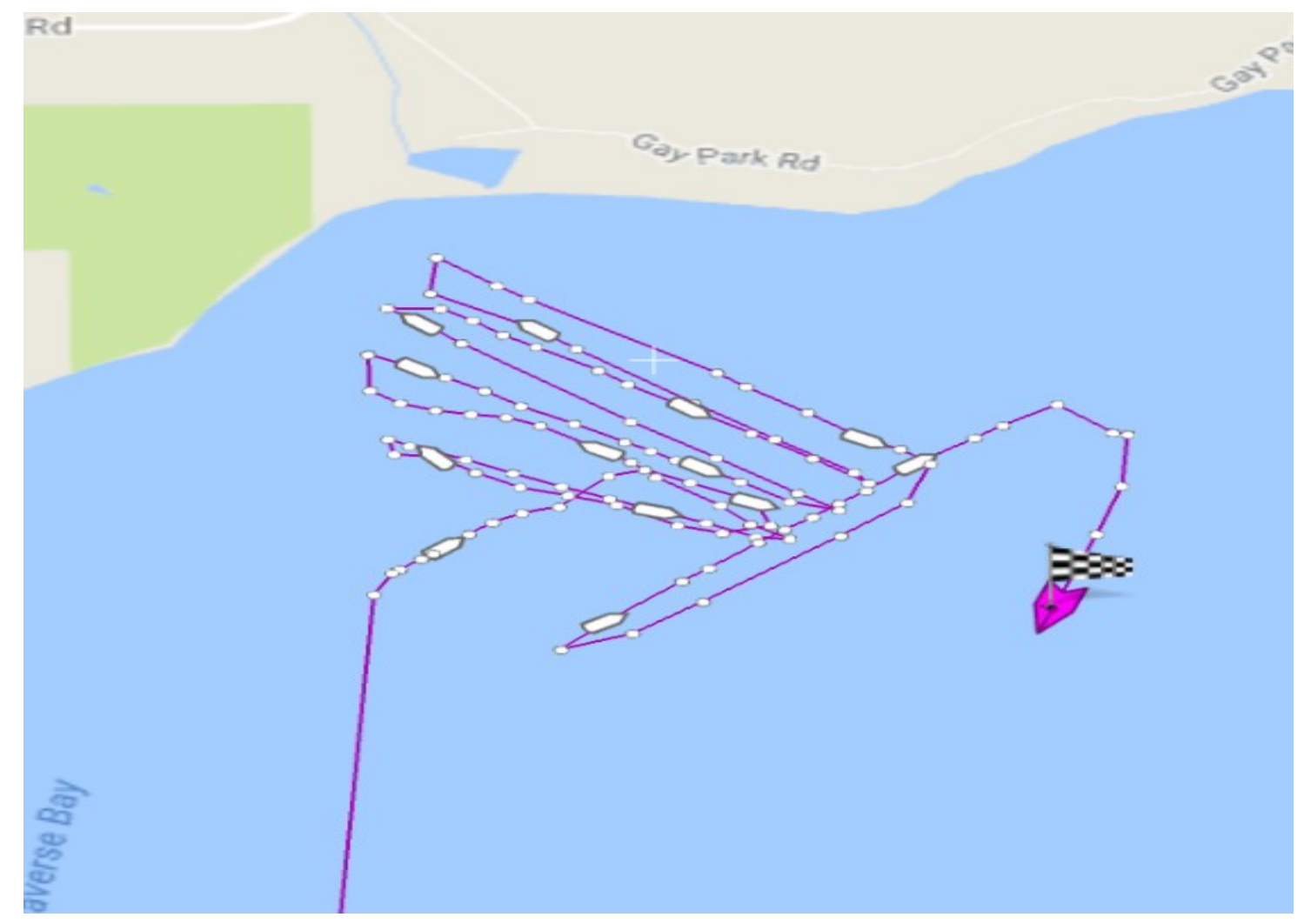

Figure 3.2. The data collection transects utilizing the Edgetech 4125 side-scan sonar, which is towed behind the survey vessel.

The results of the raw side-scan data (Figure 3.3) from the Edgetech 4125 side-scan sonar, which was towed behind the survey vessel, are not as straight as the Iver 3 sidescan data because of the survey vessel movement. 


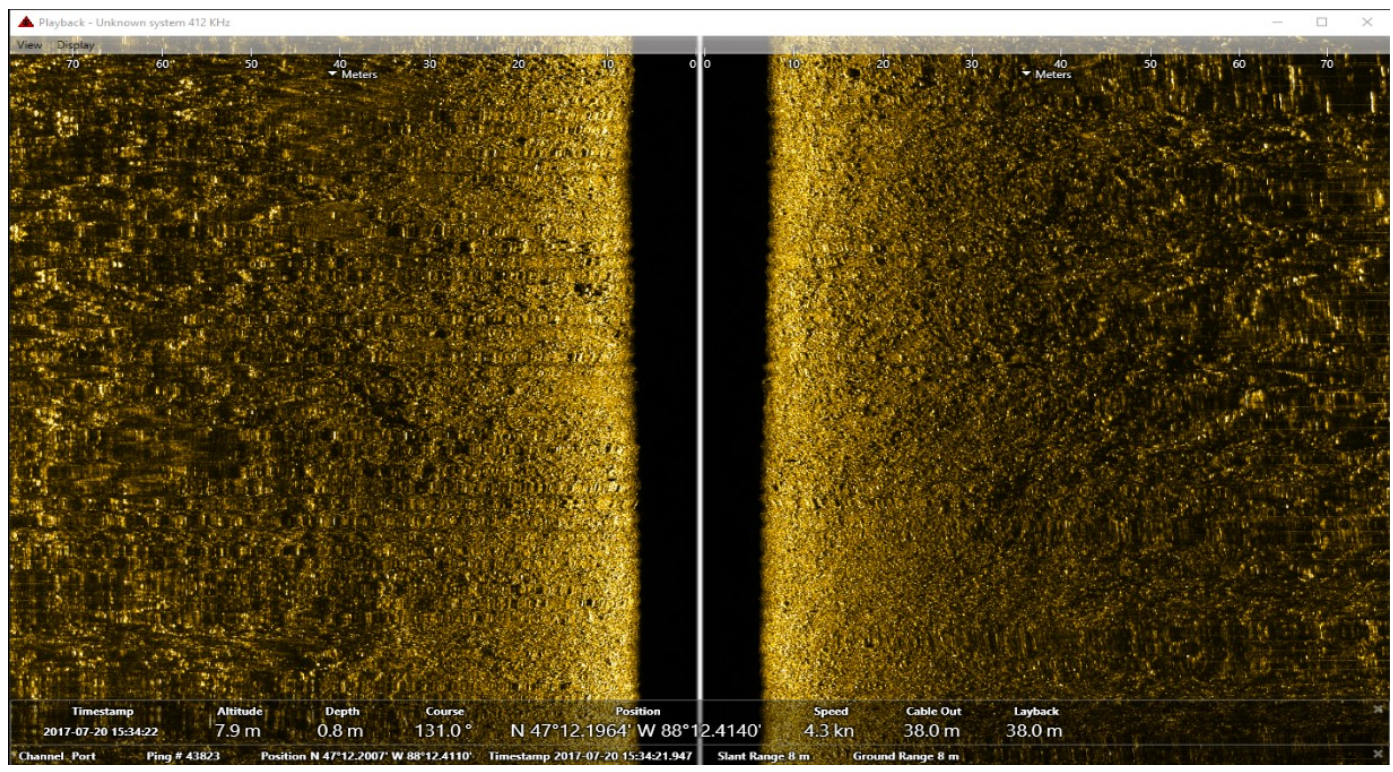

Figure 3.3. The raw side-scan data from Edgetech 4125 Side-scan sonar that is towed behind the survey vessel shown on the Discover 2 software display.

An example of the Iver 3 sonar side-scan data is shown in Figure 3.4.

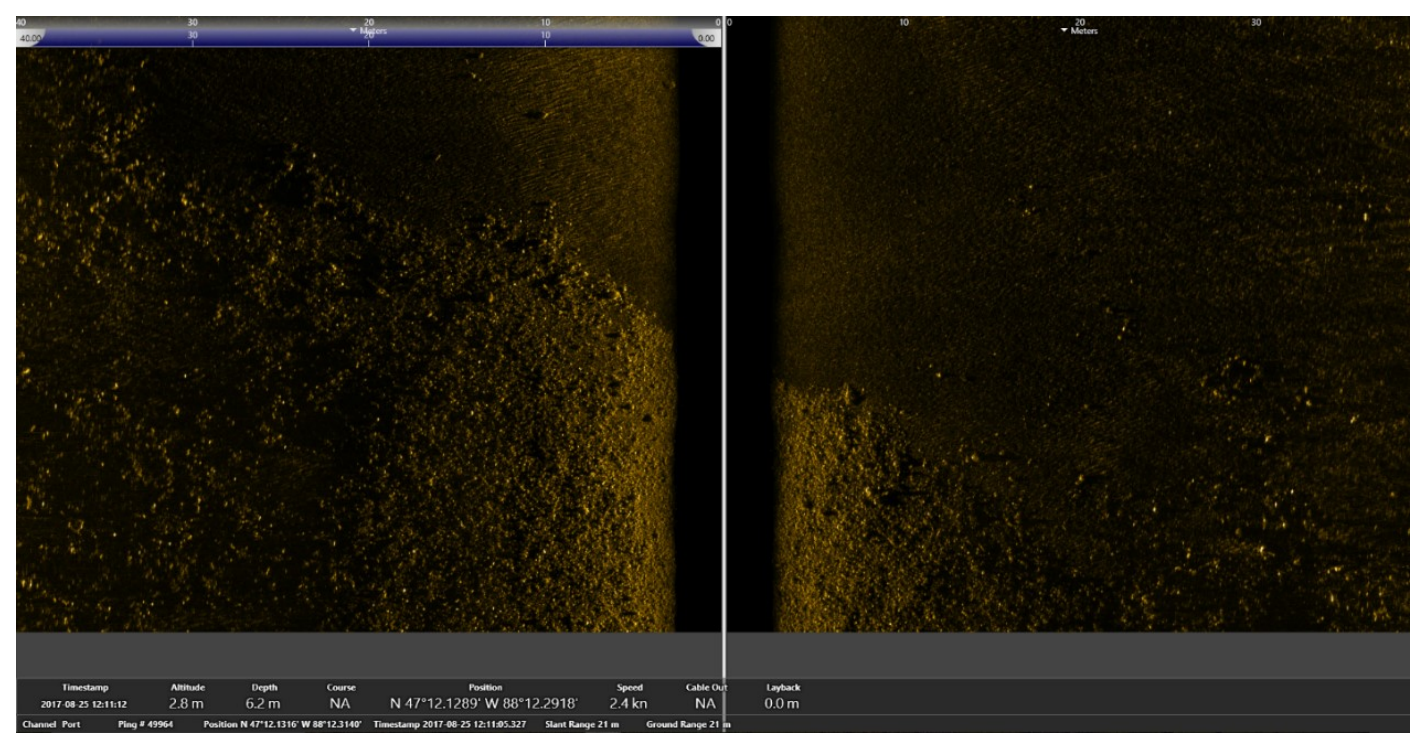

Figure 3.4. Iver 3 raw side-scan data shown on the Discover 2 software display. 


\subsection{Post Processing and Imagery Classification}

For the image classification analysis, transect 3 and the intersection area between transects 3 and 5 were selected for analyses (Figure 3.5) because they contained the bottom features of interest. SonarWiz 7, Discover 2, ArcGIS 10.5, and ERDAS Imagine software packages were used for the classification process.

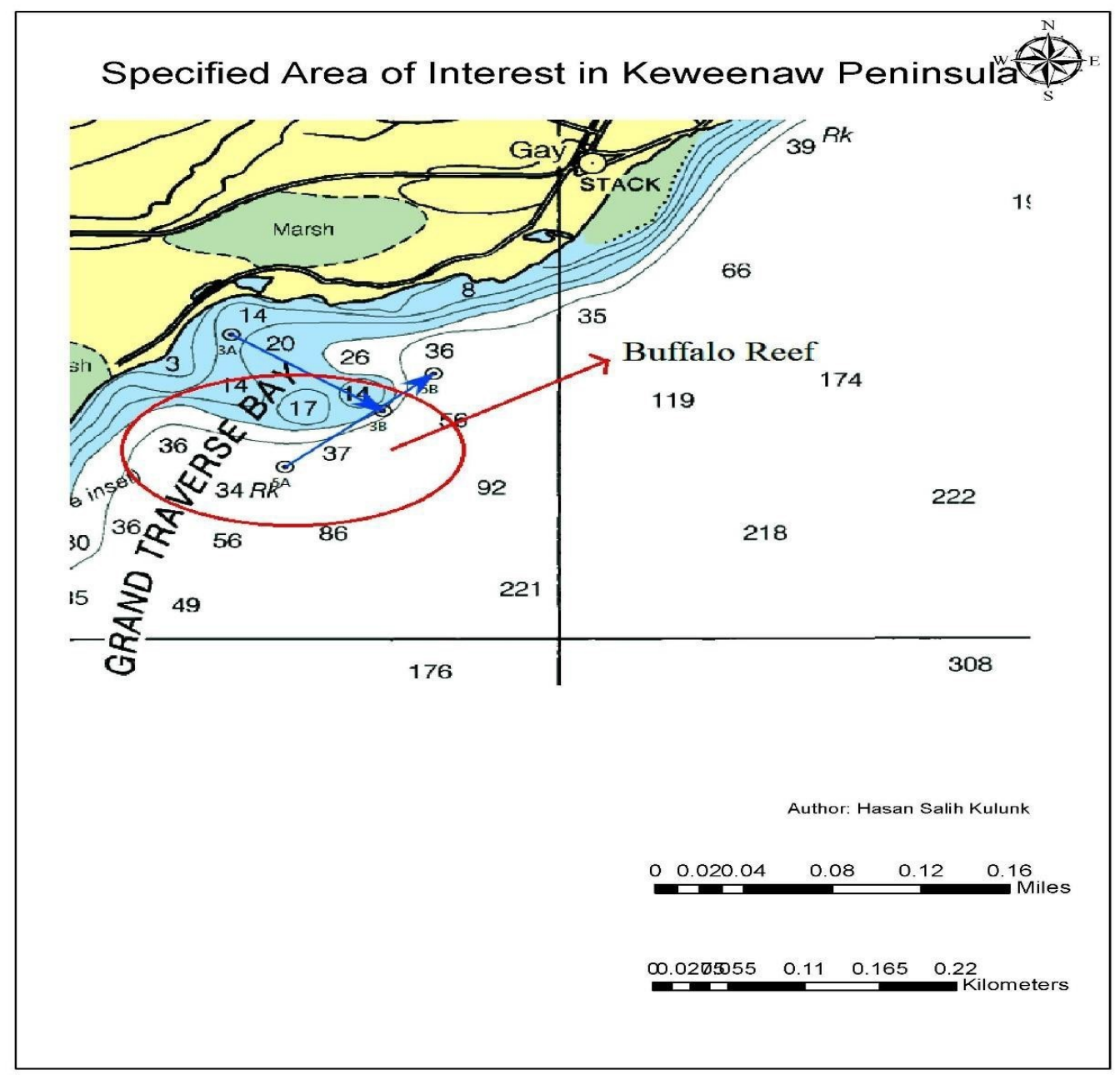

Figure 3.5. Specified area of interest for classification investigation (NOAA, http://www.charts.noaa.gov/OnLineViewer/14964.shtml 2017). 


\subsubsection{Post Process Iver 3 Side-scan and Edgetech 4125 Side-scan Sonar Data}

The first step of post processing is specifying the coordinate system used in collecting the data. Data was collected using the UTM-WGS 1984 Datum, Zone 16 N. Afterward, the raw side-scan data of line three and the intersection of line three and five were imported in SonarWiz 7 (Figure 3.6).

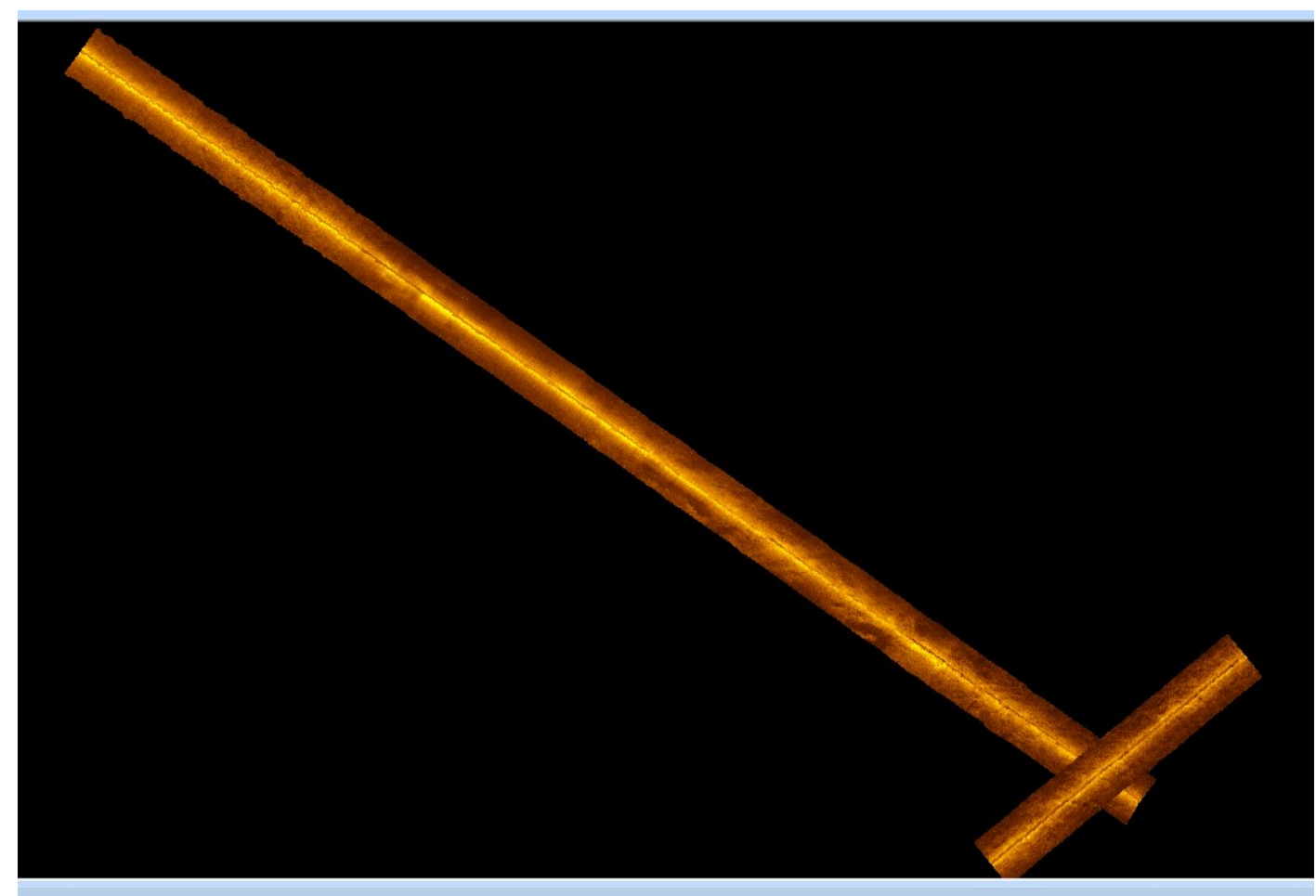

Figure 3.6. Raw side-scan data from Iver 3 displayed in SonarWiz 7.

Bottom tracking is the next processing step (Figures 3.7,3.8). The bottom track function detects the lake floor. Without bottom tracking, especially after normalization, users would get blank stripes at nadir area. Those blank areas with no information can affect the classification accuracy. 


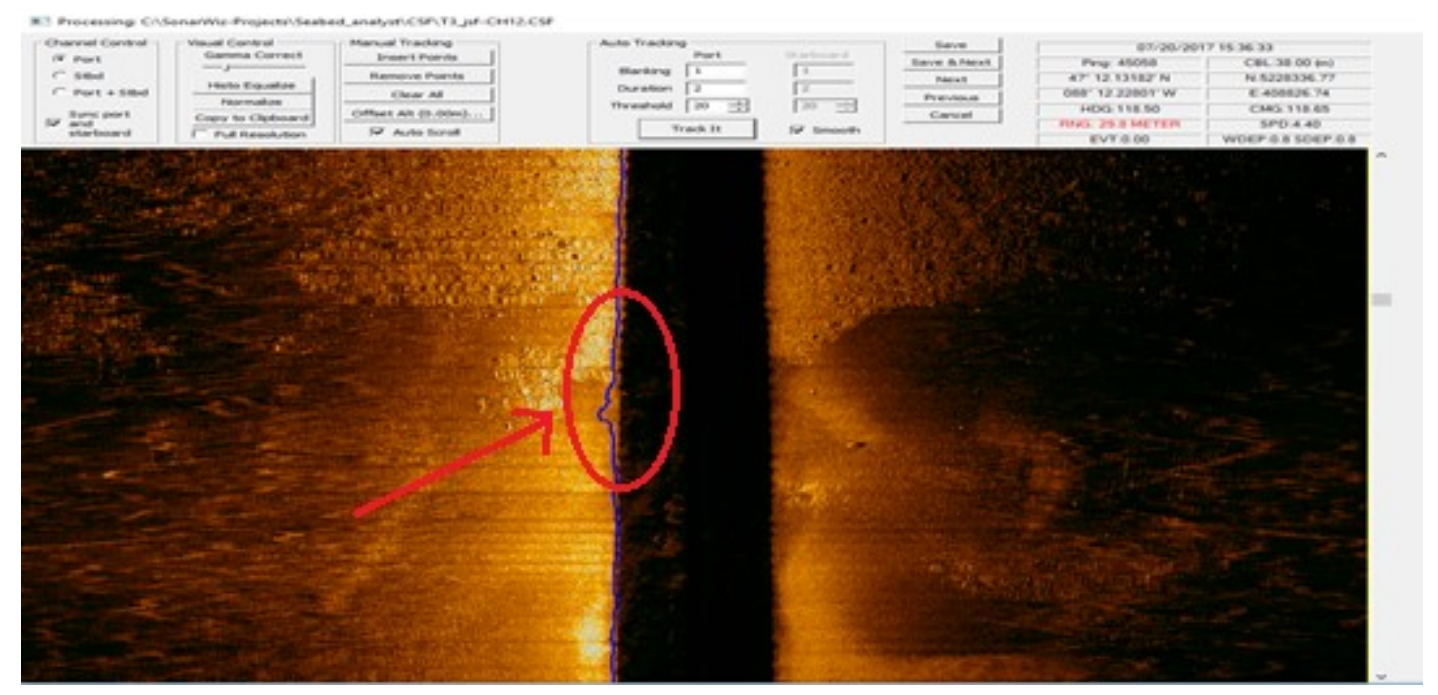

Figure 3.7. Example of bottom track processing. Note the blue lines, which represent altitude. The imagery needs to be fitted to this line.

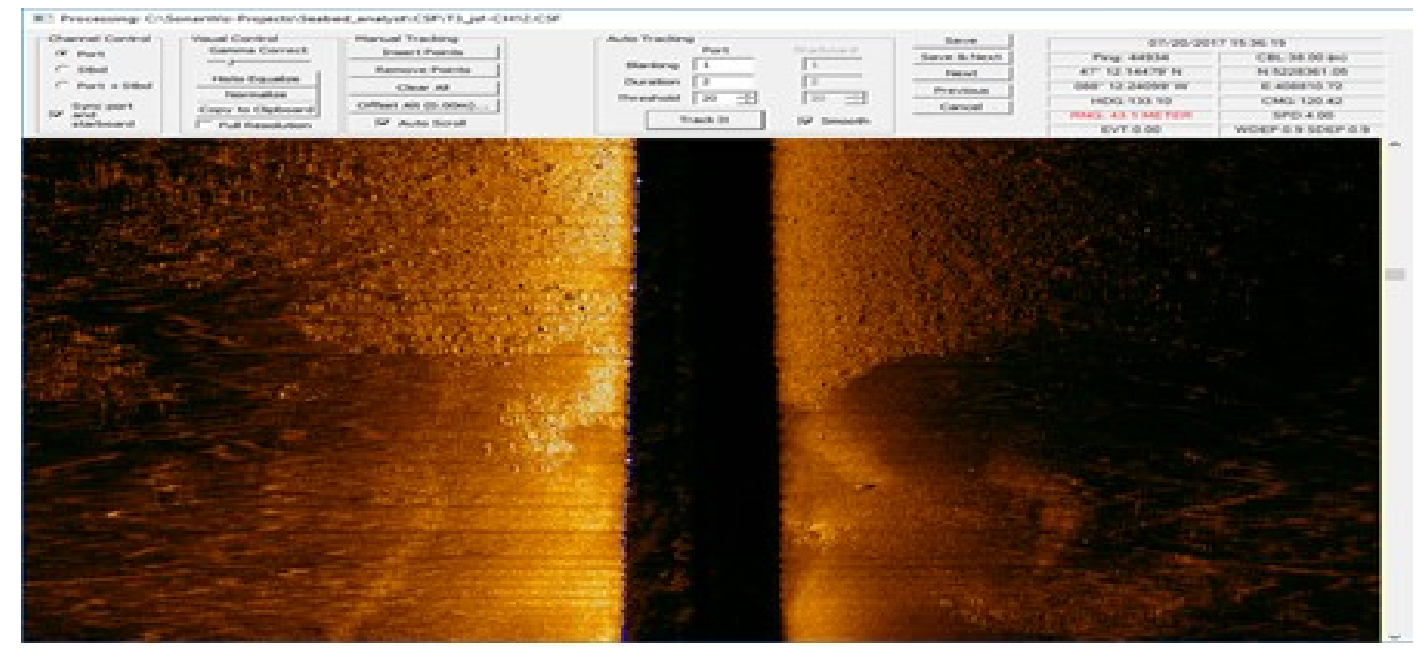

Figure 3.8. After bottom track processing at the side of the port. The side-scan data has been fitted to the blue lines.

Once the applied bottom tracking correction is completed, the next step is signal processing. Empirical gain normalization (EGN) applies a statistical correction to all sonar amplitudes and averages them based on range and amplitude (Chesapeake Technology, Inc 2010-2016 2016). Empirical gain normalization creates a normalization table composed of grids, where each of sonar amplitude placed in and 
investigates beam pattern of all sonar ping based on their geometry on the project at once.

AGC (Automatic Gain Control), an available option, was not used as part of normalization process because it normalizes each portion of the side-scan data locally (Figure 3.9). This situation affects the classification results because the local normalization could make differentiate the same feature from different portions of the side-scan data. Thus, the same class from different portions could appear as a different class in the classification result. Another disadvantage of AGC is that the nadir area has a strong effect on the classification result, mostly appeared as a different artificial class.

Figure 3.9 illustrates AGC normalized side-scan data. The nadir area is represented as a solid bright yellow line.

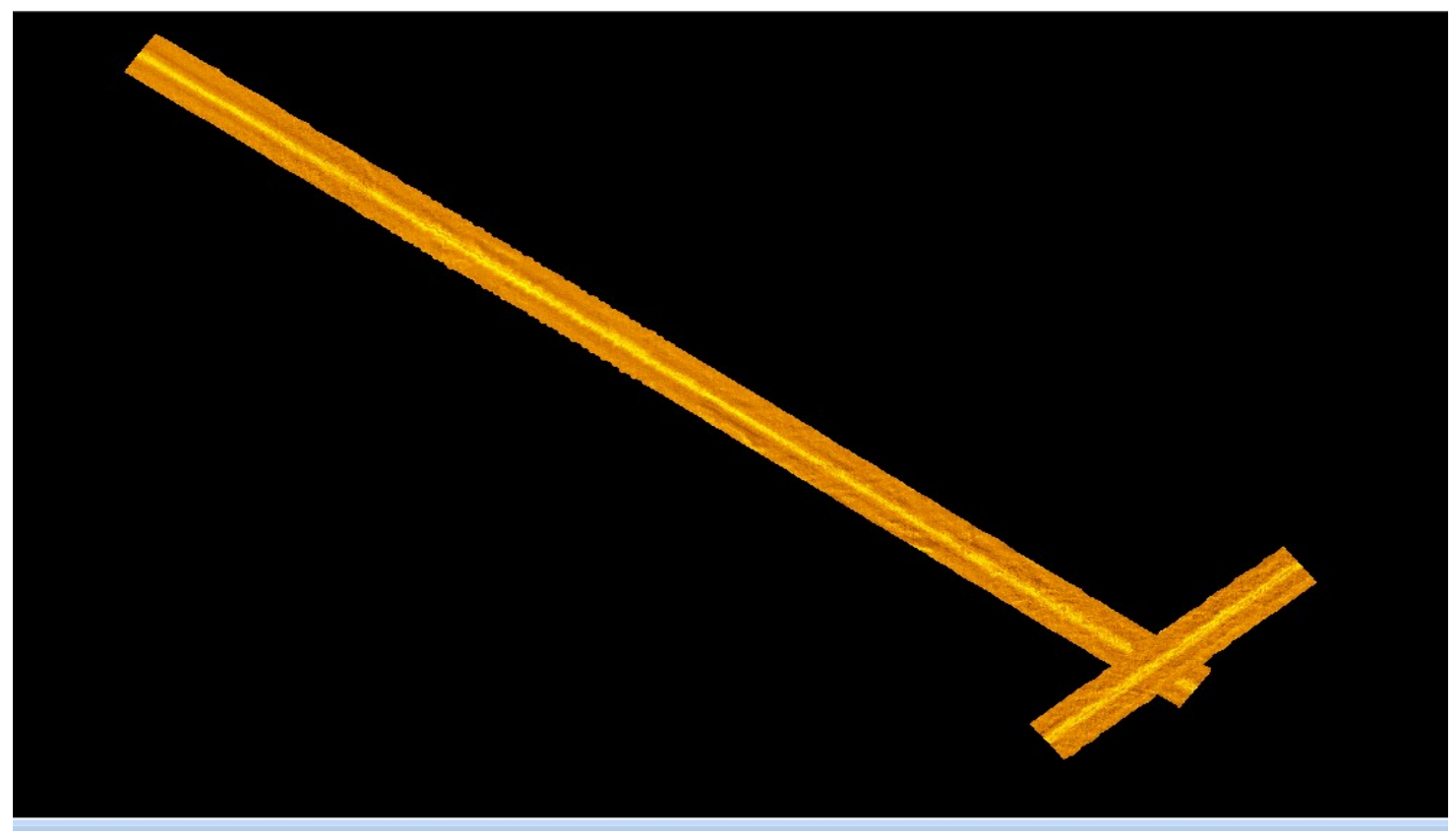

Figure 3.9. AGC normalized Iver 3 side-scan data 
The result of classification with AGC normalized data (Figure 3.10) is adversely

affected. It is because of the classification resolution and window step; nadir area is even more dominated as shown in Figure 3.10.

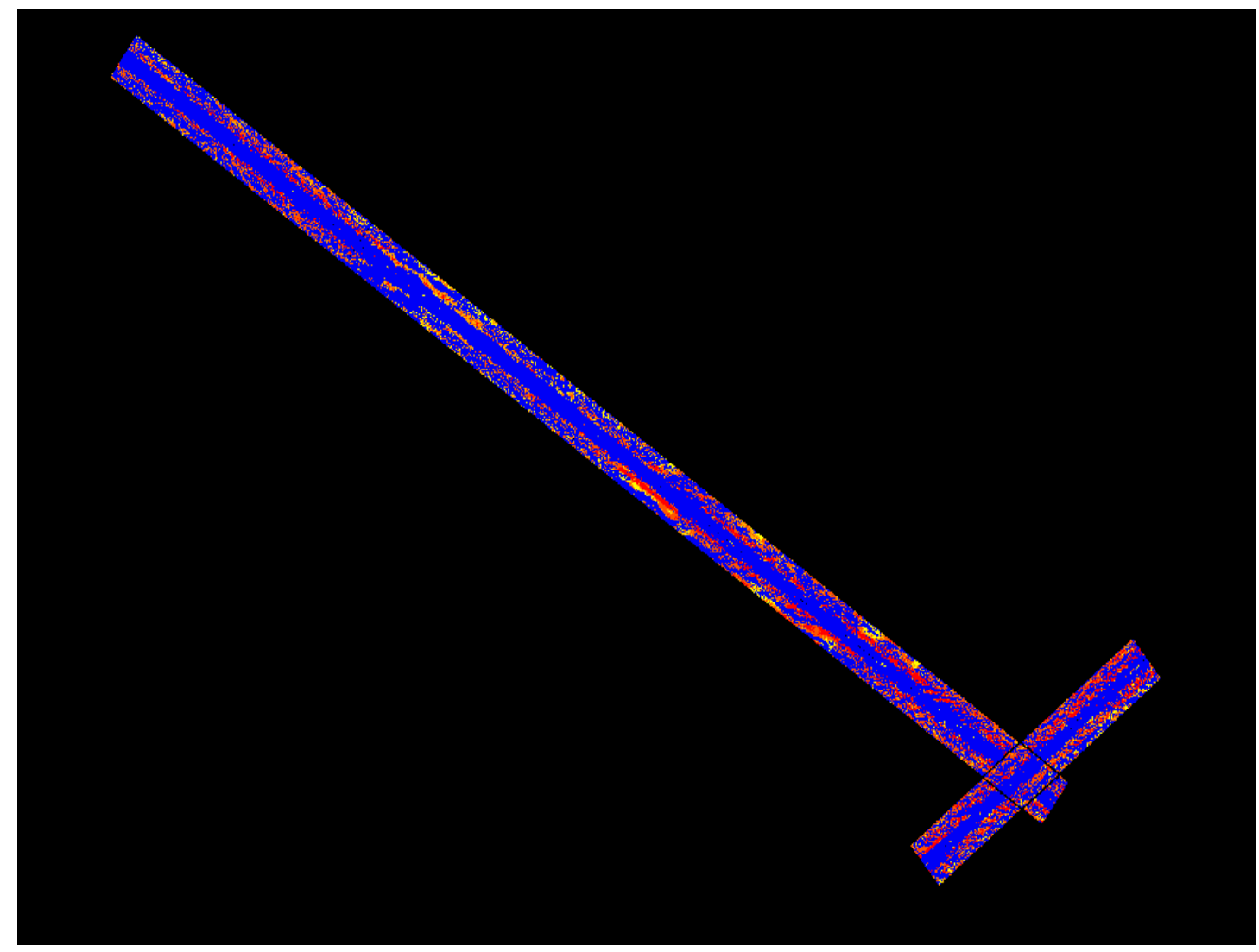

Figure 3.10. The AGC normalized Iver 3 side-scan classification result. The nadir area is dominated (artificial class, blue) and adversely affects the classification results.

The nadir effect is the same for the Edgetech 4125 side-scan data when the AGC was applied. Hence, the EGN was used for both data sets (Figures 3.11, and 3.12 (Iver 3 imagery), and Figures 3.13 and 3.14 (Edgetech 4125 Imagery)) to achieve improved classification results and eliminating the artificial nadir area effects. 


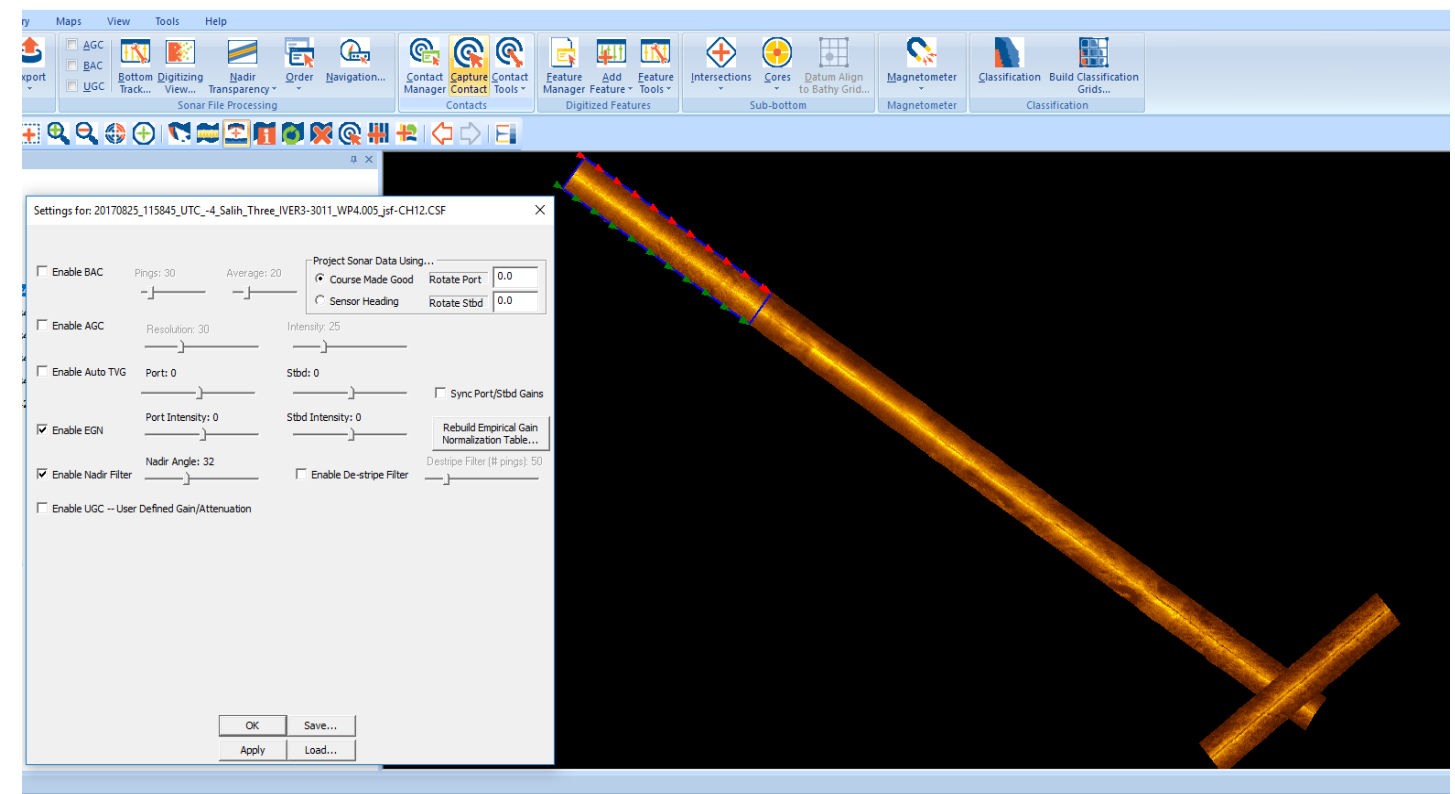

Figure 3.11. Build the EGN normalization table using all Iver 3 bottom tracked side-scan data and applying a nadir filter with a $32 \%$ nadir angle.

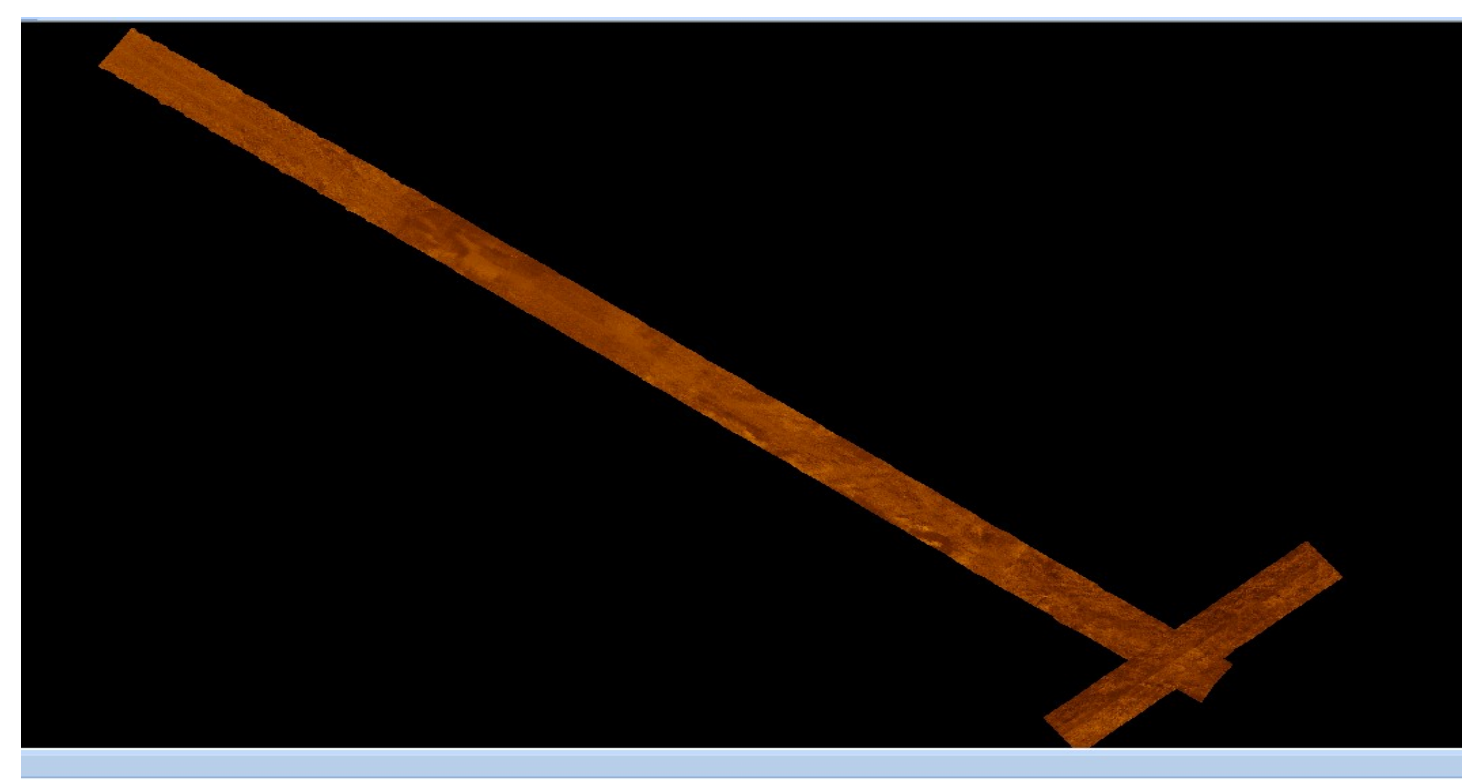

Figure 3.12. After EGN normalization, no nadir effect is seen with the Iver 3 side-scan data and all sonar values look consistent. 


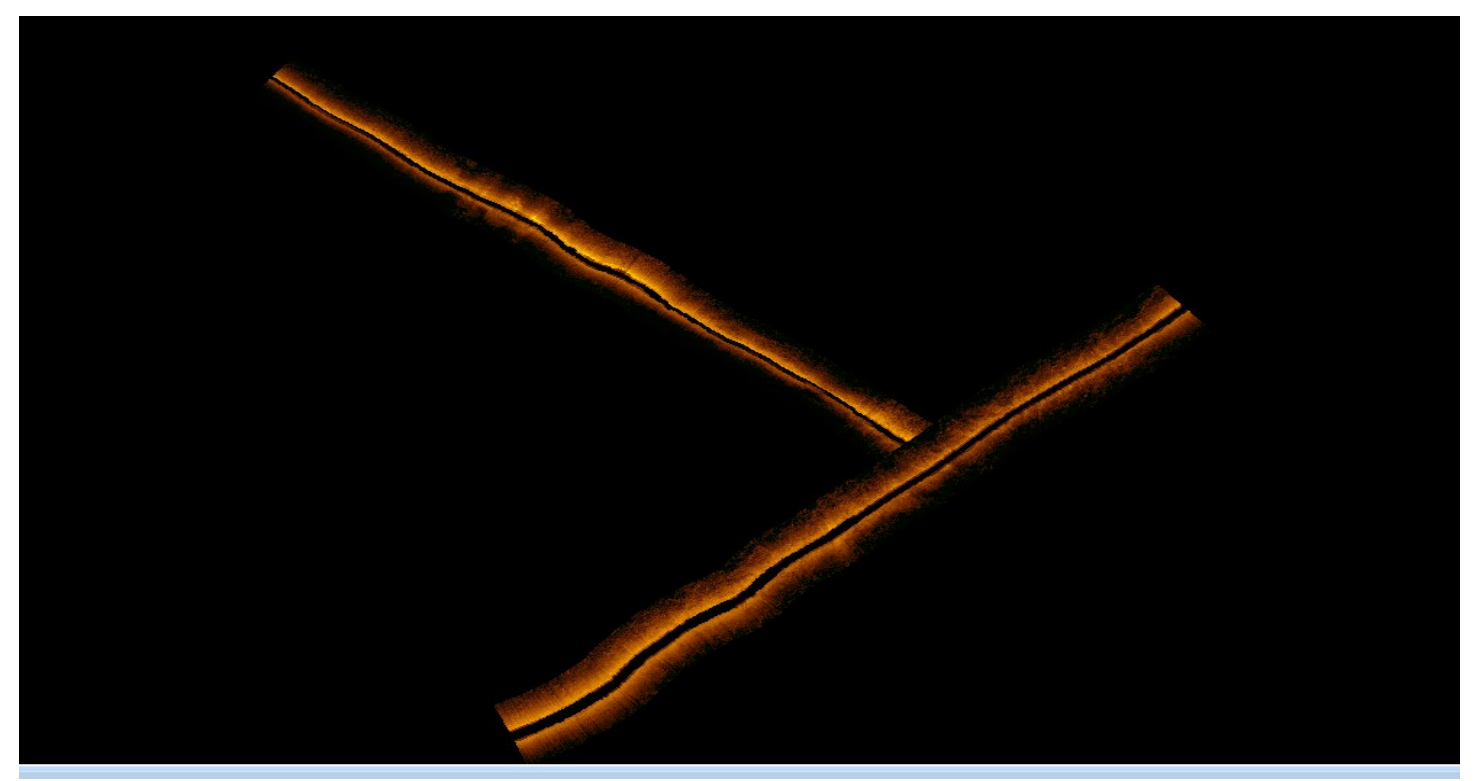

Figure 3.13. The Edgetech 4125 bottom tracked side-scan data before applying the EGN normalization with a nadir filter (20\% nadir angle).

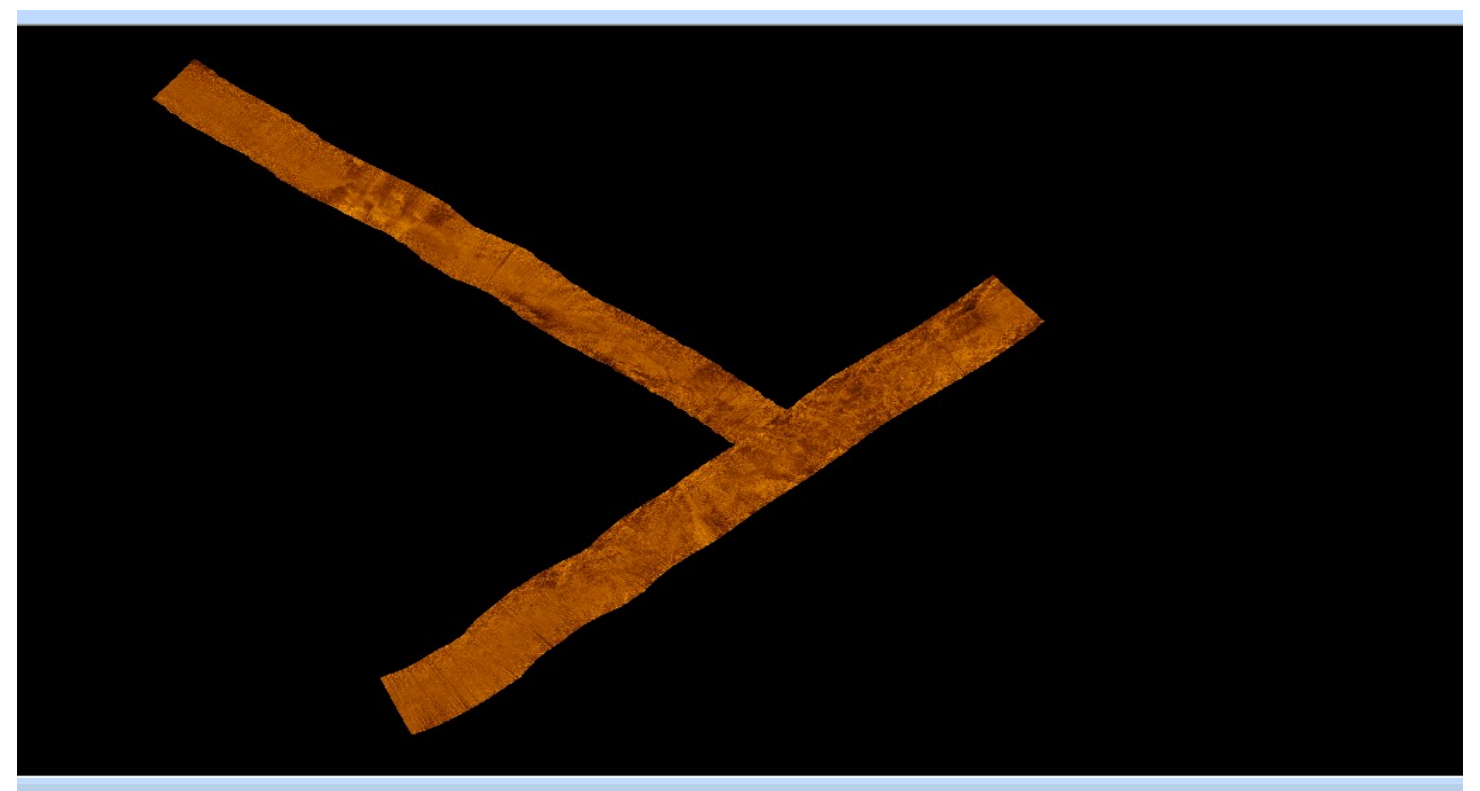

Figure 3.14. After applying the EGN normalization with a nadir filter, the Edgetech 4125 side-scan data appears uniform, and the artificial nadir effect is eliminated. 
The first step after pre-processing is classification. SonarWiz 7 has an unsupervised classification algorithm. The seabed characterization tool can establish classes from the side-scan imagery that is depending on their identical texture values (Chesapeake Technology, Inc. 2017).

For the first iteration, classification rules (5 X 5 moving window) were applied to generate 5 spectral classes (Figure 3.15).

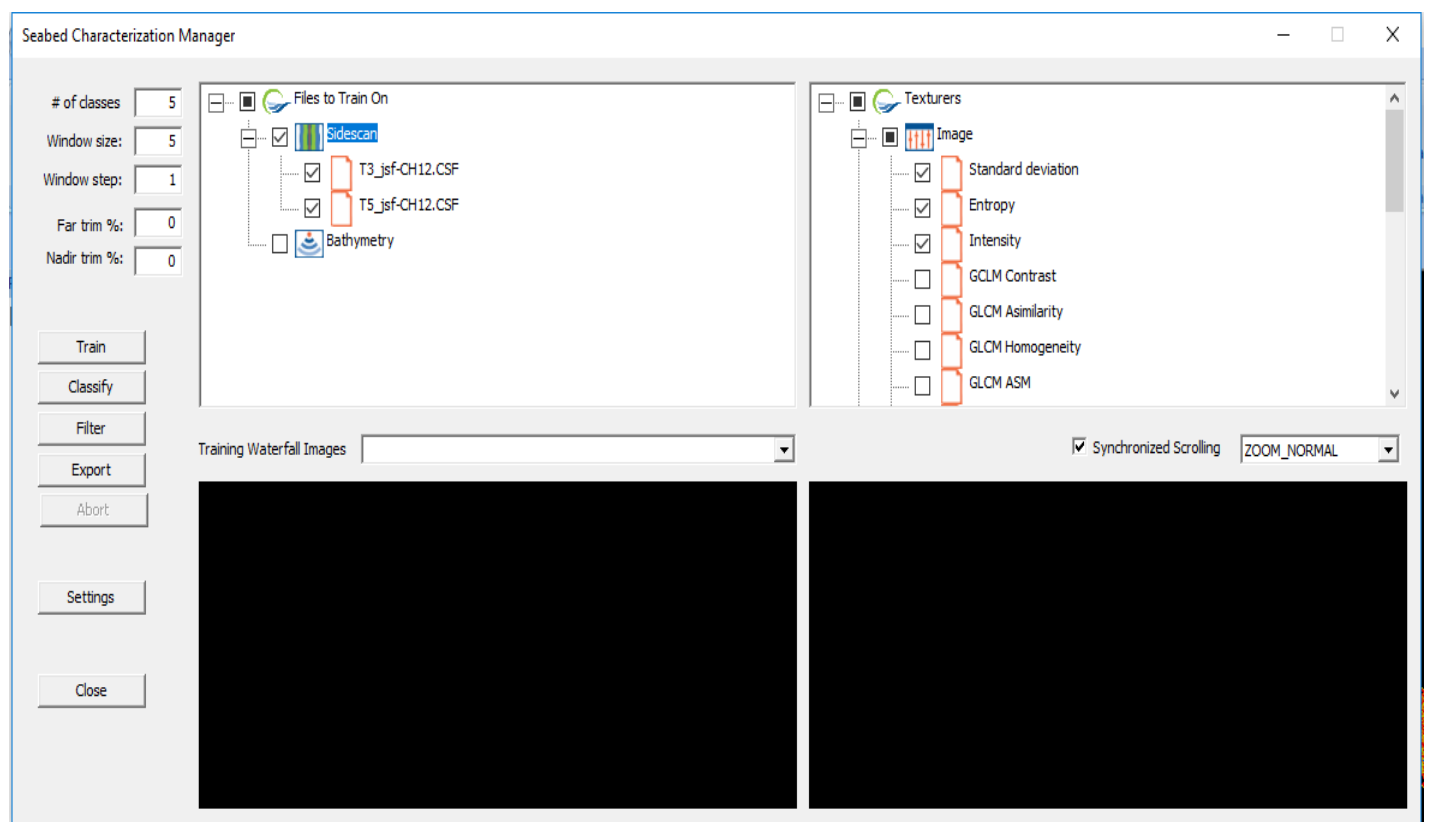

Figure 3.15. Classification rules applied to obtain 5 information classes.

The rules are:

- A number of classes that was desired to be five.

- A window size is an area where the pixel texture values are computed. In this project, the window size was set 5 X 5 .

- A window step defines the movement of texture analyzing window. If the window step increases, the system performance is faster. However, the spatial resolution is getting worse. In this project, the window step was set the value of one for greater resolution. 
- A far trim cuts the outer edge of the side-scan data that is not needed for that moment. Hence, the far trim was set $0 \%$.

- A nadir trim cuts the nadir area that is not needed for that moment. So that, the nadir trim was set $0 \%$.

- A standard deviation computes the variation of gray-scale values in the texture analyzing- window that was applied for the classification. The standard deviation can be defined as:

$$
\sqrt{\frac{1}{N}} \sum_{i=0}^{N-1}\left(x_{i}-x_{\text {average }}\right)^{2}
$$

Where $x_{i}$ is the value for the $i$ 'th pixel of side-scan data, $x_{\text {average }}$ is the average of all side-scan pixel values, and $\mathrm{N}$ is the number of pixel values in the area of interest.

- An entropy was applied for the classification that defines a regularity in the image. Low and high areas have low entropy while the area that with middle brightness has high entropy.

- Intensity was applied for the classification that measures the brightness of the area of interest. Sometimes it is a good classification rule type. However, shadow area can cause bias in the side- scan area, which is hard to differentiate from certain features.

Intensity can be indicated as:

$$
\frac{\sum_{i=0}^{N-1} x_{i}}{N}
$$

Where $\mathrm{N}$ is the number of pixel values in the area of interest, and $x_{i}$ is the value for the i'th pixel of side-scan data. 
The classification results are shown with five separate classes for both systems (Figure 3.16, and Figure 3.17) here below:

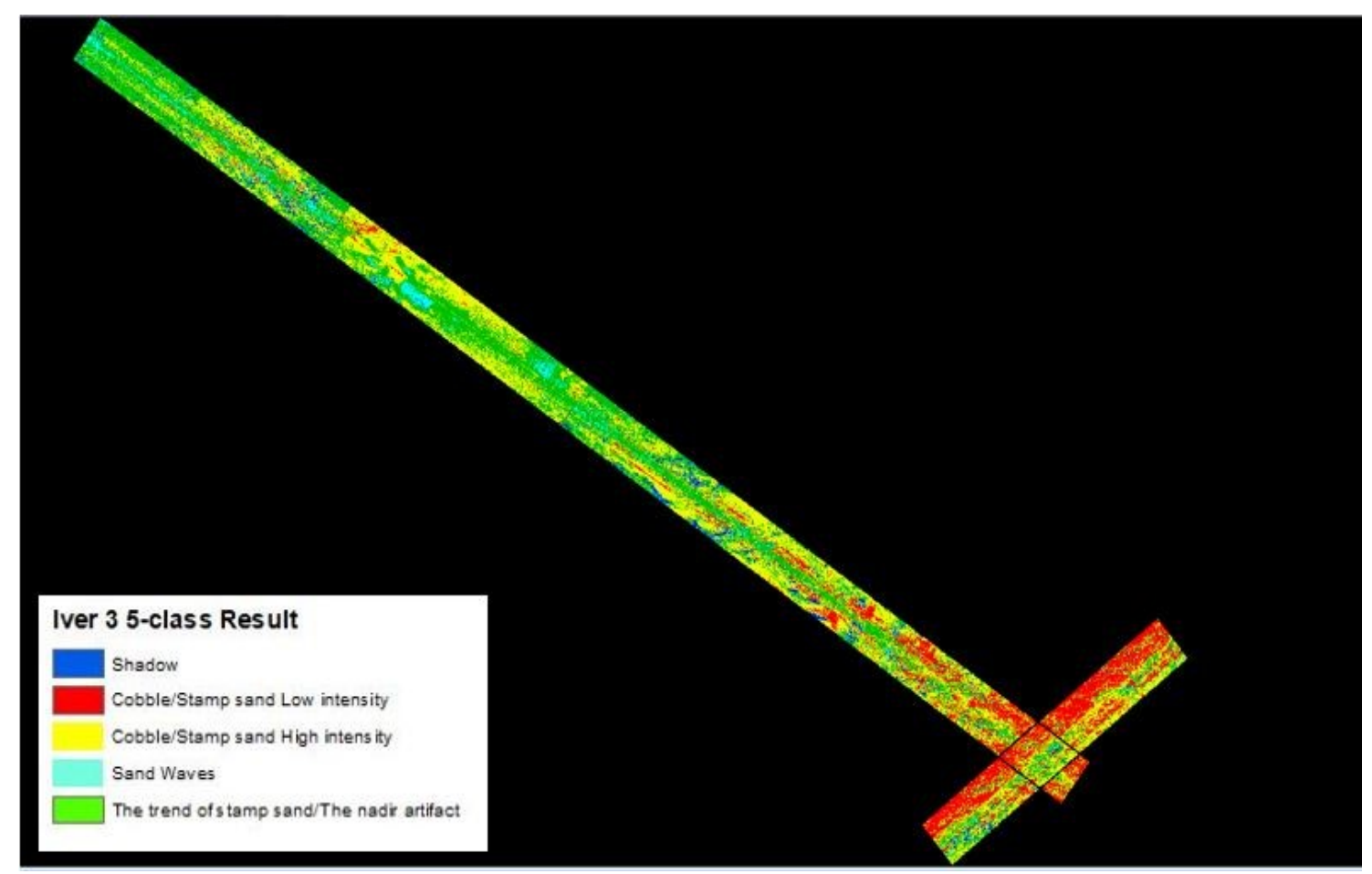

Figure 3.16. The Iver 3 classification results with five classes 


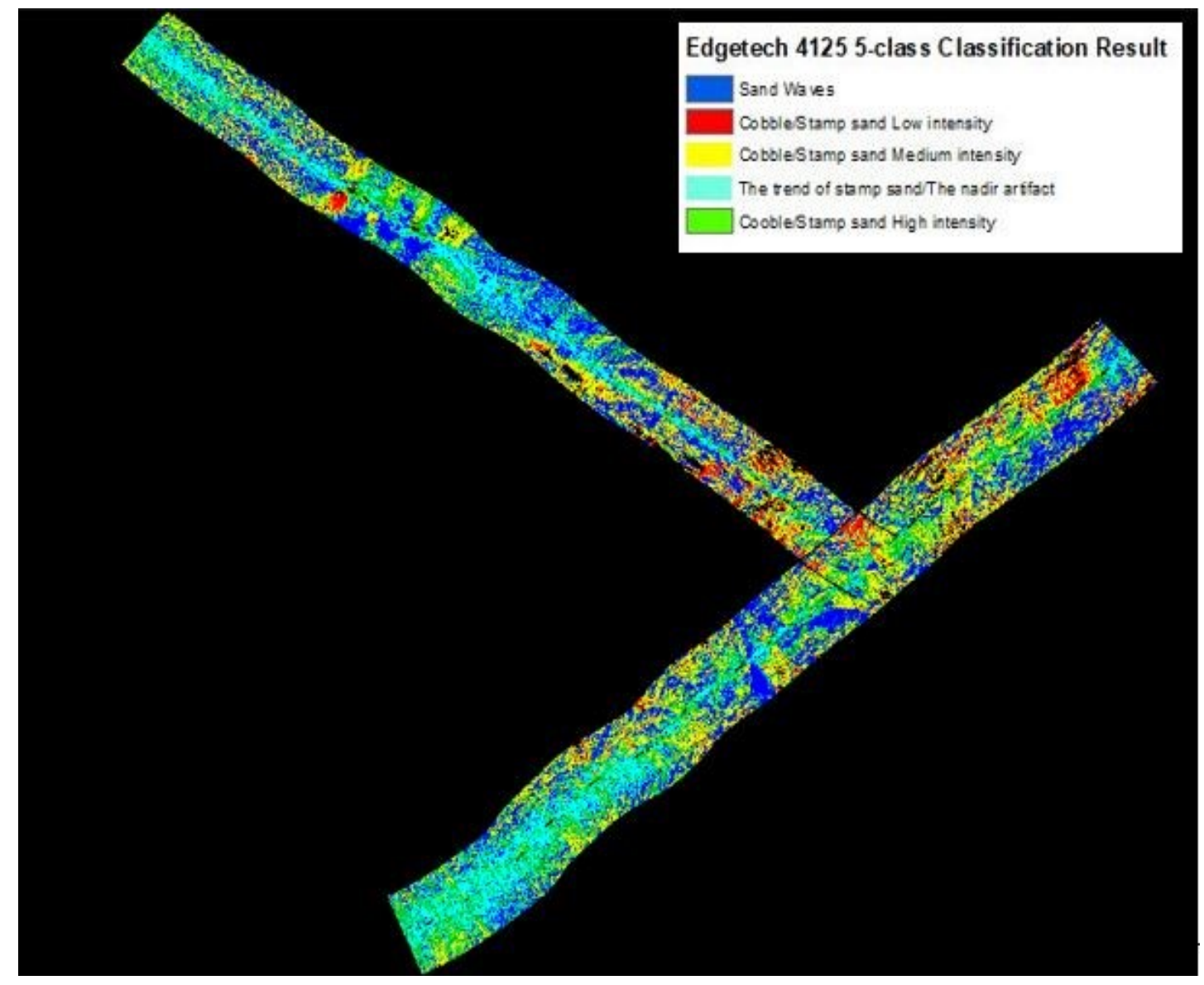

Figure 3.17. The Edgetech 4125 classification results with five classes

The SonarWiz 7 software has an only unsupervised classification type. Therefore, it is not possible to define each class without ground truth objects. Based on, the software Discover 2 and actual images from the lakebed (It was taken from Iver 3 survey that has mounted-camera), all classes can be defined.

On the other hand, Edgetech 4125 side-scan sonar has no camera. This is very problematic for distinguishing information classes. Comparing with Iver 3, Edgetech 4125 side-scan sonar has lower resolution. The Edgetech 4125 side-scan sonar has more acoustic pulse power than Iver 3. That is the reason the area of the Edgetech 4125 is wider than the area of the Iver 3.

The only thing is the survey lines with both systems coincide. Therefore, the Discover 2 could be useful for examining the lakebed features of the Edgetech 4125 side-scan data as 
well.

Here some example of the ground truth data. The Discover 2 has a perfect resolution that shows the side-scan data almost like an actual image. Using identified time values of actual images and Discover 2 views matched together (Figure 3.18, Figure 3.19 and Figure 3.20) for comparing them with the classification results.

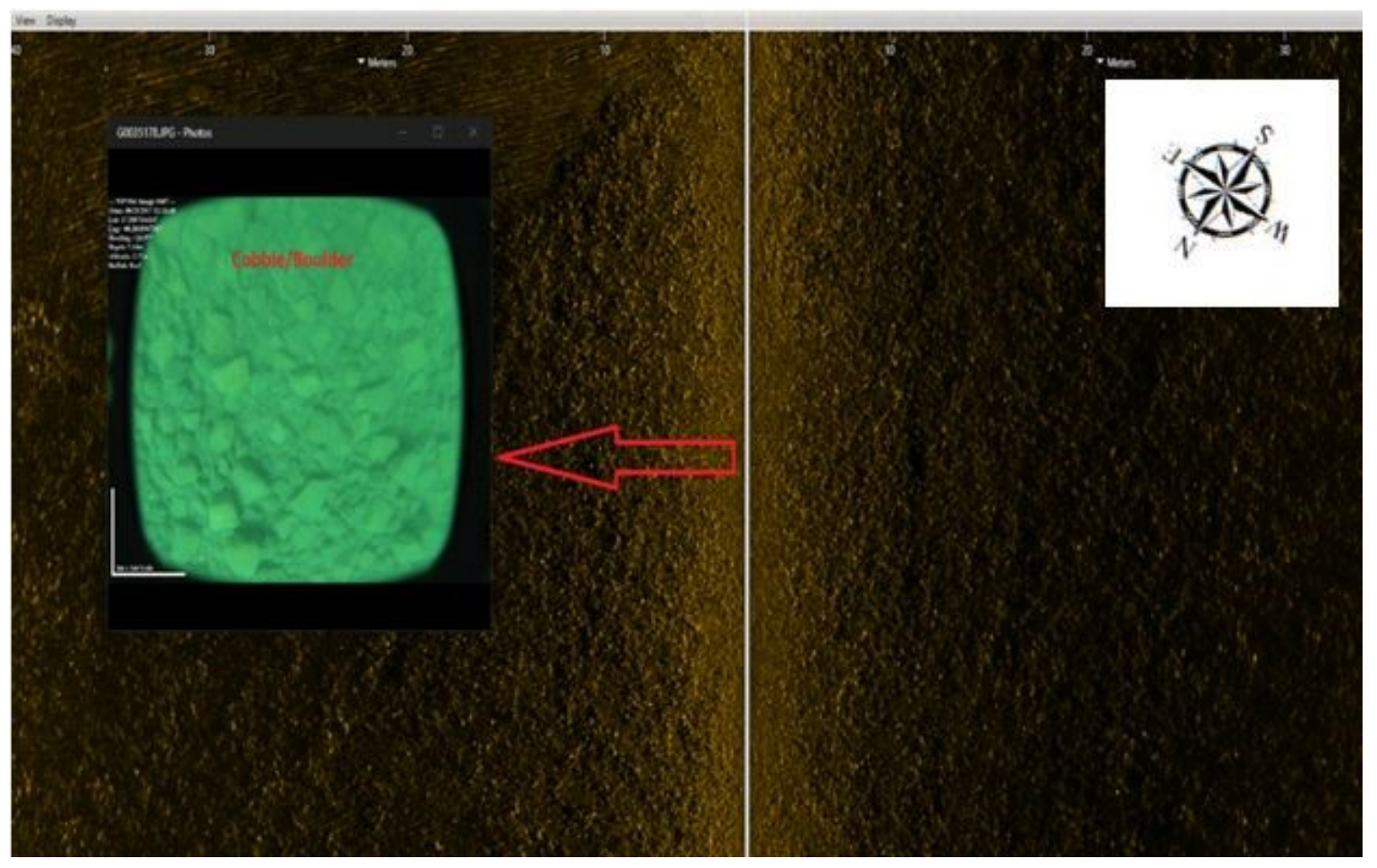

Figure 3.18. A typical cobble class image that geolocated to the Iver 3 and Discover 2 sonar data. 


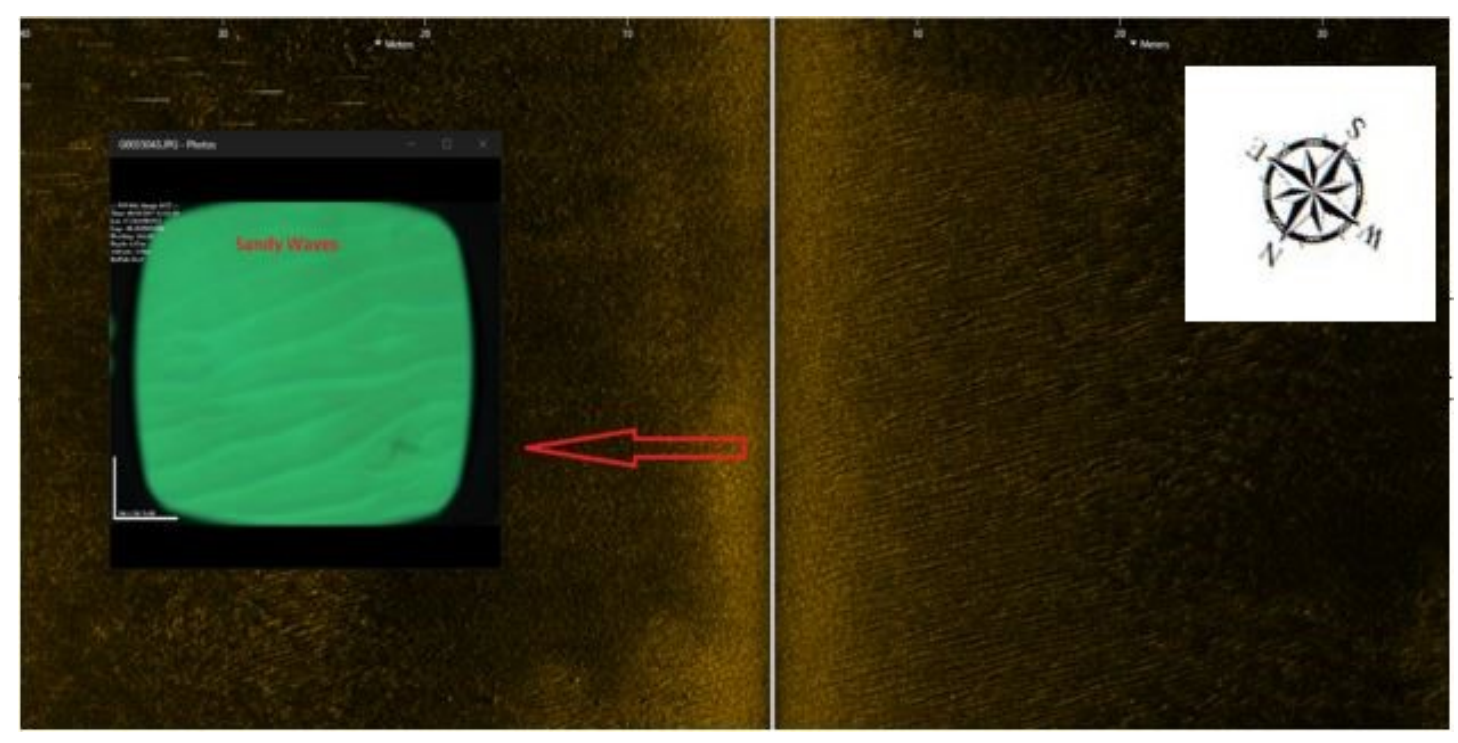

Figure 3.19. A typical sandy waves class that mostly indicates the trend of the stamp sands encroachment. The trend is from the Gay Bay to the southeast direction.

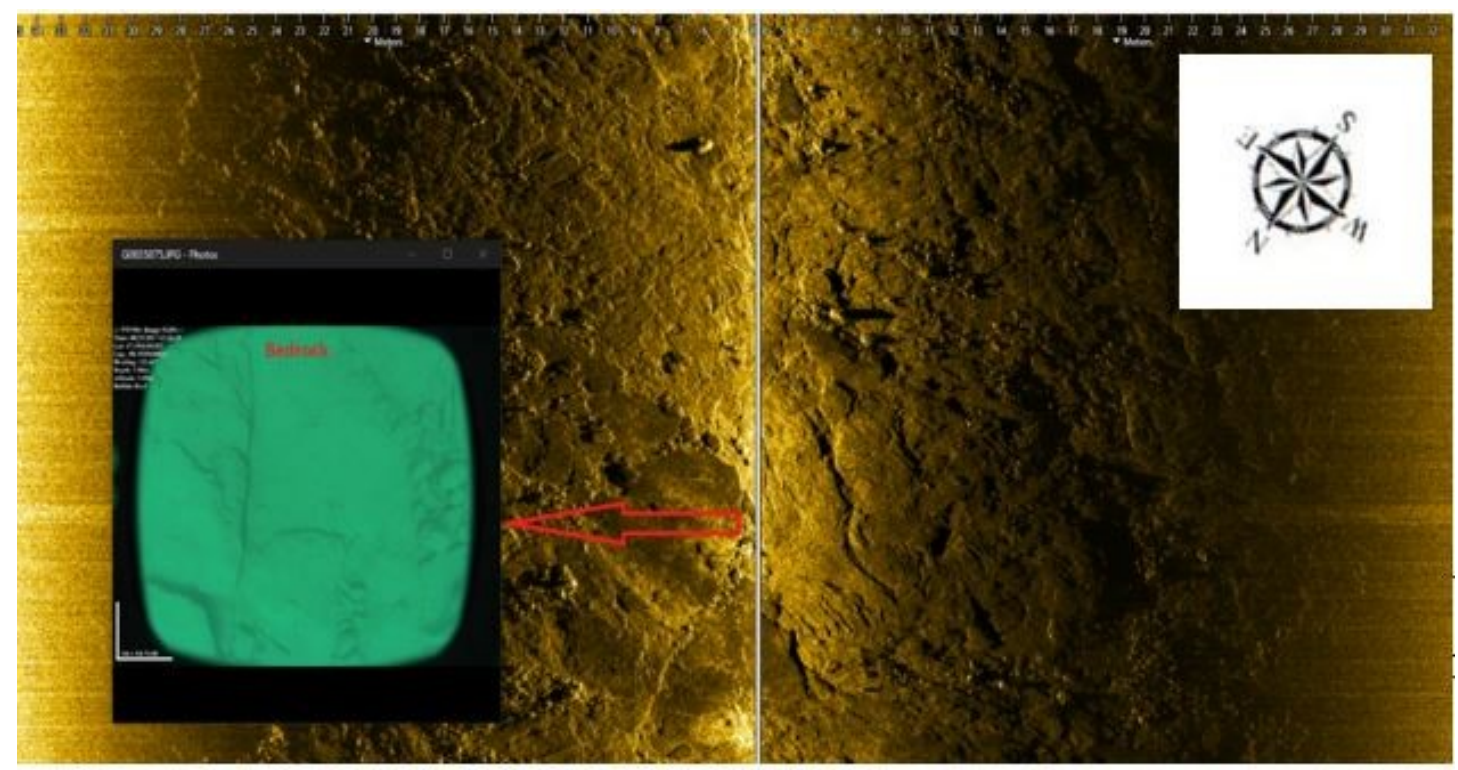

Figure 3.20. A typical bedrock class

After defining each class, the result of classification with 5-classes was investigated for Iver 3 side-scan data. It is clarified that 5-classes classification has some serious bias especially suffering from the shadow area that is usually faced when the system classifies lakebed features with side-scan data. The second problem is coming from the 
Iver 3 side-scan data because of the overstretching at each side of the board.

These problems are very challenging. Most of the time intensity is a beneficial rule for obtaining certain class. However, the lakebed topography creates some shadow area that causes a complication to differentiate certain features on the lakebed. Hence, the condition of evaluation even worse in this case.

Investigating stamp sands in the area between Grand Traverse Bay and Gay Bay, ground truth samples were used. Based on 130 samples and using kriging statistical method in the ArcGIS 10.5, the contour line (Figure 3.21, Figure 3.22, and Figure 3.23) was created that shows the rate of stamp sands and its trend (Southeastward). 


\section{The Distribution of Stamp Sands}

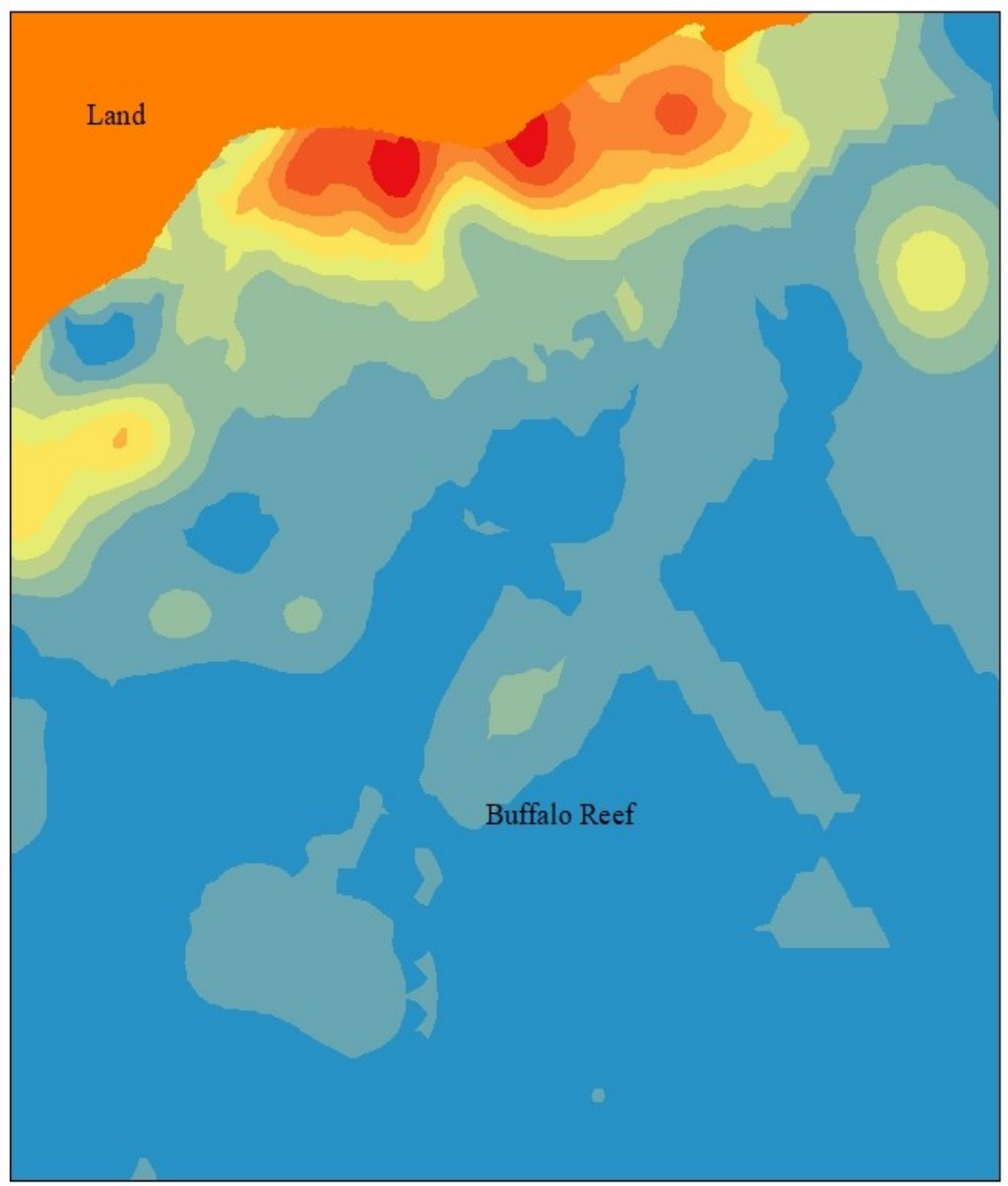

Percentage of Stamp Sands
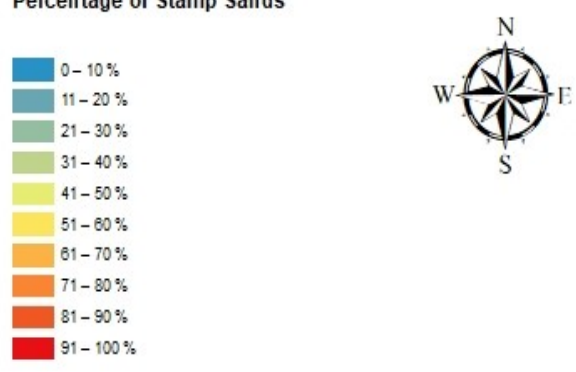

0.1750 .35
0.2750 .55

Figure 3.21. The condition map of stamp sands from the east side of Keweenaw Peninsula. 
The Iver 3 Side-scan with the Distribution of Stamp Sands

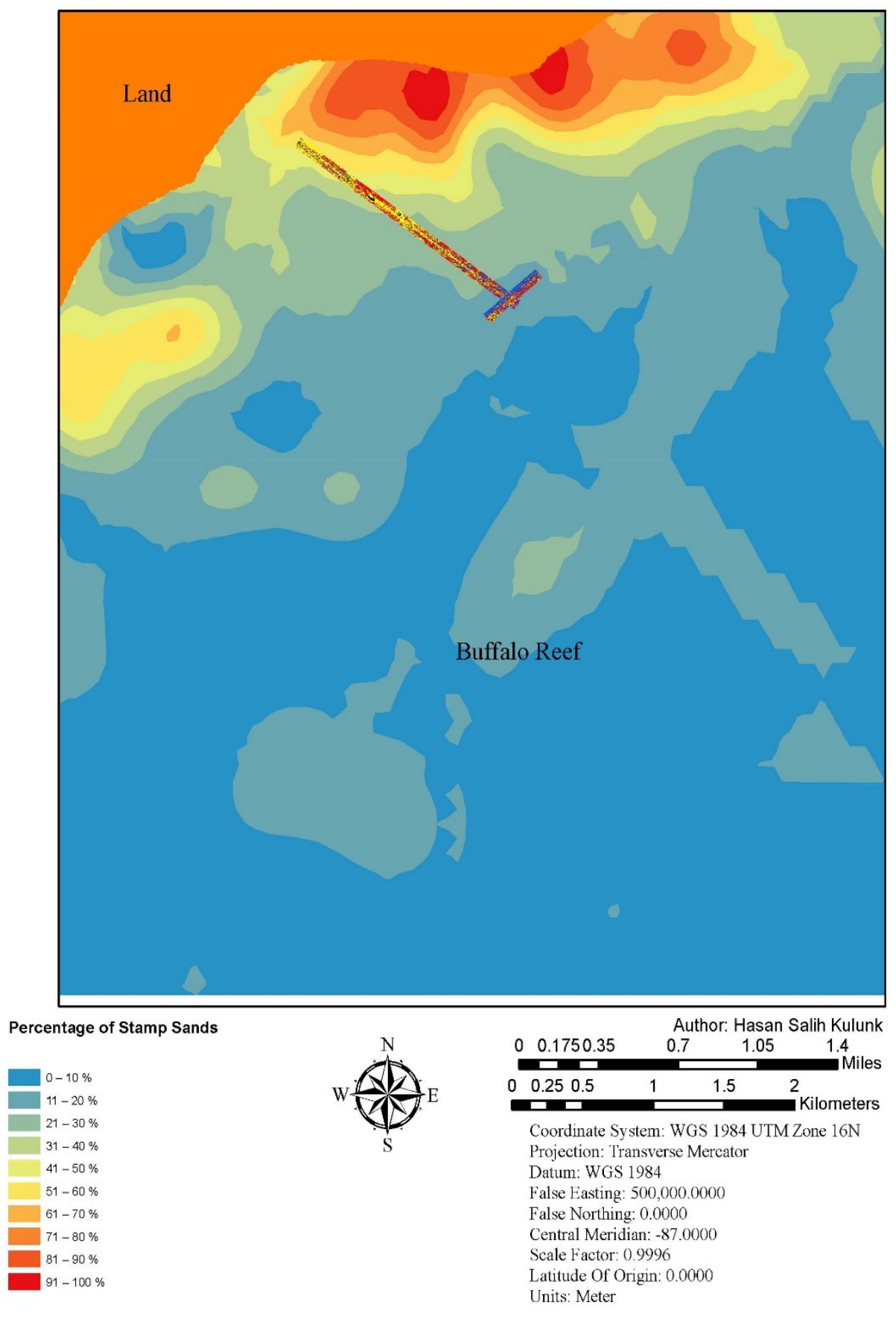

Figure 3.22. The Iver 3 side-scan showing on the contour map 


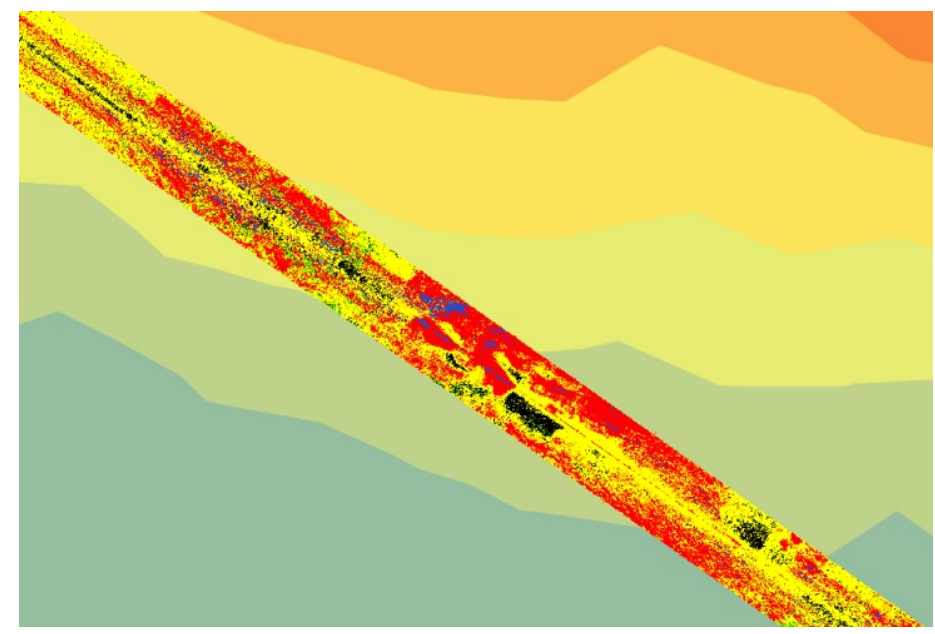

Figure 3.23. The Iver 3 side-scan data stamp sands border (red color 41-50\%)

The Iver 3 side-scan data stamp grains of sand border (red color 41-50\%) is logical based on a contour map of stamp sands. However, the area is too small comparing the contour map that is why borders could be different a little. It is because of the sample intensity in the area. There is no coincidence between either the Iver 3 side-scan or the Edgetech 4125 side-scan survey line and samples from the contour map. In addition, the time when samples of stamp sands were taken cannot show the last border condition because the Iver 3 and the Edgetech 4125 survey was done after several months and the border condition could be changed. Moreover, nadir artifact and dominated cobble class prevent showing these borders. Finally, the typical shadow problem of side-scan data affects classes.

Even so here the picture, red class shows stamp sands (41-50\%) which is meaningful comparing the contour map.

After more research and investigation of the project area, two solutions that are more possible have been decided. 


\section{Increasing the number of classes after looking histogram values}

In this step, the side-scan data was exported to the ERDAS Imagine software for looking its histogram values (Figure 3.24, and Figure 3.25). It was found that there were more than five peaks on the histogram profile, approximately 15-20 peaks.

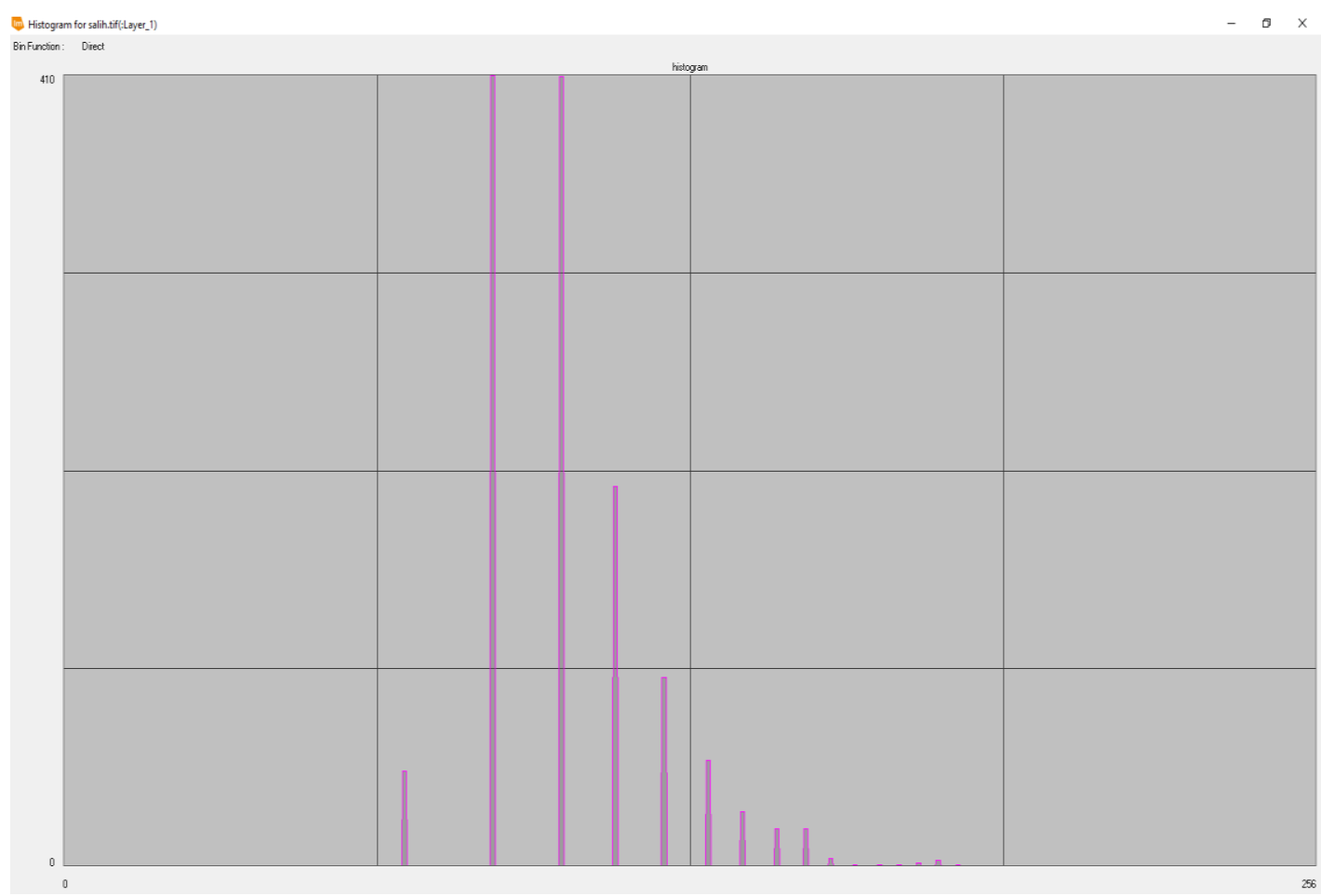

Figure 3.24. The Iver 3 band 1-histogram profile shows the near range of sonar returns that has more than five peaks 


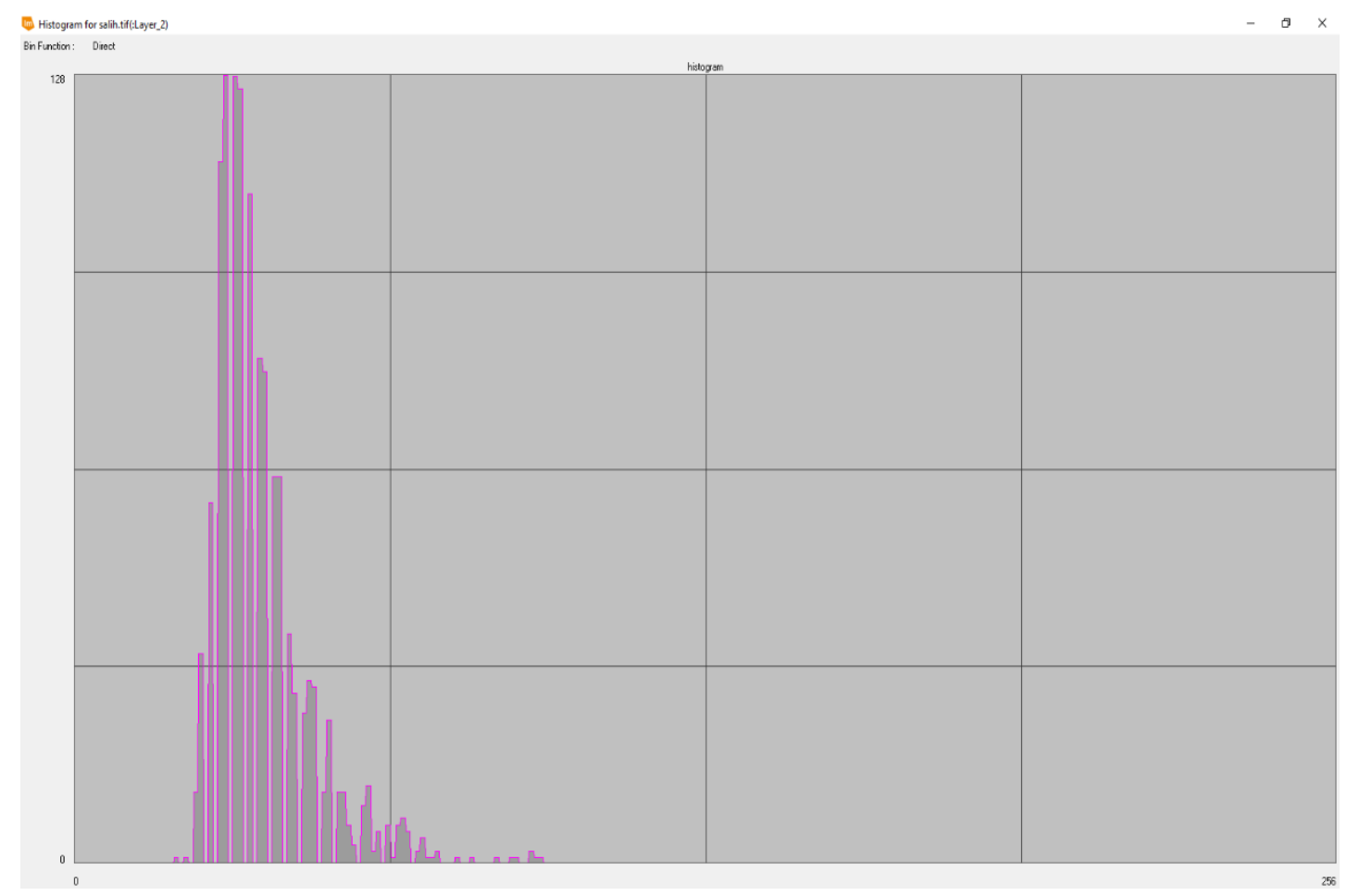

Figure 3.25. The Iver 3 band 2-histogram profile shows the far range of sonar returns that has more than five peaks

It was decided that those peaks might be the sign of required classes in that area. Increasing the class number might help to detect stamp sands more effectively. Thus, 10, 15 and 20-class classification was implemented using the same rules as 5-class classification in the SonarWiz 7. Later on, these results exported to the ArcGIS 10.5 for more investigation. It was seen that maximum 10 classes created from the SonarWiz 7. Based on the SonarWiz lakebed characterization manual, it is possible to create as much as classes if they required. Therefore, 10 classes are the maximum class number for this data.

It was found that the result of 10-class classification could detect the stamp sand with more detail (low intensity, medium intensity, and high intensity) significantly. However, the stamp sands and the cobble class appeared as the same class for two reasons. First, based on intensity rule the result would put both class into one classes 
because their intensity values are the same. Second, it is clearly seen that cobbles and sands are mixed everywhere on the survey line depending on actual images from the Iver 3 sonar. Also considering classification resolution, the system may put both cobbles and stamp sands into one class.

The figure below (3.26) has one more problem caused by the software. The intersection area of line three and line five was not classified as an intersection. This result shows the classification of line five in the intersection area.

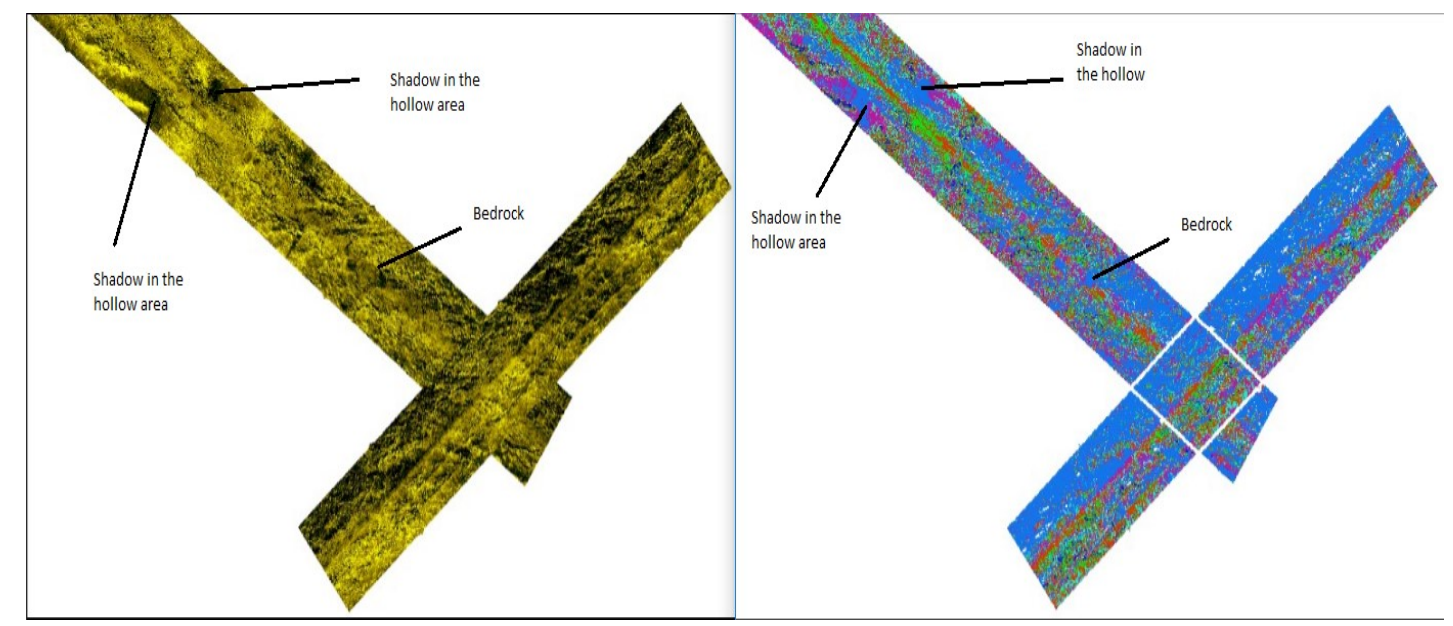

Figure 3.26. The shadow in the hollow area appeared as the same color (blue) as the rock/bedrock class that the concept is coming from the typical side-scan shadow problem.

Using the increasing classes method, the Edgetech 4125 side-scan sonar gave one more class that is very few in the entire survey line.

\section{Clip blurry side-scan area from the project}

Second possible solution to detect lakebed feature is clipping the blurry side-scan area out from the project. The Iver 3 was operated in the water with stable depth from the seafloor that was 2- meter. However, the total range was 75 meters. From the Discover 2 software, it is clearly seen that after 20-meter of each board there was over-stretched area because of the low acoustic pulse power (Figure 3.27). Those areas are blurry and do not 
give the user any information about the lakebed feature. Here one example is shown below.
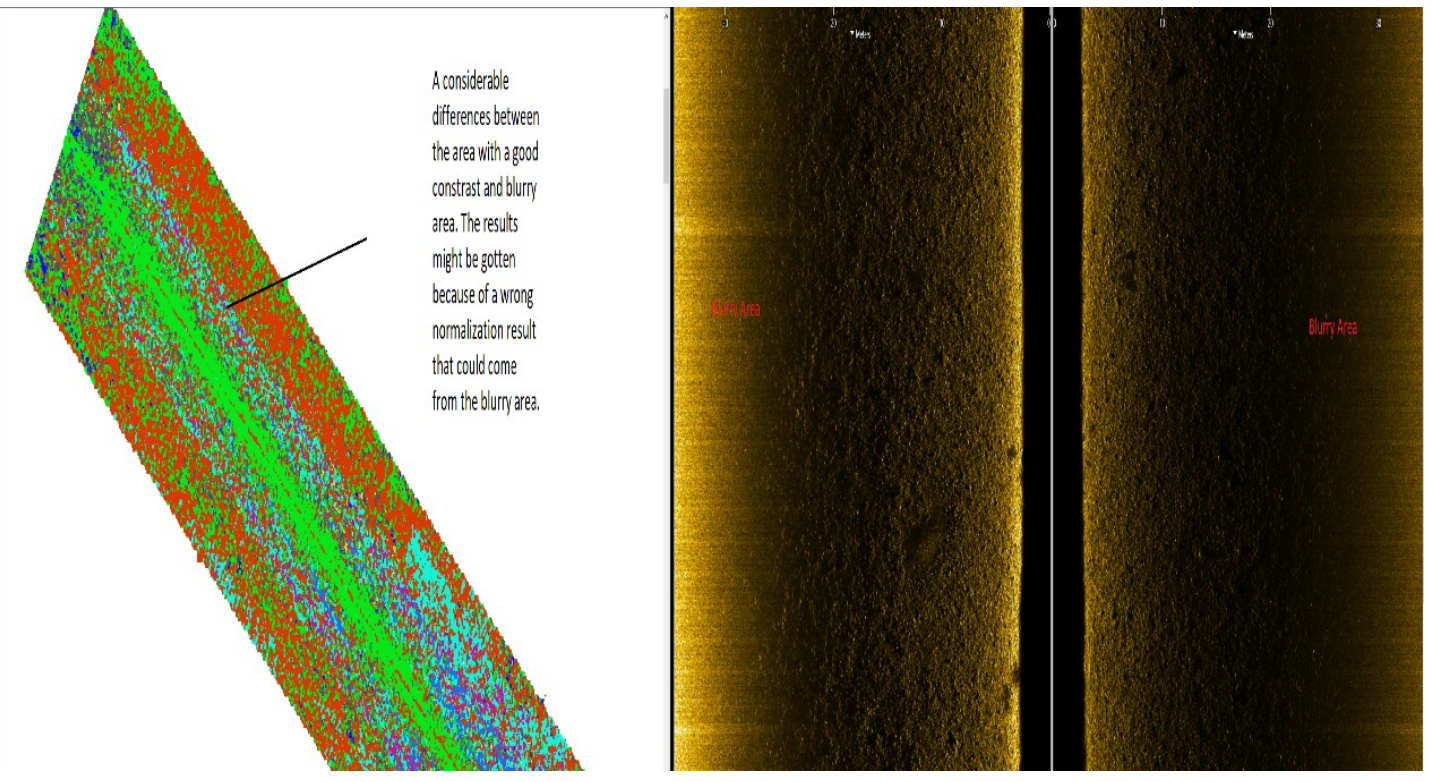

Figure 3.27. A considerable difference between the area with a good contrast and blurry area. The results might be gotten because of a wrong normalization result that could come from the blurry area.

Therefore, it is concluded to cut each board (port, and starboard), after the area of 20meter raw side-scan data from the project. Then, applied all over post-processing step again on the new clipped data. The result (Figure 3.28) was more consisted than the prior one. 


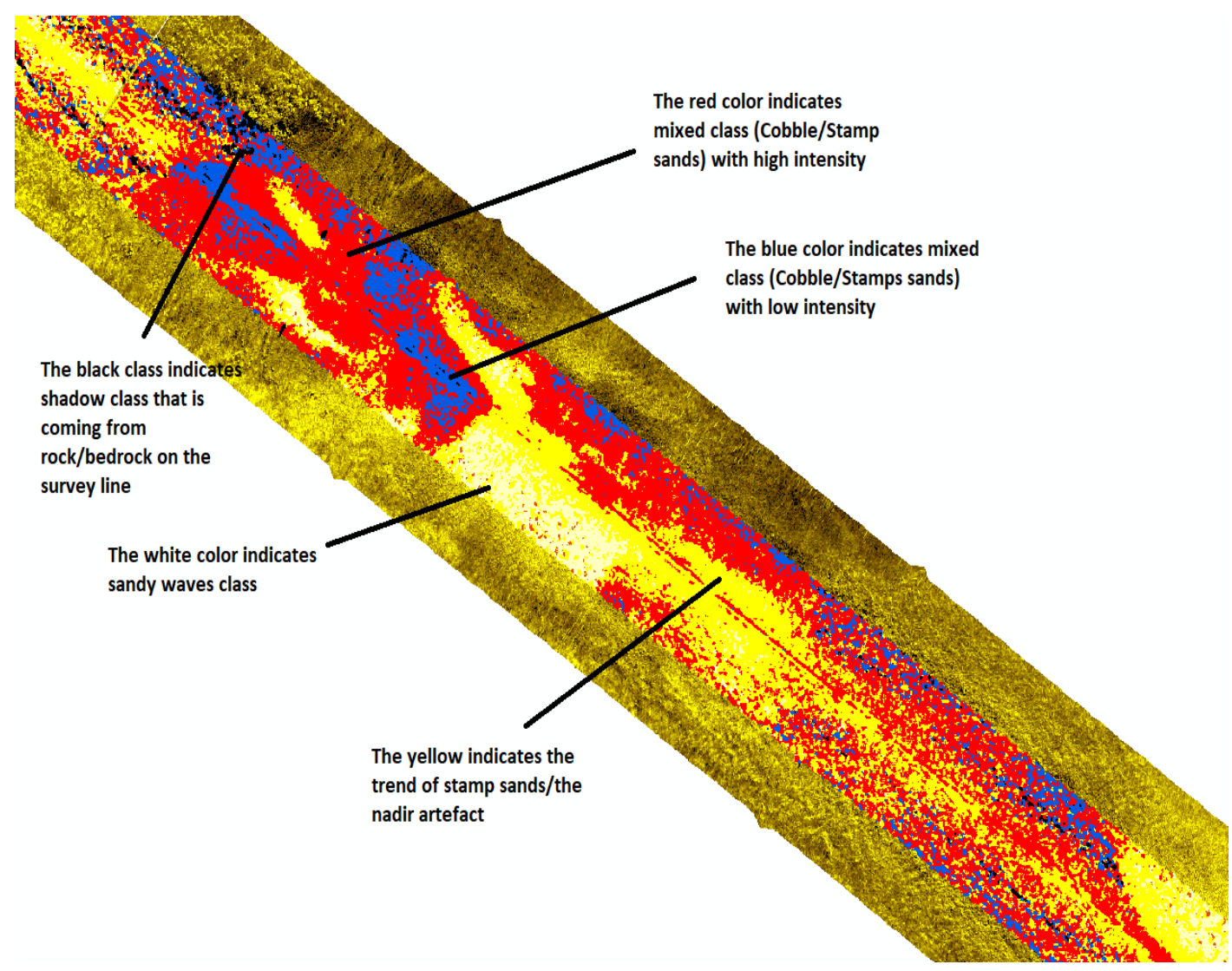

Figure 3.28. The Iver 3 side-scan 10-classes classification result For the Edgetech 4125 side-scan data, there is no clip function needed because of the lower resolution. There were no certain features like Iver 3 side-scan data; especially after EGN (empirical gain normalization), the result was smoother. Therefore, the result of the Edgetech 4125 side-scan data (Figure 3.29) here shown below. 


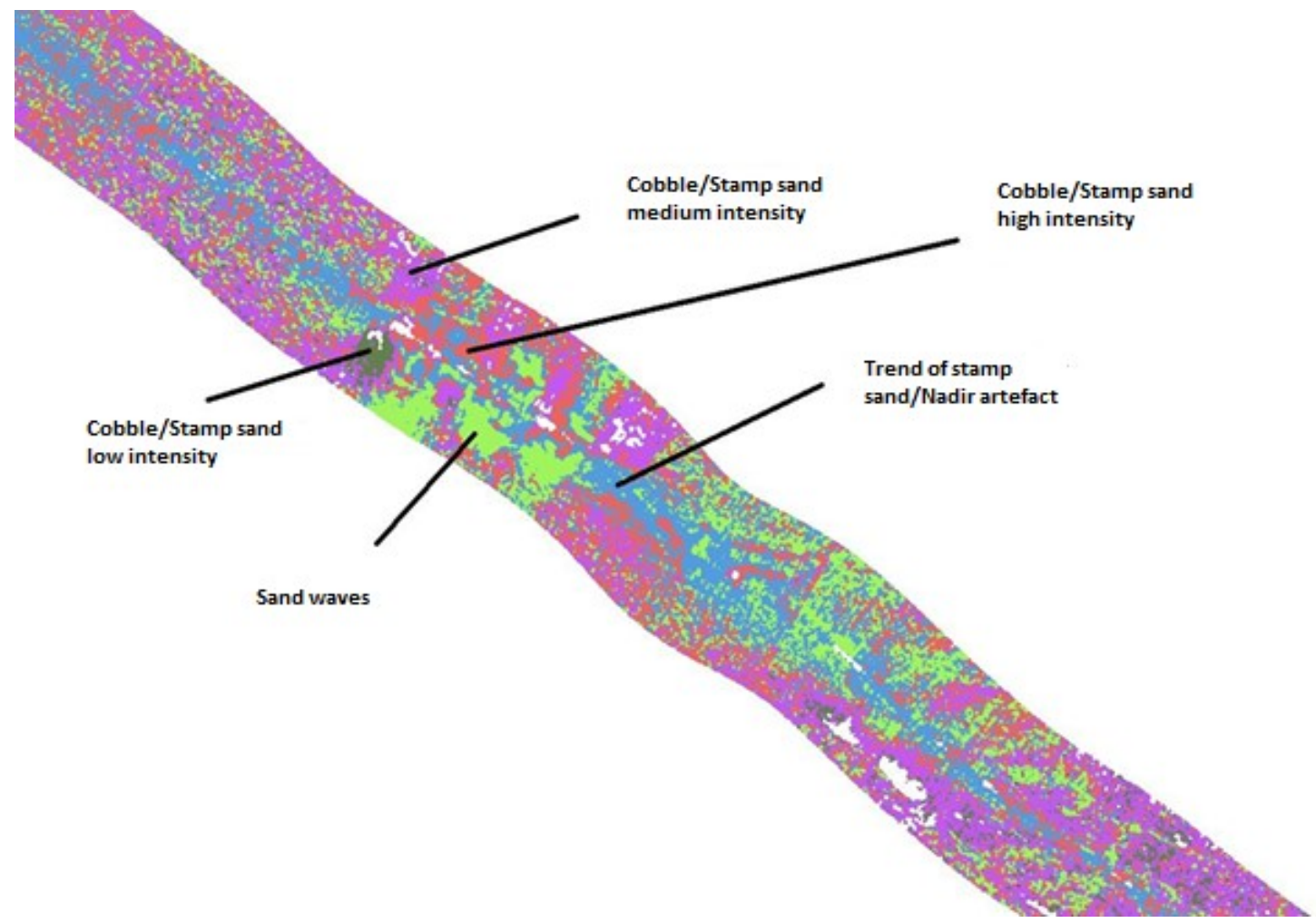

Figure 3.29. The Edgetech 4125 side-scan classification result shows that the system cut the shadow area out from the side-scan imagery. 


\section{Conclusion}

After the analyzing on both Iver 3 and Edgetech 4125 side-scan data, two lakebed-feature classification maps were created.

The classification of Iver 3 has six classes that are the shadow, cobble-stamp sands with low intensity, cobble-stamp sands with high intensity, the trend of stamp sands (from the source of stamps sands to the southeastward)-the nadir artefact, sandy waves, and cobble.

The shadow class is an indicator of single rock and bedrocks. Based on lakebed topography and the angle of sonar acoustic pulses, rocks and bedrocks have the shadow with high gray value (almost 100\%). Therefore, shadow area mostly comes from the rock and bedrock class. However, there is some hollow area on the survey line, which the acoustic pulses cannot reach their bottom, give the same result after operating classification tool in SonarWiz 7. This situation makes the confusion to claim that all shadow areas are coming from rock and bedrock. In this step, intensity matters a lot. The classification system classifies lakebed features based on mostly their intensity. So that, most of the time one side of rock appeared a class with very high intensity because of the pulse angle, and pulse range while another side of rock appeared as the shadow. Some exceptions such as very small rocks, the system classified them as cobble with low intensity. In this matter, classification resolution (based on SonarWiz Seabed Characterization User Guide the waterbody classification resolution is ten times greater than the spatial resolution.) takes a role and puts them into a different class. In conclusion, the shadow class in the lakebed-classification result map mostly comes from rock and bedrock without some exceptions.

The cobble-stamp sands with low intensity is a mixed class that includes cobbles and stamp sands up to the $60 \%$. When the Iver 3 operated on the survey line, the sonar took actual images from the survey line. After investigating actual images, it was clarified that cobbles are everywhere while sands are everywhere too. Based on the classification resolution, and intensity rules, two features on the lakebed could appear as one class that is the cobble-stamp sands class. On the other hand, stamp sands and cobbles could be 
separated from each other based on their intensity. In this case, stamp sands filled every emptiness of cobble and bedrock area with high hazardous particles that causes lower intensity returns. Depending on the sea truth sample (130 Ponar samples) from the area, borders and their related intensity values are meaningful. Even so, the time when samples were taken and the Iver 3 survey operation for lakebed classification is different from each order. Hence, new borders could consist during this time gap. Another issue is lack of samples density. The sample project area is considerably bigger than the survey line with lower density, so there is no coincide between samples and survey line. These reasons clarify the discrepancy between the sample-contour line and the survey line.

The cobble-stamp sands with high intensity is a mixed class that includes cobbles and stamp sands up to the $\% 40$. This class has stamp sands with lower hazardous particles. Thus, the intensity value is higher. All considerations are the same as the cobble-stamp sands with low-intensity class.

The third class of the Iver 3 classification is the trend of stamp sands-the nadir artefact. This class shows the direction of stamp sands on the survey line that comes from the original source of stamp sands (Gay Bay) to the southeast. However, the error of intensity still matters prominently. Around the nadir in the shallow area, intensity returns are the same as the trend of stamp sands. This is called a nadir artefact. From the Discover 2 software and actual images, the nadir area is cobble in the shallow area (Upper-left side of the Iver 3 survey line), but it reflects the trend of stamp sands because of an artificial higher intensity around the nadir. The artificiality maintains until the end of the survey line. Anywhere on the survey line around the nadir, intensity returns higher than the rest of each side (starboard, and port). Moreover, the raw side-scan has a nadir gap and the nadir filter was used for filling the gap. In addition, the normalization result could affect the final nadir area. The system tried to fill the nadir gap, and the result was stripy with high intensity because it is an unreal solution. For this reason, the nadir artefact could be a problem when the system classifies lakebed features, especially if the system (SonarWiz 7) has only an unsupervised classification method. 
From actual images of Iver 3, the sandy wave class is in the trend of stamp sands class that shows sand waves. The system caught sandy waves based on texture analysis. The sandy wave class looks consisted without complexity. Even though the nadir area was stripy like the sandy wave areas before the classification, the system (SonarWiz 7) classified based on their texture values in a successful way.

The last class is cobble that shows the single cobble around the survey line with the highest intensity because of the sonar acoustic pulse range, and the sonar acoustic pulse angle. The cobble class could indicate that it is also possible to differentiate between sands and cobble, but the first consideration before the classification would be still both feature's (cobble, and sand) intensity values.

Every class on the survey line mostly correspond to their actual lakebed features. Based On Discover 2 software and using actual images from the area, these features were confirmed. However, there is a problem exists about the confirmation. The camera for taking actual images from the lakebed mounted directly beneath the Iver 3 sonar. Every image from the lakebed is $1 \mathrm{x} 1$ meter square while the nadir gap is around five meters. So that, based on identical time information actual images were confirmed and matched to each typical lakebed features on the survey line. Demonstrations are shown above (Figure 43, Figure 44, Figure 45 - The comparison of the Discover 2, and Iver 3 actual images). Furthermore, there is no sample coincides with the survey line because there is lack sample density in the area. These reasons assess the classification even harder. The Discover 2 software has a good resolution that shows the lakebed features like actual images taken from the seafloor. However, the Discover 2 views are not actual images. Consequently, the interpretation of classes based on Discover 2 views and their generalrelated actual images that mostly expresses every class on the survey line. 


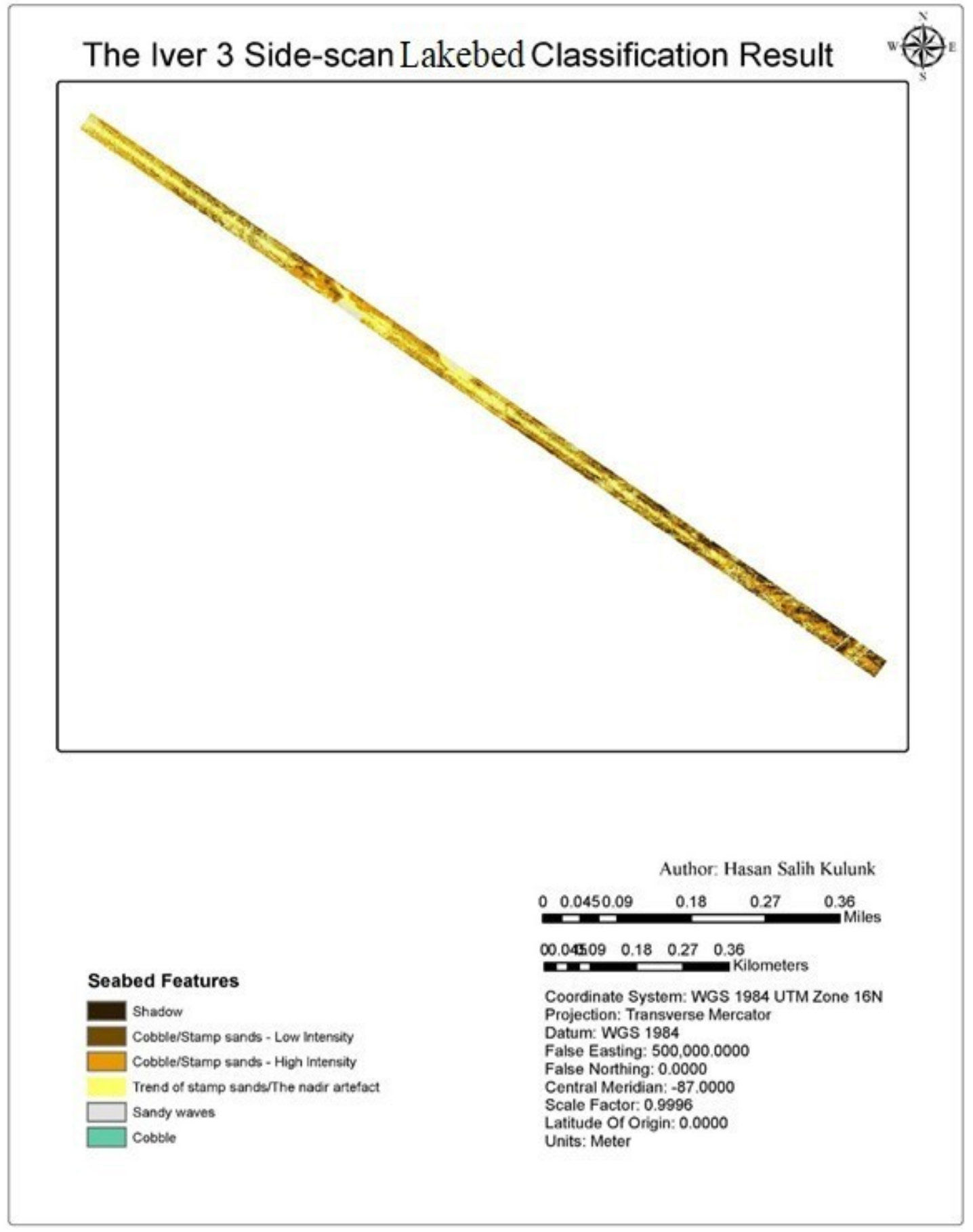

Figure 4.1. The Iver 3 Side-scan Lakebed Classification Map

The classification of the Edgetech 4125 side-scan sonar has six classes that are, cobblestamp sands with low intensity, cobble-stamp sands with medium intensity, cobble-stamp 
sands with high intensity, the trend of stamp sands (southeastward)-the nadir artefact, sandy waves, and cobble.

The Edgetech 4125 side-scan sonar has more powerful acoustic pulse range which is greater than Iver 3. That is why the Edgetech 4125 side-scan survey line is wider than Iver 3 side-scan survey line. However, the Edgetech 4125 side-scan has lower resolution than Iver 3 side-scan. For this reason, the result of normalization is smoother. It is not needed to clip the area for better normalization accuracy. When the system operates with the Edgetech 4125 side-scan data, the system cuts the shadow out from the survey line. Thus, there is no shadow class in the result. When the comparing both classification results, the main trend of class distribution was the same. However, the lower resolution and wider survey line of the Edgetech 4125 side-scan makes a difference between both classification results.

The first class of the Edgetech 4125 side-scan is cobble-stamp sands with low intensity that is a mixed class, which includes cobbles and stamp sands up to the $70 \%$. The condition why they mixed each other is the same as Iver 3. In this case, the lower resolution of the system and the classification resolution factors put these classes into a single class more than Iver 3 sonar.

The second class of the Edgetech 4125 side-scan is cobble-stamp sands with a medium intensity that is a mixed class, which includes cobbles and stamp sands up to the $50 \%$. The Edgetech 4125 side-scan survey line is wider than Iver 3 survey line that is why the percentage of stamp sands could reach higher level based on the ponar-sample contour line.

The third class of the Edgetech 4125 side-scan is cobble-stamp sands with high intensity that is a mixed class, which includes cobbles and stamp sands with $<50 \%$. It looks the brightest one comparing other two classes.

The fourth class of the Edgetech 4125 side-scan is the trend of stamp sands (southeastward)-the nadir artefact that has the same condition as Iver 3. More intensity at nadir area, the nadir filter and EGN normalization filled the area of nadir artificially. So 
that, the result appeared as the same as the trend of stamp sands class, which shows the direction (southeastward). In addition, the resolution of the Edgetech side-scan sonar is lower, so the normalization results is smoother than Iver 3 side-scan result. The smoother normalization result makes the nadir area wider than Iver 3 nadir area. Hence, it can be interpreted that nadir area is more dominated by the Edgetech 4125 side-scan classification data than Iver 3 side-scan classification data.

The fifth class of the Edgetech 4125 side-scan is sandy waves. The system classified the sandy waves based on their textural values. It was successful classification but not as much as Iver 3 because of the side-scan resolution. The system could separate between the nadir stripy area and sandy waves, which is a good sign of lakebed texture classification for future research and development.

The last class of the Edgetech 4125 side-scan is the cobble class. This class is similar to the Iver 3 cobble class. The cobble class of the Edgetech 4125 defines single cobble around the survey line with the highest intensity because of the sonar acoustic range, and its angle. The result of the single cobble class shows that it could be possible to separate both grains of sand and cobble. However, the principle of intensity still matters. The cobble class with the highest intensity comes into one class because they are considerably higher than their neighbors on the seafloor. So that, they have the highest intensity and the system puts them into a single class.

Comparing the Edgetech 4125 side-scan classes and actual lakebed features is even harder than Iver 3 lakebed feature comparison. It is because the Edgetech 4125 side-scan has no camera mounted. There are no actual images from the seafloor. On the other hand, the direction of the survey was the same and actual images of Iver 3 coincide the Discover 2 Edgetech side-scan views. Based on two sources, the interpretation of classes mostly indicates every class on the survey line. 


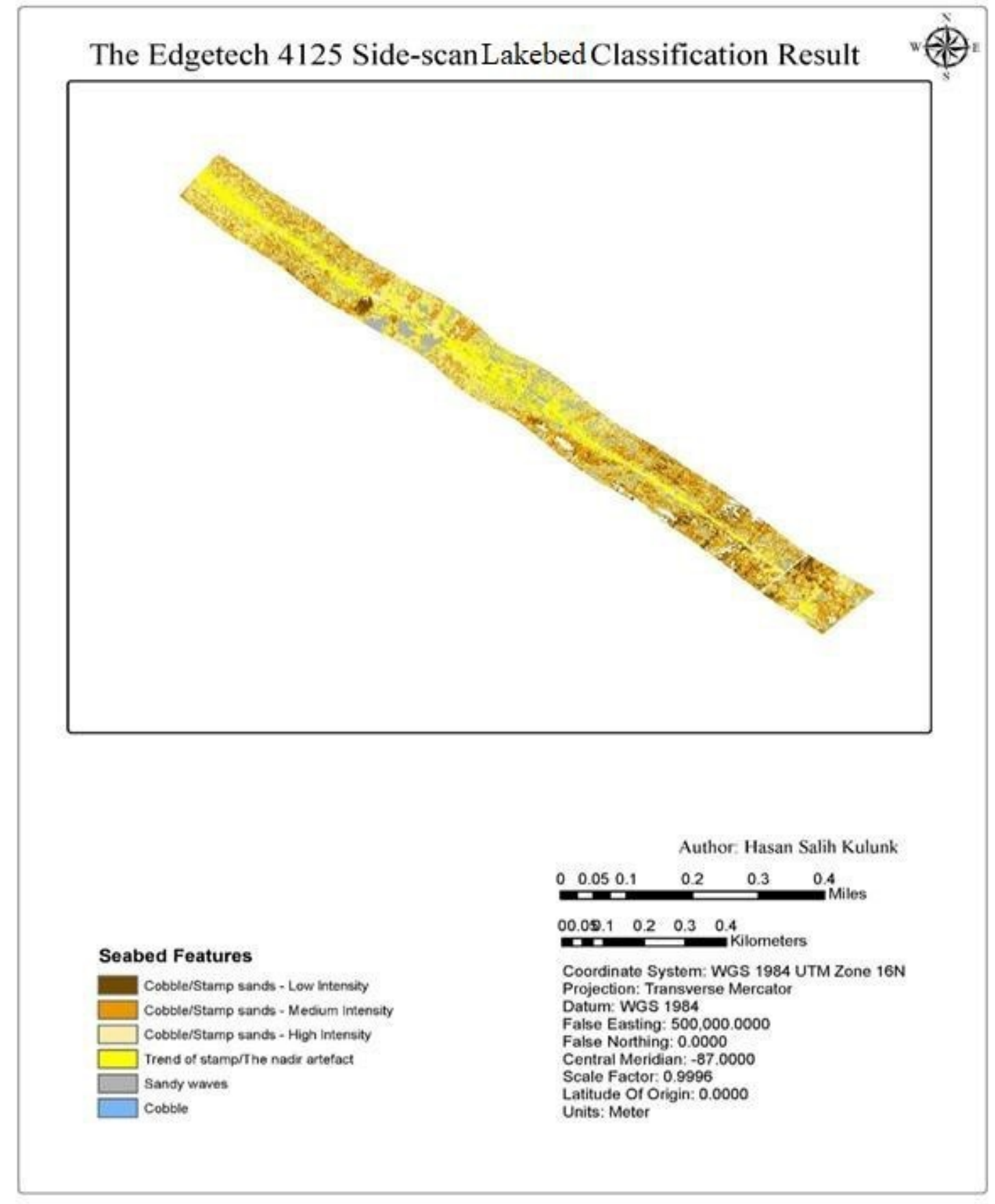

Figure 4.2. The Edgetech 4125 Side-scan Lakebed Classification Map 


\section{Recommendations}

Both results show that a lakebed classification from side-scan has some serious problems.

One comes from the shadow. The actual reason for choosing an intersection area is eliminating shadows from the survey line. However, the system (SonarWiz 7) cannot manage the intersection area. Instead of the intersection area, the system chose the fifth survey line that overlays the third survey line. So that, the classification result showed the fifth survey line result in the intersection area. Apparently, this condition could not eliminate the shadow from the intersection area. For eliminating the shadow problem of side-scan, intersection areas could be useful if the system support with appropriate tools.

Second, comes from the dominance of intensity when the system classified side-scan data. The intensity rule is crucial for the classification and describes lakebed classes well. However, with an unsupervised classification option classes could be mixed such as the nadir artefact, cobble and stamp sands. The texture analysis more than intensity such as separation between the stripy nadir area and sandy waves could be a sign for the future requirement about side-scan lakebed classification. Therefore, the side-scan data might be separated into single rock, bedrock, cobble, and sand. On the other hand, the separation of sands from each other based on their included particles, the intensity rules could be the first thing that we need to consider.

A recommendation of an accuracy assessment for side-scan data is using actual images from the seafloor. Actual images that are taken, should be out of the nadir gap. In this way, actual images from the seafloor can match to the side-scan feature to compare lakebed features and lakebed feature classes. An accuracy assessment with points could be implemented using the actual images and the classification map. So that, the classification error table can be created for the side-scan classification map. 


\section{Copyright Permission}

Figure 1.1 Modern Sonar Systems, Figure 1.4 Single Beam Echo Sounder Principle, Figure 1.5 Multi Beam Echo Sounder Principle, Figure 1.7 Airborne Lidar, Figure 1.14 GPS Accuracy for Maritime Projects, \& Figure 1.15 RTK GPS Method for Maritime Projects

Figures are free of charge depending on the USGS website copyright permission statement. Proper credits were given for all figures.

https://www2.usgs.gov/laws/info policies.html

Figure 1.3. Hydrographic Survey by Lead Line methods \& Figure 1.4. Drag Wire method for the safety of navigation

A copyright permission was requested from TeamSurv Ltd. It was concluded that those images are free of copyright restrictions.

https://www.teamsurv.com/Why/Hydrographic-survey-methods

Figure 1.6. Multiphase Echo Sounder

A copyright permission was requested from RJ Jablonski, Director of Sales Marketing at Edgetech. The permission was accepted on November 2, 2017.

Figure 1.8. Optical SDB Method for Hydrographic Survey

A copyright permission was requested from Mr. Andrew Talbot. The permission was accepted on November 1, 2017 with following citation: Courtesy UKHO, contains WorldView-2 satellite imagery CDigitalGlobe, 2013. 


\section{Figure 1.9. Satellite Radar Altimetry Method}

Figures are free of charge depending on the NOAA website copyright permission statement. Proper credit was given for this figure.

https://www.star.nesdis.noaa.gov/star/productdisclaimer.php

\section{Figure 1.10. Theodolite Horizontal Position Fixing Method}

Based on the EPA website, Figure 1.10 was used as freely. https://publicaccess.zendesk.com/hc/enus/articles/211395598?input_string=copyright+permission

Figure 1.11. The Parallel Line Method \& Figure 1.12. The Depth Recording with Traditional Parallel Line Method

A copyright permission was requested from copyright@fao.org. The permission request was accepted on November 2, 2017 with following citation: Source: Food and Agriculture Organization of the United Nations, [year], [authors], [title of publication], [URL].

\section{Figure 1.13. Bathymetric Survey Vessel Tracked with Total Station}

A copyright permission was requested from Mr. Myrthe van der Schiut, Account Manager. The permission request was accepted on November 2, 2017.

\section{Figure 2.1. Ellipse model for different region}

A copyright permission was requested from Dr. James R. Clynch. The permission request was accepted on November 2, 2017 with following citation: DMA TECHNICAL MANUAL 8358.1 DATUMS, ELLIPSOIDS, GRIDS, AND GRID REFERENCE SYSTEMS, http://clynchg3c.com/ 


\section{References}

Base Platform. n.d. Base Platform . Accessed 08 16, 2017. http://baseplatform.com/project/technology/optical-sdb.

Benedict, C H. 1952. Red metal: The Calumet and Hecla story. Univ. of Michigan Press.

Brison, Dr. Tom Hiller. 2015. "Multiphase Echosounder to Improve Shallow-Water Surveys." Published monthly, 4.

n.d. Business Dictionary. Accessed 8 8, 2017.

http://www.businessdictionary.com/definition/confidence-level.html.

Chesapeake Technology, Inc 2010-2016. 2016. SonarWiz User Guide. User Guide, Chesapeake Technology.

Chesapeake Technology, Inc. 2017. SonarWiz Seabed Characterization User Guide. User Guide, Chesapeake Technology.

Clynch, James R., DMA TECHNICAL MANUAL 8358.1 DATUMS, ELLIPSOIDS, GRIDS, AND GRID REFERENCE SYSTEMS, http://clynchg3c.com/. 2006. Introduction to Datums. James R. Clynch.

CSPSWG. 2015. "Satellite Derived Bathymetry ." CSPWG MEETING. CSPSWG. 10. 
Dodd, David. 2013. Research Gate. March. Accessed 08 13, 2017. https://www.researchgate.net/publication/257306354_Uncertainty_Evaluation_of _the_EdgeTech_4600_Swath_Bathymetry_System.

DPWE. n.d. DPWE NCTU . Accessed 08 15, 2017. http://dpwe.nctu.edu.tw/en/research/E3.

Elhassan, Prof Ismat. 2015. "Bathymetric Techniques." FIG Working Week 2015. 17.

EPA. 1987. EVALUATION OF SURVEY POSITIONING METHODS FOR NEARSHORE MARINE AND ESTUARINE WATERS. Final Reports, Washington: Tetra Tech.

ESRI. 2017. Desktop ArcGIS. Accessed 10 3, 2017.

http://desktop.arcgis.com/en/arcmap/latest/extensions/maritimebathymetry/essential-bathymetricvocabulary.htm\#ESRI_SECTION1_C00202E7177D46E5A84356E4B64726F5.

FIG . 2007-2010. Guidelines for the Planning, Execution and Management of Hydrographic Surveys in Ports and Harbours . FIG Publication No 56, Copenhagen: International Federation of Surveyors (FIG).

Figure 1.8. Optical SDB Method for Hydrographic Survey (Courtesy UKHO, contains WorldView-2 satellite imagery CDigitalGlobe. 2013. Slide Player. Accessed 08 16, 2017. http://slideplayer.com/slide/7240729/. 
GIM International. 2016. GIM iNTERNATIONAL. 11 28. Accessed 08 23, 2017. https://www.gim-international.com/content/news/bathymetric-survey-vesseltracked-with-total-station.

—. 2016. "Technology in Focus: Bathymetric Lidar." 11 22: 2.

Hiller, Tom. n.d. Slide Share Net. Accessed 08 14, 2017. https://www.slideshare.net/hydrographicsocietybn1/advantages-of-a-combinedsonar-data-acquisition-system-for-auvs-and-asvs.

Hoffman, Adam. 2013. Godfrey Hoffman. 3 2013. Accessed 08 22, 2017. http://www.godfreyhoffman.com/civil-engineering-blog/bid/278047/the-totalstation-land-surveys-a-background-story.

Howlett, Chris. n.d. Hydro Conferences. Accessed 08 08, 2017. http://www.hydroconferences.org/documents/hydroconferences/downloads/1/pap er_12_-_chris_howlett.pdf.

IEEE. 2005. Bathymetry from satellite altimetry: present and future. Washington: IEEE.

2008. "IHO Standards for Hydrographic Surveys." 5th Edition Special Publication No.44. Monaco: International Hydrographic Bureau, February.

Karacelebi, Utku. 2014. "BALTHMETRIC SURVEY IN THE KEWEENAW WATER WAY IN MICHIGAN, USA, MAKING 3D MODEL, AND COMPARING SONAR EQUIPMENT OF THE MODERN AUV AND THE TRADITIONAL SINGLE BEAM SONAR." 1-2. 
MapServer. 2017. Map Server. 11 4. Accessed 11 7, 2017. http://mapserver.org/input/vector/S57.html.

Murdoch, W A. 1943. "Boom copper: The story of the first United States mining boom. Macmillan."

NOAA. 2017. Hydrographic Surveys Specifications and Deliverables. NOAA.

NOAA, http://www.charts.noaa.gov/OnLineViewer/14964.shtml. 2017. Charts NOAA. 10 2. Accessed 11 18, 2017. http://www.charts.noaa.gov/OnLineViewer/14964.shtml.

NOAA/NESDIS/STAR. 2016. Star Nesdis NOAA. 12 8. Accessed 08 17, 2017. https://www.star.nesdis.noaa.gov/sod/lsa/AltBathy/.

Ocean Engineering. n.d. English Bathymetric Survey. Accessed 08 13, 2017. http://111.89.138.69/english/bathymetricsurvey/.

Office of Coast Survey. 2016. Nautical Charts NOAA. 07 2016. Accessed 08 14, 2017. https://www.nauticalcharts.noaa.gov/hsd/lidar.html.

—.n.d. Nautical Charts NOAA. Accessed 11 7, 2017. https://www.nauticalcharts.noaa.gov/hsd/control.html.

PennState College of Earth and Mineral Science. n.d. E-Education PSU. Accessed 08 23, 2017. https://www.e-education.psu.edu/geog862/node/1828. 
n.d. Pyhsics Umd. Accessed 8 8, 2017.

https://www.physics.umd.edu/courses/Phys276/Hill/Information/Notes/ErrorAnal ysis.html.

Sandwell, and Smith. 1990. EXPLORING THE OCEAN BASINS WITH SATELLITE ALTIMETER DATA. David T. Sandwell, Walter H. F. Smith.

Sciortino, Food and Agriculture Organization of the United Nations. 2010. "Fishing harbour planning, construction and management. FAO Fisheries and Aquaculture Technical Paper." Rome: FAO. 539.

Teamsurv, https://www.teamsurv.com/Why/Hydrographic-survey-methods. n.d. Teamsurv. Accessed 08 11, 2017. https://www.teamsurv.com/Why/Hydrographicsurvey-methods.

n.d. The Constructor. Accessed 08 22, 2017. https://theconstructor.org/surveying/totalstation-operation-uses-advantage/6605/.

U.S. Geological Survey Deapartment of the Interior/USGS, https://coastal.er.usgs.gov/capabilities/shipboard/sonar/bathysonar.html. 2016. USG16. 12 5. Accessed 11 4, 2017. https://coastal.er.usgs.gov/capabilities/shipboard/sonar/bathysonar.html.

U.S. Geological Survey Deapartment of the Interior/USGS, https://coastal.er.usgs.gov/capabilities/shipboard/sonar/sidescan.html. 2016. Coastal Er USGS. 12 5. Accessed 08 10, 2017. https://coastal.er.usgs.gov/capabilities/shipboard/sonar/sidescan.html. 
U.S. Geological Survey Deapartment of the Interior/USGS, https://woodshole.er.usgs.gov/operations/sfmapping/singlebeam.htm. n.d. Woodshole Er USGS. Accessed 08 12, 2017. https://woodshole.er.usgs.gov/operations/sfmapping/singlebeam.htm.

U.S. Geological Survey Department of the Interior/USGS . 2016. Pubs USGS. 1128. Accessed 08 23, 2017. https://pubs.usgs.gov/ds/722/html/position_nav.html.

—. 2017. Water USGS. 04 06. Accessed 08 23, 2017. https://water.usgs.gov/osw/gps/.

U.S. Geological Survey Department of the Interior/USGS. 2016. Gulf Sci USGS. 0420. https://gulfsci.usgs.gov/tampabay/data/1_bathymetry_lidar/images/Eaarl1.gif.

W. Charles Kerfoot et al. 2012. Light detection and ranging (LIDAR) and multispectral studies of disturbed Lake Superior coastal environments. The Association for the Sciences of Linology and Oceanography.

Weignen Huang, Bin Fu. 2004. "A Spaceborne SAR Technique for Shallow Water Bathymetry Surveys." Journal of Coastal Research 223-228. 